\title{
A Recent Overview of 1,2,3-Triazole-Containing Hybrids as Novel Antifungal Agents: Focusing on Synthesis, Mechanism of Action, and Structure-Activity Relationship (SAR)
}

\author{
Mahrokh Marzi (D), ${ }^{1}$ Mojtaba Farjam $\left(\mathbb{D},{ }^{1,2}\right.$ Zahra Kazeminejad, ${ }^{3}$ Abolfazl Shiroudi $\left(\mathbb{D},{ }^{4}\right.$ \\ Amin Kouhpayeh $\left(\mathbb{D},{ }^{2}\right.$ and Elham Zarenezhad $\mathbb{C I}^{1}$ \\ ${ }^{1}$ Noncommunicable Diseases Research Center, Fasa University of Medical Sciences, Fasa, Iran \\ ${ }^{2}$ Department of Medical Pharmacology, School of Medicine, Fasa University of Medical Sciences, Fasa, Iran \\ ${ }^{3}$ Young Researchers and Elite Club, Tonekabon Branch, Islamic Azad University, Tonekabon, Iran \\ ${ }^{4}$ Young Researchers and Elite Club, East Tehran Branch, Islamic Azad University, Tehran, Iran
}

Correspondence should be addressed to Elham Zarenezhad; el.zarenezhad@gmail.com

Received 1 October 2021; Revised 16 November 2021; Accepted 25 November 2021; Published 6 January 2022

Academic Editor: Vinod Kumar Tiwari

Copyright (c) 2022 Mahrokh Marzi et al. This is an open access article distributed under the Creative Commons Attribution License, which permits unrestricted use, distribution, and reproduction in any medium, provided the original work is properly cited.

\begin{abstract}
A pharmacophore system has been found as 1,2,3-triazole, a five-membered heterocycle ring with nitrogen heteroatoms. These heterocyclic compounds can be produced using azide-alkyne cycloaddition processes catalyzed by ruthenium or copper. The bioactive compounds demonstrated antitubercular, antibacterial, anti-inflammatory, anticancer, antioxidant, antiviral, and antidiabetic properties. This heterocycle molecule, in particular, with one or more 1,2,3-triazole cores has been found to have the most powerful antifungal effects. The goal of this review is to highlight recent developments in the synthesis and structure-activity relationship (SAR) investigation of this prospective fungicidal chemical. Also there have been explained drugs and mechanism of action of a triazole compound with antifungal activity. This review will be useful in a variety of fields, including medicinal chemistry, organic chemistry, mycology, and pharmacology.
\end{abstract}

\section{Introduction}

One of the most important fields of medicinal chemistry is the study of heterocyclic bioactive molecule containing nitrogen atoms $[1,2]$. Triazole have been found as a potential heterocyclic component in a wide range of drug scaffolds. It has a five-membered nitrogen heterocycle core with three nitrogen atoms and two carbon atoms. The core has a substantial impact on biological activity [3]. The influences of the nitrogen heteroatom on the reactivity of the lead compound target medication pharmacokinetics and metabolism are affected by interactions between the lead chemical and several target inhibitors [4].

A fungus is one of the most diverse organisms in the world. Since eukaryotes share many potential drug-receptor targets with humans [5], the synthesis of the new fungicidal compounds with high selectivity is essential for fungal receptors and low affinity for human receptors $[6,7]$. There are approximately recognized two million fungi types and 600 fungi species as human fungal pathogens with only $3-4 \%$ of these species leading to fungal infection [8]. Unfortunately, this kind of invasive fungal infections resulted in a high mortality rate [9]. Fungal infections have recently risen and are responsible for 1-2 million fatalities annually [10]. Most of the deaths ( $90 \%)$ are assigned to the Aspergillus and Candida species [11]. Invasive candidiasis species including Candida tropicalis, Candida glabrata, Candida parapsilosis, Candida krusei, and Candida albicans enhanced rate of mortality (75\%). Furthermore, the Aspergillosis family containing fumigatus, niger, flavus, terreus, and parasiticus caused mortality rate of $50-90 \%$ [12]. Azole derivatives achieved antifungal activity by linking ergosterol in the 
active site of the cell membrane [13]. Researchers confirm that azoles with inhibiting the lanosterol $14 \alpha$-demethylase enzyme inhibit the synthesis of ergosterol [14]. Certain 1,2,3triazole derivatives have been generated and evaluated for antifungal activity in the last few years, with some potential activity against different fungi. This review is focused on the latest papers (2015-2021) on the synthesis of new series of 1,2,3-triazole antifungal agents and the evaluation of structure-activity relationship (SAR) to provide insight into the logical synthesis of more effective 1,2,3-triazole antifungal candidates. The process of selecting publications for this review is reported in the diagram below (Figure 1).

\section{Synthesis of 1,2,3-Triazoles}

2.1. Click Chemistry (Azide-Alkyne Cycloaddition). Huisgen introduced the first azide-alkyne cycloaddition in 1960 [15], which reported the 1,3-dipolar cycloaddition between alkyne (terminal) and azide to produce 1,2,3-triazoles. Unfortunately, high temperatures were required for this type of reaction, which resulted in low yield mixture of the two regioisomers consisting of 1,4- and 1,5-substituted triazoles [16] (Scheme 1).

Sharpless proposed the term "click chemistry" in 2001, which is explained as "chemistry tailored to produce a substance by linking small molecules together very quickly and simply" [17, 18]. Separately, Tornøe et al. [19] and Rostovtsev et al. [20] used $\mathrm{Cu}(\mathrm{I})$-catalyzed azide-alkyne cycloaddition (CuAAC) as one of the most reliable click reactions to generate 1,2,3-triazole derivatives. Sharpless demonstrated reactions with high yields, moderate reaction conditions, the generation of stereospecific products without the need of chromatography, and ease of use.

The copper-catalyzed reaction, in particular, leads to the synthesis of 1,4-disubstituted regioisomers; this suitable reaction can be accomplished in aqueous solutions, even at room temperature $[21,22]$. However, researchers discovered that ruthenium-catalyzed reaction yields 1,5-disubstituted triazoles with opposite regioselectivity [23] (Scheme 2).

2.1.1. Mechanism of the Huisgen Azide-Alkyne 1,3-Dipolar Cycloaddition. Huisgen cycloaddition is a type of DielsAlder reaction which is a 1,3-dipole reacting with a dipolarophile to produce 1,2,3-triazole in a $(3+2)$ cycloaddition (Scheme 3) [24].

This exothermic reaction occurs at high temperatures, as illustrated in Scheme 4, despite the fact that the rate of reaction is insignificant. Since the layers' two potential HOMO-LUMO interactions are nearly dependent in terms of energy, this results in almost $1: 1$ mixes in both the 1,5substituted and 1,4-substituted regioisomers [20].

2.1.2. Mechanism of the Copper-Catalyzed Azide-Alkyne Cycloaddition (CuAAC). The reliable click reaction, coppercatalyzed azide-alkyne cycloaddition (CuAAC), has been expanded in medicinal and organic chemistry [25]. In this method for preparing $\mathrm{Cu}(\mathrm{I})$ in solution, in situ reduction of $\mathrm{CuSO}_{4} \cdot 5 \mathrm{H}_{2} \mathrm{O}$ by sodium ascorbate was performed in 1,2,3-triazole of water/alcohol $(\mathrm{MeOH}, \mathrm{EtOH}$, or $\mathrm{BuOH})$ mixtures. The product was separated by easy purification without the use of chromatography (Scheme 5) [26].

The mechanism of CuAAC is described in Scheme 6. Firstly, sodium ascorbate as a reducing agent can produce active $\mathrm{Cu}(\mathrm{I})$ from $\mathrm{Cu}(\mathrm{II})$ salts. Homocoupling products are not produced by adding a small amount of sodium ascorbate. In addition, DFT computations confirmed that the coordination of an alkyne to $\mathrm{Cu}(\mathrm{I})$ is somewhat endothermic in $\mathrm{MeCN}$ but exothermic in water. The rate of reaction then increased in water. DFT analysis showed that acetylene coordination to $\mathrm{Cu}$ does not catalyze a 1,3-dipolar cycloaddition. As shown in Scheme 6, a $\pi$-bound copper coordinates with the azide. The intermediate copper metallacycle is then prepared. The second copper atom acts as a stabilizing donor ligand. Finally, the catalytic cycle is closed with the generation of a triazolyl-copper derivative. As a result, 1,2,3-triazole derivatives are synthesized by Proteolysis [27].

2.1.3. Mechanism of the Ruthenium-Catalyzed Azide-Alkyne Cycloaddition (RuAAC). The researchers confirmed that pentamethylcyclopentadienyl ruthenium chloride $[\mathrm{Cp} * \mathrm{RuCl}]$ complexes may be used as effective catalysts in the reaction of terminal alkynes with azides, resulting in 1,5disubstituted 1,2,3-triazoles (Scheme 7) [28].

The mechanism of the ruthenium-catalyzed azide-alkyne cycloaddition (RuAAC) is shown in Scheme 8; therefore, RuAAC appears from an oxidative coupling of the alkyne and the azide, yielding a six-membered ruthenacycle. The initial carbon-nitrogen bond is formed between the terminal nitrogen of alkyne and azide in the next step. The product 1,2,3-triazole is then formed by reductive elimination [28].

2.2. Synthesis and Structure of 1,2,3-Triazole-Based Marketed Drugs. Only a few 1,2,3-triazole-containing hybrids have been developed as therapeutic agents in the medicine industry in recent years, with a wide range of pharmacological applications. The antibiotics Tazobactam/Ceftolozane [29], Radezolid [30], Cefatrizine [31], Tertbutyldimethylsilylspiroaminooxathioledioxide (TSAO) [32], and the Carboxyamidotriazole (CAI) [33] are examples of pharmaceutical drugs containing 1,2,3-triazoles scaffold (Scheme 9). We discuss the synthesis process of these pharmaceutical medicines in this study.

\subsubsection{General Synthetic Pathway for the Preparation of Pharmaceutical Drugs Containing 1,2,3-Triazole}

(1) Synthesis of Tazobactam. Tazobactam is a pharmaceutical that inhibits the bacterial activity of $\beta$-lactamases, particularly those attached to the SHV-1 and TEM groups. In other words, it is a substance that can be added to some antibiotics to make bacteria more vulnerable to antimicrobial resistance. Tazobactam is coupled with the broad-spectrum $\beta$-lactam piperacillin antibiotic to form the drug piperacillin/ tazobactam, which is used to treat Pseudomonas aeruginosa infections [34]. This medication was developed in 1982 and 


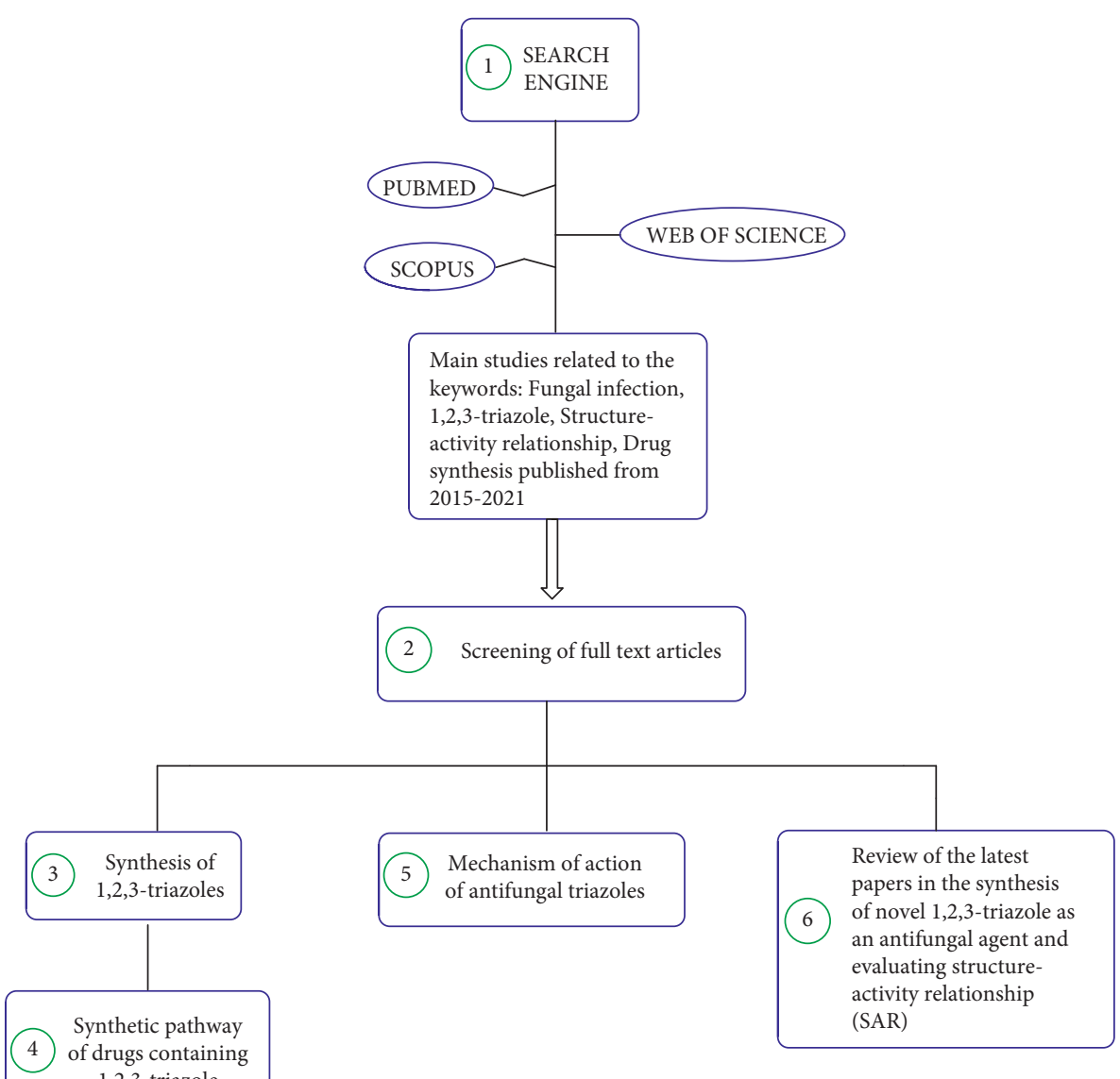

FIGURE 1: Diagram of identification of the provided content in this review.

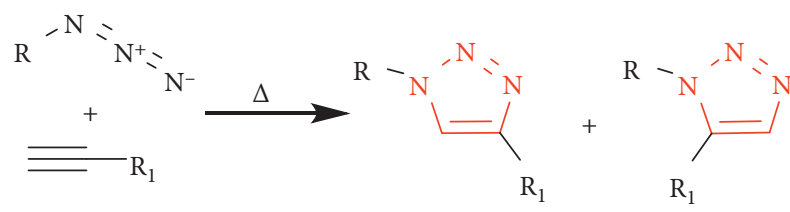

Scheme 1: Azide-alkyne Huisgen cycloaddition.

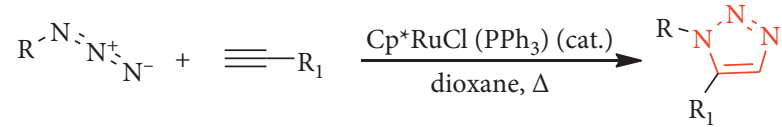

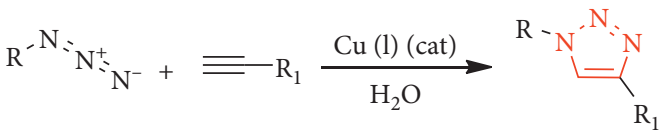

Scheme 2: Copper-catalyzed and ruthenium-catalyzed reaction on azide-alkyne cycloaddition.

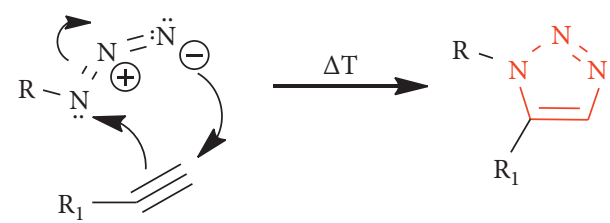

Scheme 3: Huisgen cycloaddition.

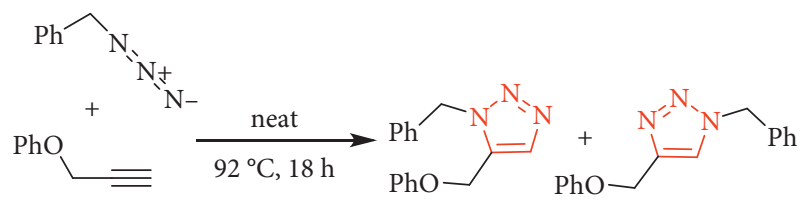

1: 1.6

Scheme 4: Thermal reactions and mixtures in both 1,4- and 1,5substituted regioisomers.

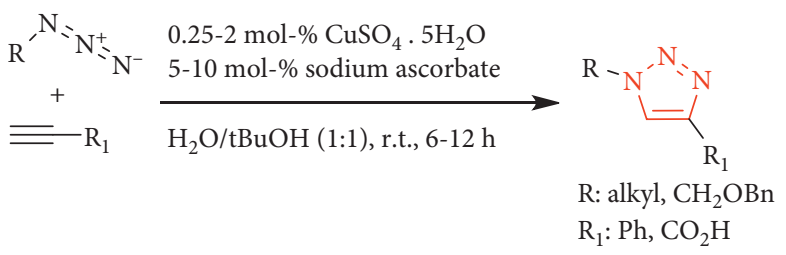

Scheme 5: Copper-catalyzed azide-alkyne cycloaddition.

used in medicine for the first time in 1992. It is a combination of a penicillin and a sulfone [35].

Micetich et al. [36] described a novel route to the synthesis of Tazobactam, which resulted in the cycloaddition of the synthetic intermediate $\mathbf{1}$ with acetylene gas $\mathbf{2}$ in water and the dissociation of $\mathbf{1}$. Finally, the reaction in MIBK without the excess sodium ascorbate supported Tazobactam yields ranging from 4 to $91 \%$ (Scheme 10). 


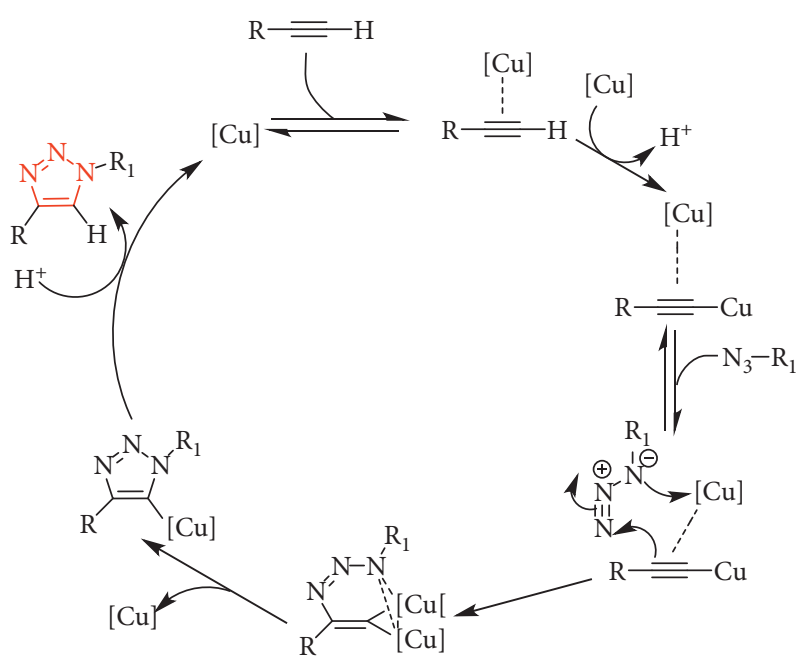

Scheme 6: Mechanism of the copper-catalyzed azide-alkyne cycloaddition (CuAAC).

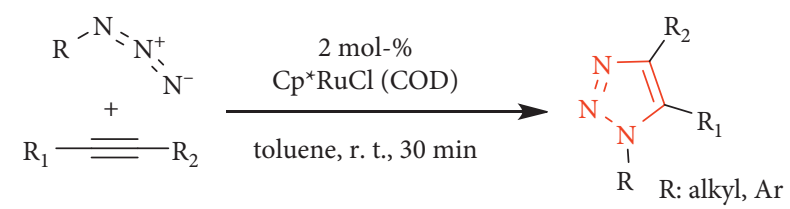

Scheme 7: Ruthenium-catalyzed azide-alkyne cycloaddition.

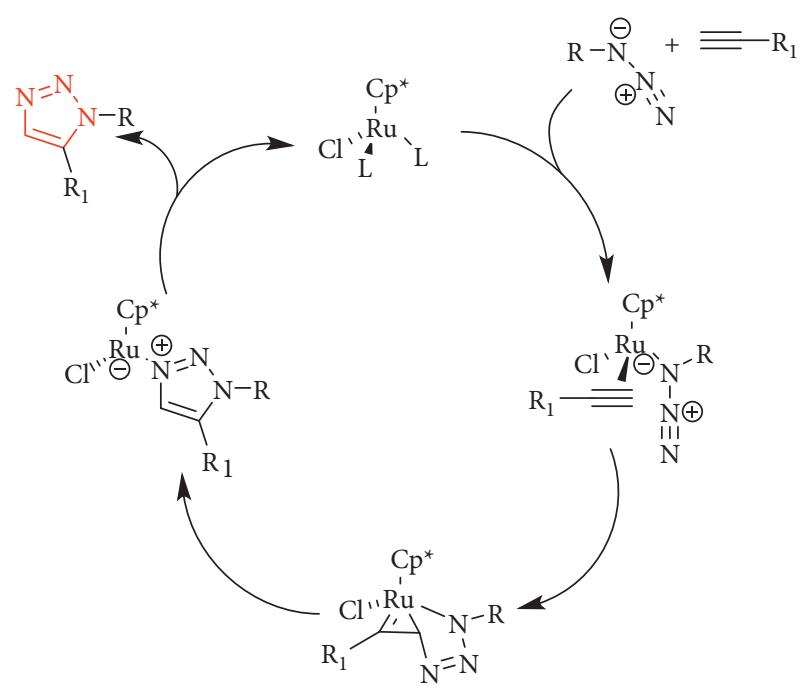

Scheme 8: Mechanism of the ruthenium-catalyzed azide-alkyne cycloaddition (RuAAC).

(2) Synthesis of Radezolid. Oxazolidinones are an antimicrobial agent with a wide range of activity toward important Gram-positive and nosocomial pathogens such as methicillin-resistant Staphylococcus aureus (MRSA), enterococci, and pneumococci [37]. $N$-\{[(5S)-3-[3-Fluoro-4- $(4-\{[(1 H-$ 1,2,3-triazole-5-ylmethyl)amino]methyl\}phenyl)phenyl]-2oxo-1,3-oxazo-lidin-5-yl]methyl $\}$ acetamide (Radezolid) is a new antibacterial agent of biaryl oxazolidinone that is in clinical expansion; the first clinical experiments were performed on simple skin and skin structure infections (USSSI) and the second on community-acquired pneumonia (CAP) [38-40].

The most significant stage in Radezolid synthesis is the cross-coupling reaction of the iodooxalidinone derivative $\mathbf{1 3}$ and boroorganic acid derivative $\mathbf{1 8}$ catalyzed by tetrakis(triphenylphosphine)palladium(0) relying on Suzuki reaction mechanism. Compound $\mathbf{1 8}$ was acquired by combining 4-methoxybenzyl chloride with the triazole ring. Intermediate 13 was provided from R-glycidyl butyrate and an introduced starting material to be used in the reaction of a carbamate, $\mathrm{N}$-carboxyloxy-3-fluoroaniline, an oxazolidinone ring, allowing only one, enantiomerically pure, desired oxazolidinone derivative to be produced in four simple steps. Gravestock and coworkers [41] proposed critical modifications to the synthesis of Radezolid that focused on the phase leading to compound $\mathbf{1 9}$. Other changes included raising the number of solvents and increasing the amount of a novel one, extending the reaction time and temperature, and using a contemporary approach including crystallization of the terminal product 21 (Schemes 11 and 12) [42].

(3) Synthesis of Carboxyamidotriazole (CAI). Carboxyamidotriazole (CAI) was initially developed as a noncytotoxic anticancer drug. Numerous studies [43-46] show that carboxyamidotriazole (CAI) has moderate anticancer efficacy in vitro and in vivo. Despite this, many preclinical investigations have revealed its antiproliferative, antiangiogenic, and antimigratory properties [44, 45, 47, 48].

In the proposed synthesis scheme, compound $\mathbf{2 2}$ is reacted with $\mathbf{2 4}$ to produce compound $\mathbf{2 5}$ after the alcohol group is shielded as the tert-butyldimethylsilyl (TBDMS) ether step (23). To form 3,5-dichloro-4-(4-chlorobenzoyl) benzyl azide, benzophene is reacted with thionyl chloride $\mathbf{2 6}$ and then with sodium azide (27). The reaction of cyanoacetamide with this azide constructs L651582 (29). Compounds 29 and 30 were produced by the interaction of component 29 with orotic acid (Scheme 13) [49].

(4) Synthesis of Cefatrizine. Cefatrizine is a wide-spectrum cephalosporin antibiotic [50] and one of the first 3-heterocyclic thiomethylcephalosporins produced in the laboratories [51]. Cephalosporin compounds are replaced at the 3 -situation by a heterocyclic thiomethyl group and at the 7position by free or substituted $\alpha$-aminophenylacetamido. They are synthesized by combining a 3-acetoxymethyl ring to a mercaptoheterocycle. Antibacterial factors are found in products (Scheme 14) [51].

(5) Synthesis of Tertbutyldimethylsilylspiroaminooxathioledioxide (TSAO). TSAO reported a completely novel class of HIV-1-particular factors in 1992 [52-56]. Human replication of immunodeficiency virus type 1 (HIV-1), simian immunodeficiency virus (SIV), or RNA viruses, and other DNA are inhibited by TSAO nucleoside analogs. They are designed to interact with RT-virus encoding at a nonsubstrate binding position $[57,58]$.

The 5- $\mathrm{N}$-alkyl carbamoyl substituted TSAO triazoles were synthesized in two phases, with the aim of obtaining the 5 -substituted 1,2,3-triazole derivative 36 [59] by reacting the 


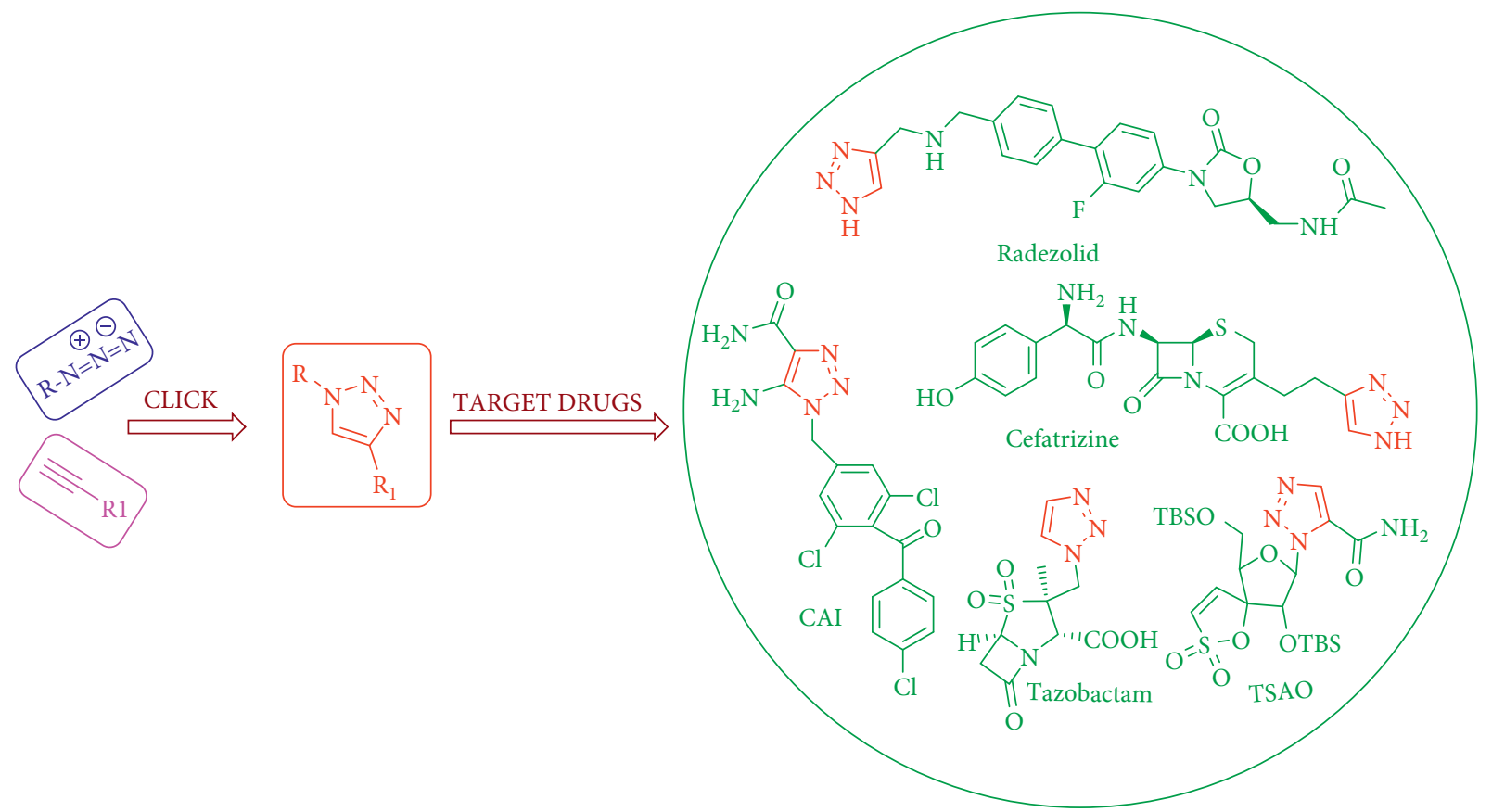

Scheme 9: Chemical structure of 1,2,3-triazole-based marketed drugs.
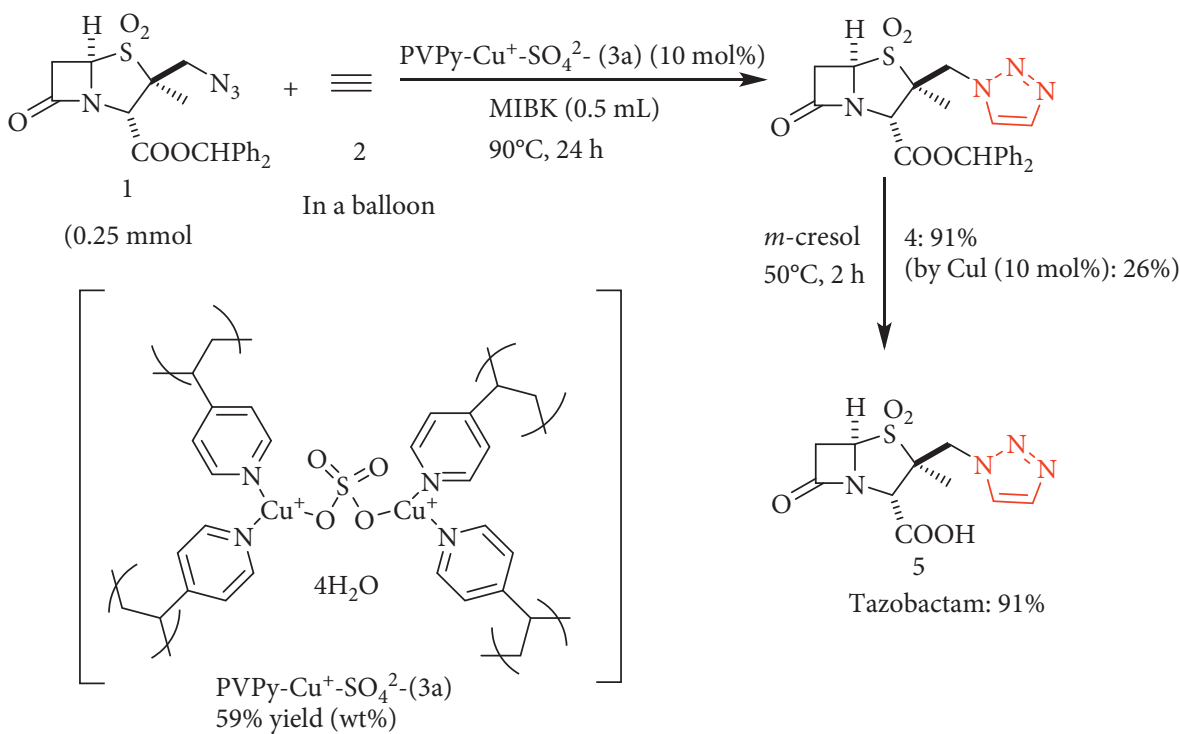

Tazobactam: 91\%

Scheme 10: Synthesis of tazobactam.

azide intermediate 34 [59] with 2-oxo-alkylidentriphenylphosphorane 35 [60] in refluxing xylene. Compound 37 was synthesized by aminolyzing these ester derivatives with the proper amine (Scheme 15) [61, 62].

2.3. Mechanism of Action of Antifungal Triazoles. Woolley originally reported the antifungal activity of an azole derivative in 1944 [63], but it was not until the early 1970s that this drug was subjected to a comprehensive assessment. Fluconazole (FLC), Itraconazole (ITC), Voriconazole (VCZ), Posaconazole, and Ravuconazole are examples of synthetic compounds that include one or more azole rings with three nitrogen atoms in a five-membered ring (as antifungal triazoles) (Figure 2). In general, azoles have become a more important antifungal drug, since they are less toxic than Amphotericin B (AmB), act against different types of fungi, and have clinical effects in many cases. By inhibiting the fungus cytochrome P-450 3A-dependent enzyme lanosterol 14-alpha-demethylase, the antifungal azoles disturb the conversion of lanosterol to ergosterol [64]. The conversion of lanosterol to ergosterol, which is used in cell wall synthesis, is one of the important functions of this enzyme. The essential nitrogen of the azole ring binds firmly to the 


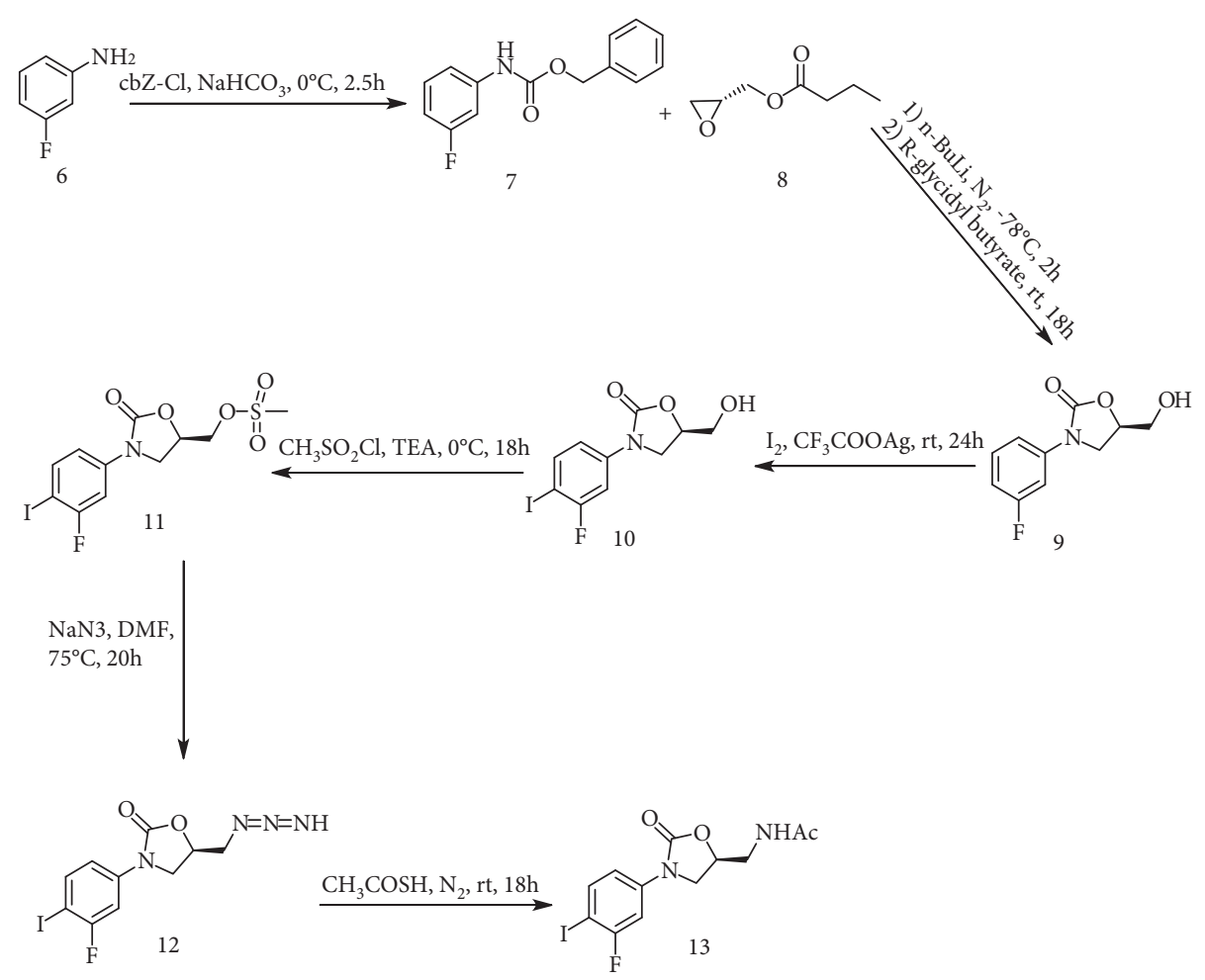

Scheme 11: Pathways of intermediate 13 synthesis.

fungus cytochrome P450 hemiron in this mechanism, preventing the bond between the substrate and oxygen. Accumulation of sterols, alteration of permeability, and dysfunction of membrane proteins are the result of $14 \alpha$ demethylase inhibition. The inhibitory pathway of ergosterol biosynthesis is shown in Scheme 16 [65].

Azole antifungal drugs have shown a modern period in antifungal chemotherapy. Despite sharing a similar mechanism, they vary in pharmacokinetics, toxicity, and fungal spectrum (Table 1) [66]. Other key factors in the early steps of development may increase the options available in this significant group of compounds. The addition of broadspectrum triazoles provides physicians with more effective and less toxic alternatives to Amphotericin B [67].

2.4. Review of the Latest Papers in the Synthesis of Novel 1,2,3Triazole as an Antifungal Agent and Evaluating StructureActivity Relationship (SAR)

2.4.1. 1,2,3-Triazole-Coumarin, Chromene, and Pyrane Hybrids. A series of novel 1,2,3-triazole-tethered coumarin conjugates linked by $N$-phenyl acetamide were effectively generated in high yields. Investigation of antifungal effect was performed against Fusarium oxysporum, Candida albicans, Aspergillus niger, Cryptococcus neoformans, and Aspergillus flavus. As shown in Figure 3, Compounds 39a, 39b, 39c, 40a, and 40b showed a high antifungal activity compared with Miconazole [68].

Dharavath et al. [69] reported a method for synthesizing several coumarin-based 1,2,3-triazole compounds using a
copper(I)-catalyzed click reaction between different substituted aryl azides and the end alkynes. All of the synthesized compounds were investigated for in vitro fungistatic effect against three fungus strains, Aspergillus flavus, Fusarium oxysporum, and Aspergillus niger, and the results were compared with standard drug (Clotrimazole). Six compounds (41a-f) showed better efficacy in contrast with the three pathogenic fungi (Figure 4).

A series of new 1,2,3-triazole derivatives of quinolinone, benzyl, and coumarin were synthesized and tested for antifungal activity (Figure 5). All of the azole derivatives were tested for antifungal activity against 8 different fungal strains, four of which were Candida species (yeast samples) and the other four were Aspergillus species (filamentous fungi). Almost all of the compounds demonstrated excellent antifungal efficacy. According to the findings of SAR investigations, electron withdrawing or donating groups do not seem to be a main factor in decreasing or increasing antifungal activity [70].

A novel class of 1,2,3-triazole based on coumarin was synthesized and assessed for antifungal behavior against three fungi (Penicillium chrysogenum, Curvularia lunata, and Aspergillus niger). All of the compounds displayed modest to good activity toward $P$. chrysogenum, C. lunata, and A. niger strains (Figure 6) [71].

Shaikh et al. [72] reported a class of new ethyl-7-((1(benzyl)-1H-1,2,3-triazole-4-yl)methoxy)-2-oxo- $2 H$-chromene-3-carboxylates as a possible fungicide. The fungicidal property assessed the impact of five human pathogenic fungal strains, like Candida albicans, Aspergillus flavus, Aspergillus niger, Fusarium oxysporum, and Cryptococcus 

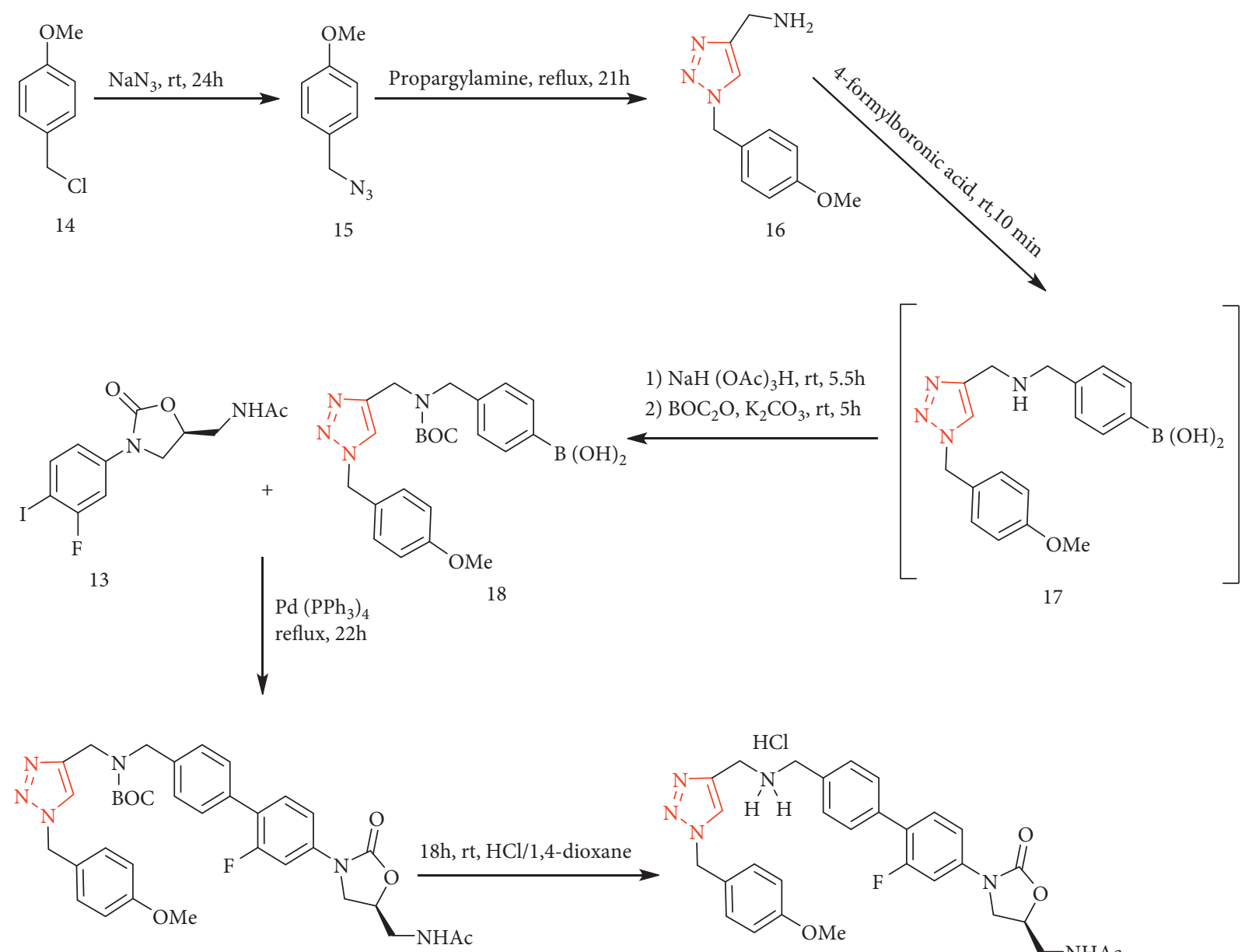

19

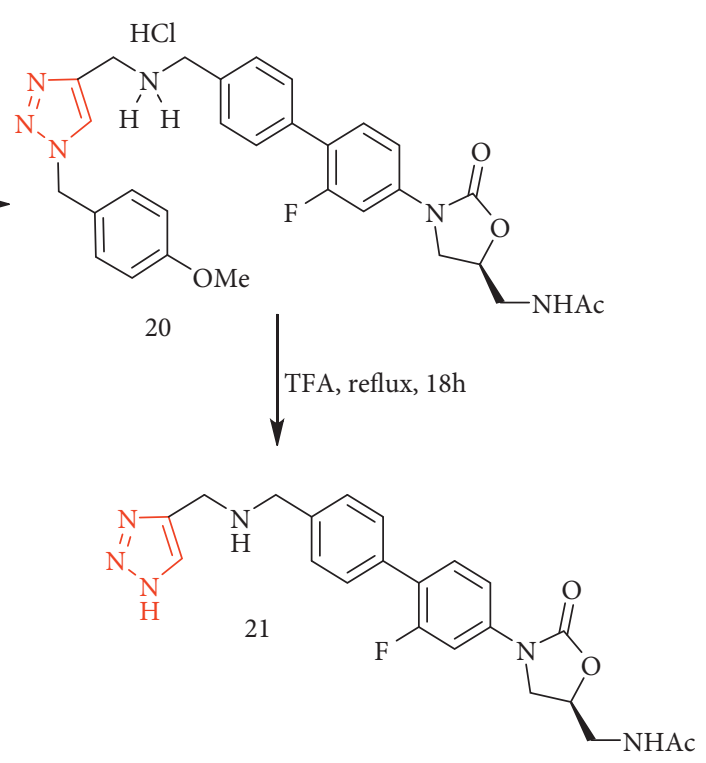

Scheme 12: Pathway of Radezolid synthesis.

neoformans. As shown in Figure 7, compounds 46a, 46b, 46c, and 46e had comparable activity against Candida albicans to Miconazole, while compound 46d was twofold more active than the standard drug, which is similar to Fluconazole against Candida albicans. When compared to Miconazole, compounds $46 \mathrm{~b}\left(R_{2}=\mathrm{Cl}\right)$ and $46 \mathrm{~d}\left(R_{3}=\mathrm{F}\right)$ displayed equivalent effectiveness against the fungal strain A. niger. The addition of a triazole ring to coumarin increased the antifungal activity of the synthesized compounds. The addition of a triazole ring to coumarin improved the antifungal activity of the synthesized compounds.

Gondru et al. [73] developed a new series of triazolethiazole hybrids using the multicomponent reaction approach. In vitro antimicrobial activity investigations were evaluated. The results showed that, among the synthesized compounds, $48 \mathbf{a}-\mathbf{d}$ and $48 \mathrm{e}$ were active and exhibited activity that is equal to or more than that of the conventional medicine against several Candida strains. Although the compounds did not have a broad antifungal range, they were less active than the standard drug against some pathogenic strains (Figure 8).

The $1 H$-1,2,3-triazole-tethered $4 H$-chromeneD-glucose conjugates were synthesized using click chemistry of tetraO-acetyl-b-D-glucopyranosyl azide and propargyl ethers. As it is seen in Figure 9, the antifungal activities of $1 \mathrm{H}-1,2,3$ triazoles against Aspergillus flavus (ATCC 204304), Aspergillus niger (ATCC439), Saccharomyces cerevisiae (SH 20), 


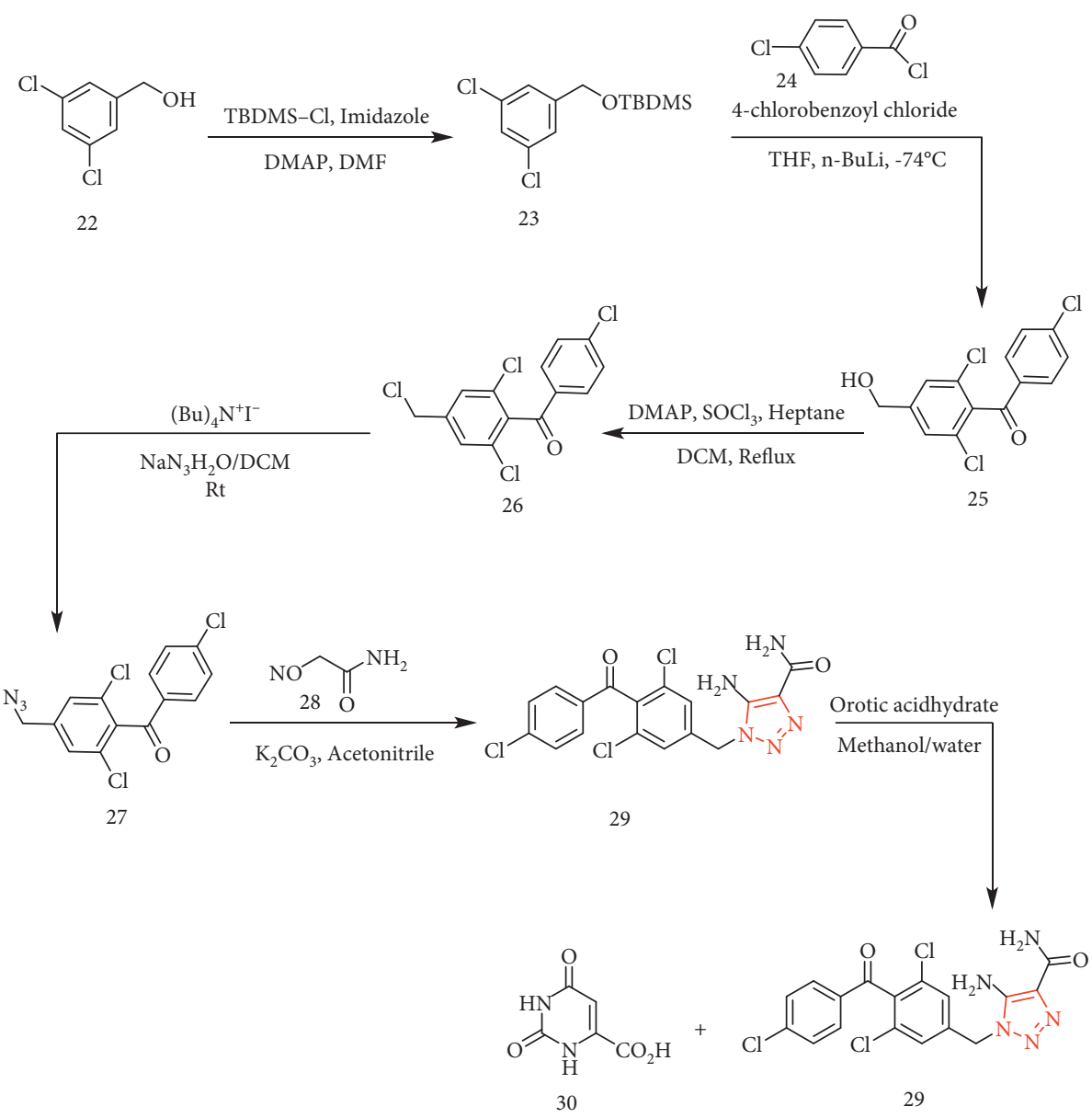

Scheme 13: Path of CAI synthesis.

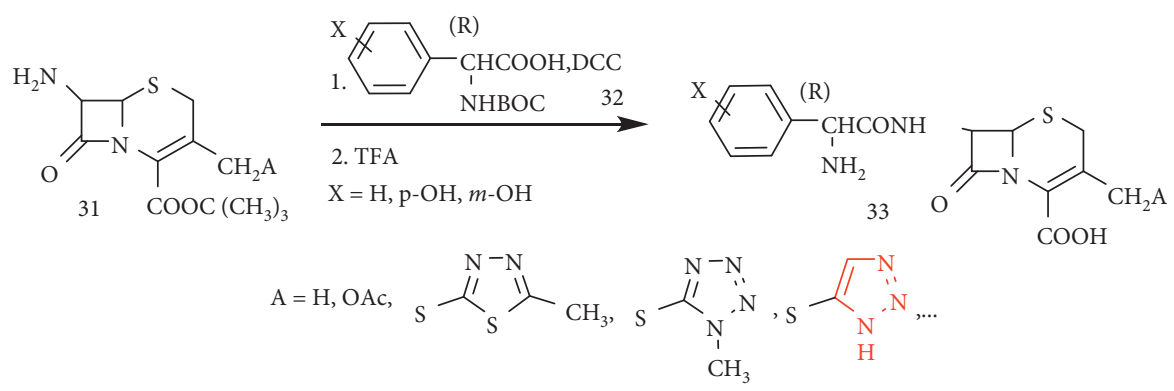

Scheme 14: Path of Cefatrizine synthesis.

and Candida albicans (ATCC7754) were evaluated. Fluconazole and Miconazole were used as standard drugs. Surprisingly, nearly all tested diazoles were more active against fungi C. albicans, S. cerevisiae, and A. flavus. Nonetheless, the triazoles were more resistant to $A$. niger than standard drugs. In fungi $A$. niger, approximately all of the compounds were less active than common medicines, with the exception of triazole 49c, with an MIC value of $1.56 \mu \mathrm{M}$. Compound 49a was more active against $C$. albicans than Miconazole but less active than Fluconazole, and compounds $49 \mathrm{f}$ and $49 \mathrm{~g}$ against $S$. cerevisiae were more active than Miconazole. In total, triazoles with big groups (methyl, methoxy, and isopropyl) in their phenyl ring were less active. Nevertheless, there are several unusual compounds (49b, 49c, and 49e) [74].

Khare et al. [75] developed a green and impressive protocol for the synthesis of new 1,2,3-triazole-chromene conjugates using ultrasound-assisted and $\mathrm{NaHCO}_{3}$-catalyzed reactions. Triazole-chromene compounds were evaluated for fungicidal activity against five different fungal strains: Fusarium oxysporum, Aspergillus flavus, Aspergillus niger, Cryptococcus neoformans, and Candida albicans, and several of them (50a-f) showed stronger activity $(\mathrm{MIC}=6.25-25 \mu \mathrm{g} / \mathrm{mL})$ compared to the standard drug 


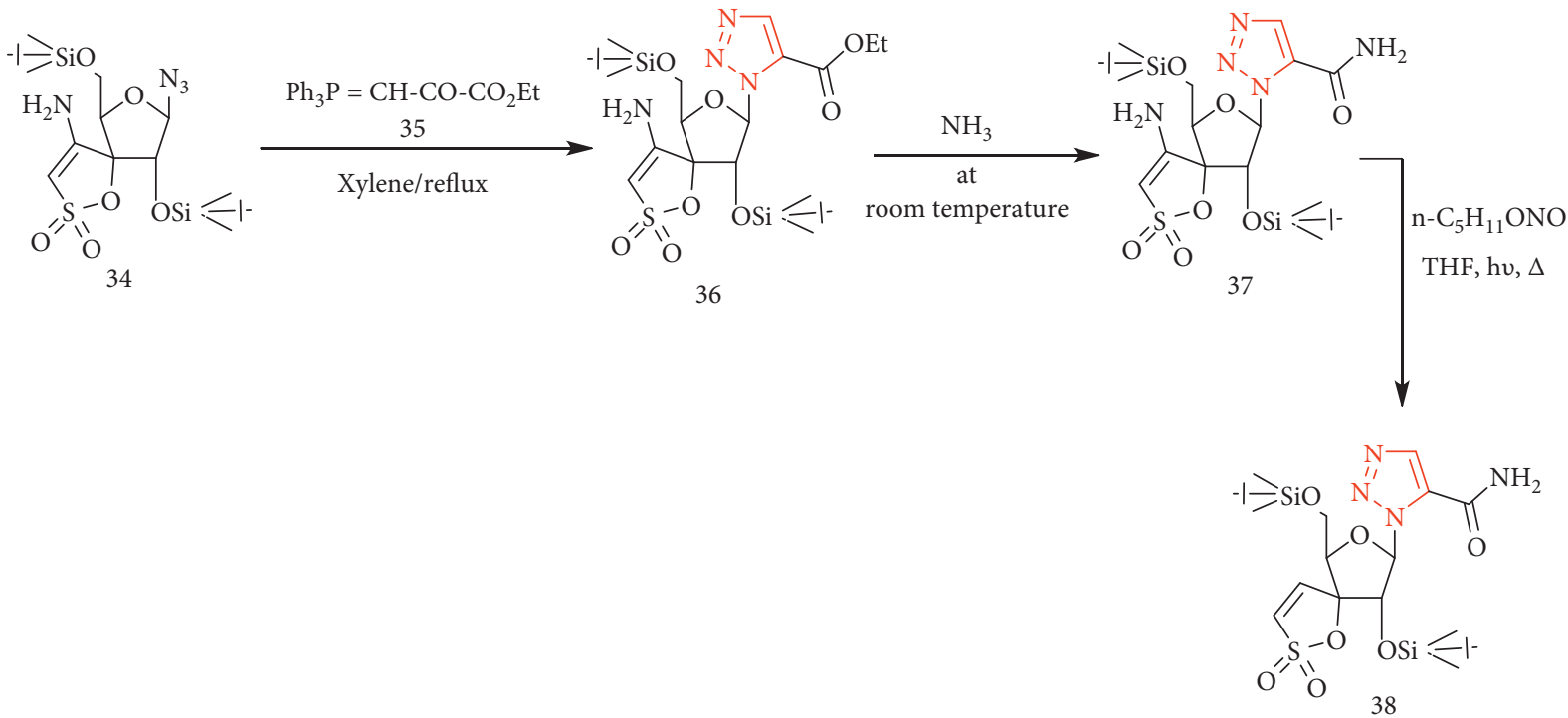

Scheme 15: The path of TSAO synthesis.

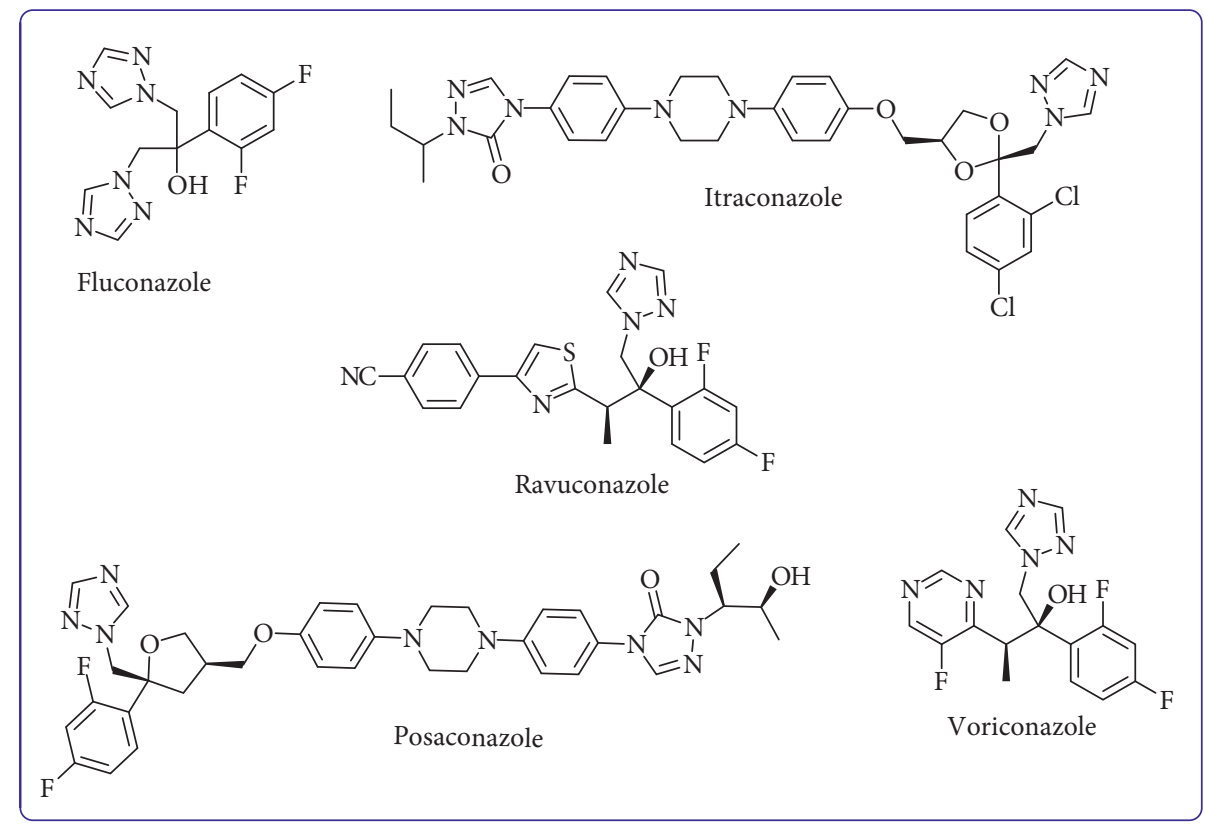

FIgURE 2: A few examples of antifungal triazoles.

Miconazole. Compound 50d (with $R=2$-OMe) was more active than Miconazole against $C$. albicans and displayed less antifungal activity against remaining fungal strains. Only compound 50f has displayed greater activity against A. flavus as compared to the other strains (Figure 10).

Dofe et al. [76] prepared a sequence of 3-((1-benzyl- $1 H$ 1,2,3-triazole-4-yl)methoxy)-2-(4-fluorophenyl)-4H-chromen-4-ones (51) via click chemistry. As shown in Figure 11, all of the compounds were tested for in vitro fungicidal activity toward Candida albicans, Candida tropicalis, and Candida glabrata. Significantly, 1,2,3-triazole-based chromones are more sensitive to C. glabrata and C. tropicalis fungal strains. When compared to the reference drug
Miconazole, compounds 51a and 51b displayed equivalent activity against $C$. albicans. Compounds 51a and $\mathbf{5 1 b}$ with an MIC of $12.5 \mu \mathrm{g} / \mathrm{mL}$ are very strong antifungal agents against C. glabrata and C. tropicalis, respectively.

Kant et al. [77] described the synthesis of 1,2,3-triazoleconnected chalcone and flavone hybrids. The recent synthesized compounds were screened for their antifungal behavior toward Candida parapsilosis, Candida tropicalis, Cryptococcus neoformans, Dermatophyte, and Candida albicans and also molds Aspergillus fumigatus and Aspergillus niger. Figure 12 shows that compounds 52b, 53a, 53b, 54a, 55a, 55b, 55c, 56a, and 56b displayed good antifungal behaviors as compared to the corresponding reference 


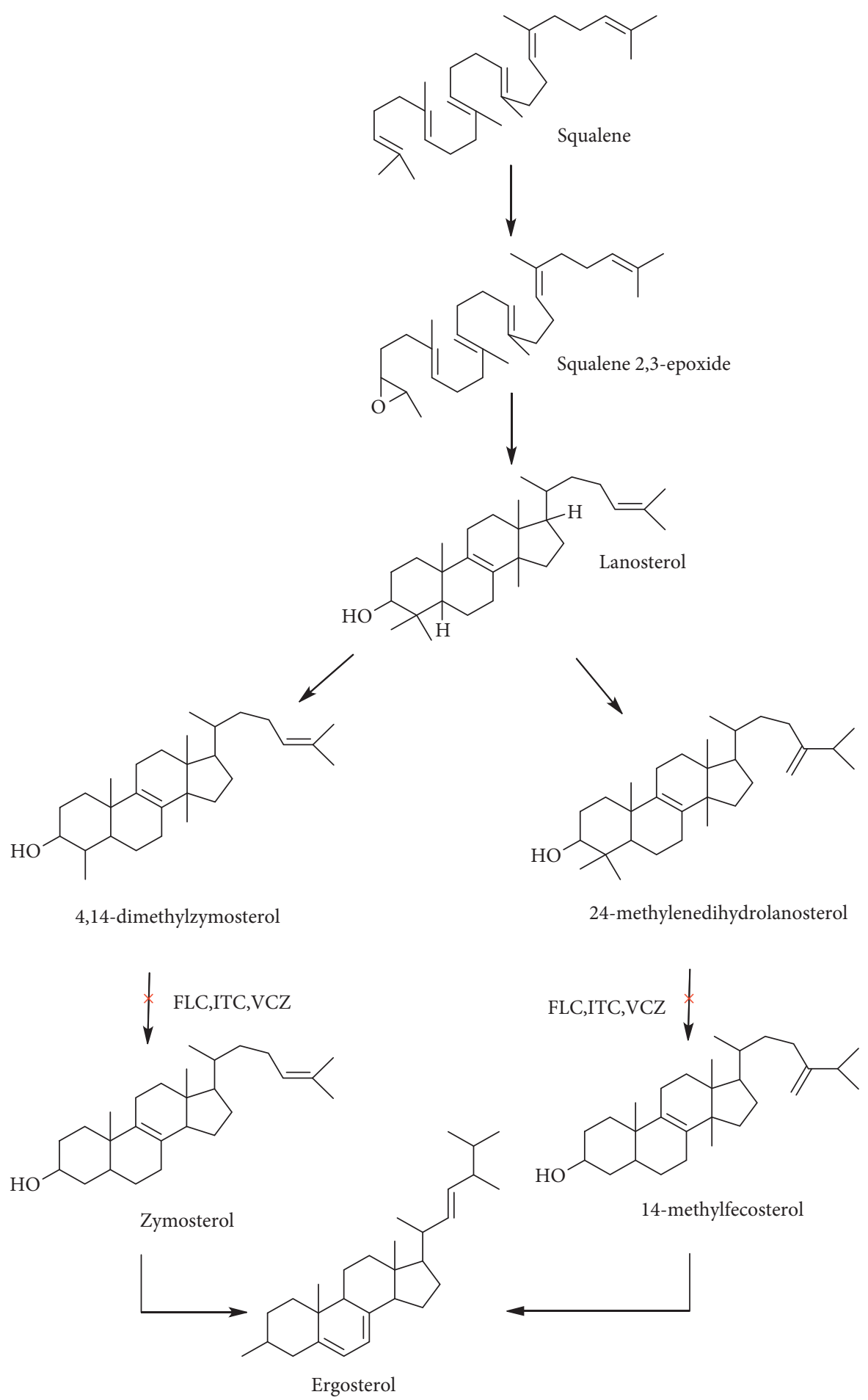

Scheme 16: Ergosterol biosynthesis inhibitor pathway.

medications. Compound 52a, including 2-chloro-4-fluorosubstituted benzene ring, displayed modest to good activity with MIC ranges of $25-100 \mu \mathrm{g} / \mathrm{mL}$ and $100 \mu \mathrm{g} / \mathrm{mL}$ compared to Fluconazole in the range of $0.5-4.0 \mu \mathrm{g} / \mathrm{mL}$ against all examined strains. Flavone compounds $\mathbf{5 5 a}$ and $\mathbf{5 5 b}$ containing 2-chloro-4-fluoro- and 3-chloro-4-fluorosubstituted benzene ring in order displayed good activity against four strains. Amalgamation of chloro and fluoro atoms in benzene ring has greater antifungal activity than monohalogen compounds in one-triazole-connected flavones. But the existence of 2-chloro or its composition with fluoro group in phenyl ring displayed stronger activity than other groups and their combinations in flavones included two triazole units.

A new model has been proposed and synthesized, consisting of the development of double pharmacophores of 
TABLE 1: Mechanism of action of 1,2,3-triazole-based marketed drugs.

\begin{tabular}{|c|c|c|c|}
\hline Name & Type of triazole & Mechanism of action & Ref. \\
\hline Cefatrizine & 4-monosubstituted & $\begin{array}{l}\text { Second-generation cephalosporin. } \\
\text { Cefatrizine is utilized to treat many types of infections, including } \\
\text { respiratory tract, skin, ear, and urinary tract infections. }\end{array}$ & $\begin{array}{l}{[51]} \\
{[66]}\end{array}$ \\
\hline Tazobactam & 1-monosubstituted & $\begin{array}{c}\text { Powerful irreversible } \beta \text {-lactamase (SHV-1 and TEM) inhibitory activity } \\
\text { and very low antibacterial activity. Tazobactam is combined in the drug } \\
\text { piperacillin/tazobactam, which is used in infections caused by } \\
\text { Pseudomonas aeruginosa. }\end{array}$ & {$[34,66]$} \\
\hline $\begin{array}{l}\text { Carboxyamidotriazole } \\
\text { (CAI) }\end{array}$ & $\begin{array}{l}\text { 1,4,5-trisubstituted } \\
\text { triazole }\end{array}$ & $\begin{array}{l}\text { CAI has antiangiogenic, antimetastatic, and antitumor properties owing to } \\
\text { its ability to indirectly participate in the Store-Operated Calcium Entry. }\end{array}$ & {$[66]$} \\
\hline Radezolid & 4-monosubstituted & $\begin{array}{l}\text { Antibiotic, active against bacteria (Gram-negative and Gram-positive) that } \\
\text { connect to the } 50 \mathrm{~S} \text { ribosomal subunit. Radezolid has been used in the } \\
\text { treatment of abscess and infectious skin diseases. }\end{array}$ & {$[40,66]$} \\
\hline TSAO & $\begin{array}{l}\text { 4- or 5-substituted } 1,2,3- \\
\text { triazoles }\end{array}$ & $\begin{array}{c}\text { TSAO nucleoside analogs inhibit human replication of immunodeficiency } \\
\text { virus type } 1 \text { (HIV-1), simian immunodeficiency virus (SIV), or RNA } \\
\text { viruses and other DNA }\end{array}$ & [61] \\
\hline
\end{tabular}

The Compounds $39 \mathrm{a}, 39 \mathrm{~b}$ respectively with having $\mathrm{CH}_{3}$ group at ortho and para situations of the phenyl ring and compound $39 \mathrm{c}$ with $\mathrm{Cl}$ group at ortho position exhibited an equal or twice more powerful than Miconazole against all the fungal strains

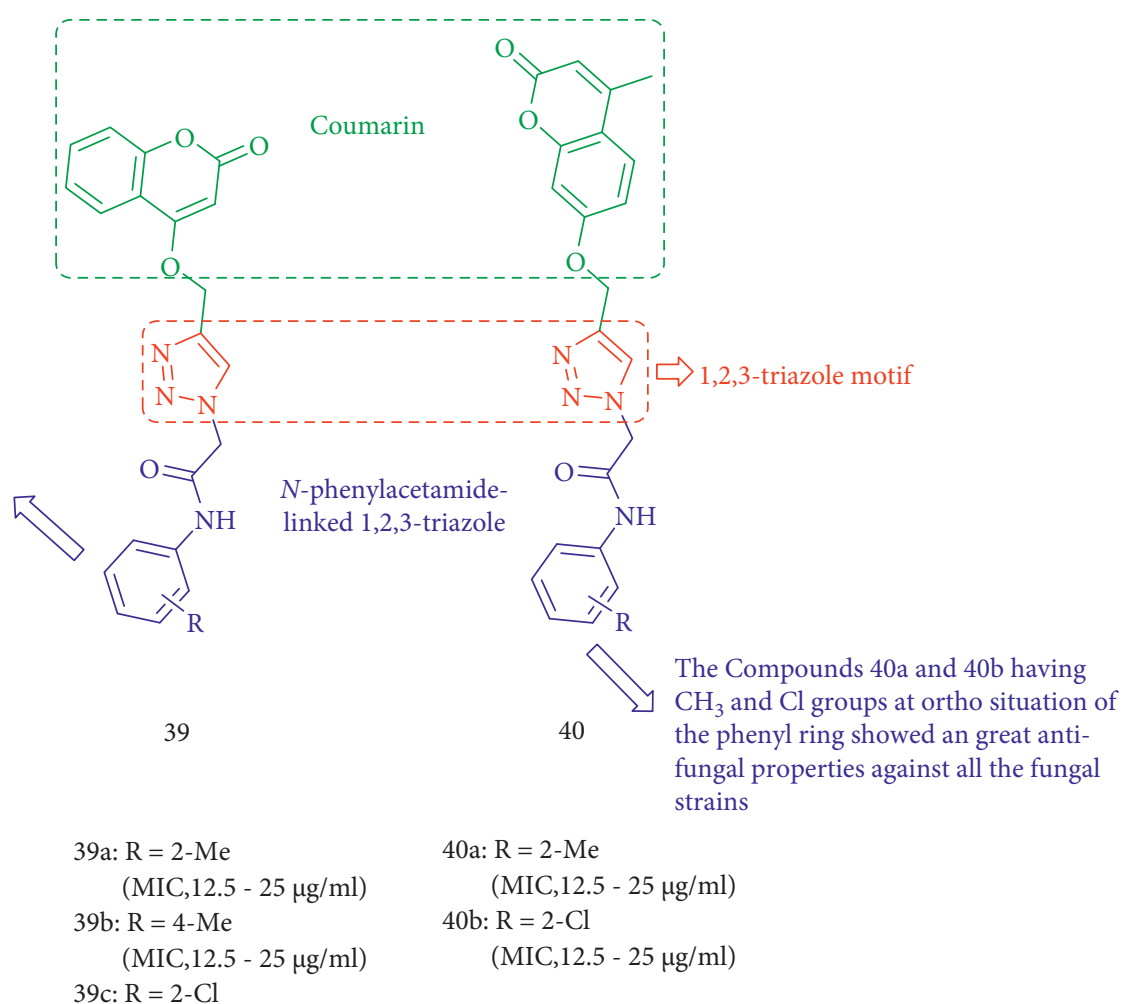

(MIC, $12.5-25 \mu \mathrm{g} / \mathrm{ml}$ )

FIgURE 3: Chemical structure of new N-phenylacetamide-linked 1,2,3-triazole-coumarin conjugates.

pyrano-[2,3-d]-pyrimidine-attached 1,2,3-triazole derivatives in an exceptional molecular hybrid with antimicrobial activity (bacteria and fungi). The antifungal efficacy of the target compounds toward Aspergillus flavus and Candida albicans is outstanding. Ketoconazole (zone of inhibition $14.0-20.5 \mu \mathrm{g} / \mathrm{mL}$ ) was applied as the standard medicine for antifungal activity (Figure 13). Meanwhile, three compounds $(57 \mathbf{a}-\mathbf{c})$ exhibited significant fungicidal activity against all of the studied fungi when compared to ketoconazole owing to groups (nitro and fluoro) linked to the 1,2,3triazole of the pyranopyrimidine ring [78].
A class of dehydroacetic acid chalcone-1,2,3-triazole hybrids were synthesized as possible antibacterial agents. All of the compounds were screened in vitro toward two fungal strains (Candida albicans and Aspergillus niger) and four bacterial strains (Figure 14). Almost all of the compounds performed better than DHA, which is an antimicrobial agent. The antifungal activity of combination $\mathbf{5 8 h}$ $\left(R_{1}=\mathrm{OCH}_{3}\right)$ against $A$. niger and $C$. albicans showed MIC values of 0.0068 and $0.0034 \mu \mathrm{M} / \mathrm{mL}$, respectively. When compared to $A$. niger, compounds $\mathbf{5 8 a}-\mathbf{h}$ were more potent than the standard drug, but in the case of C. albicans, 


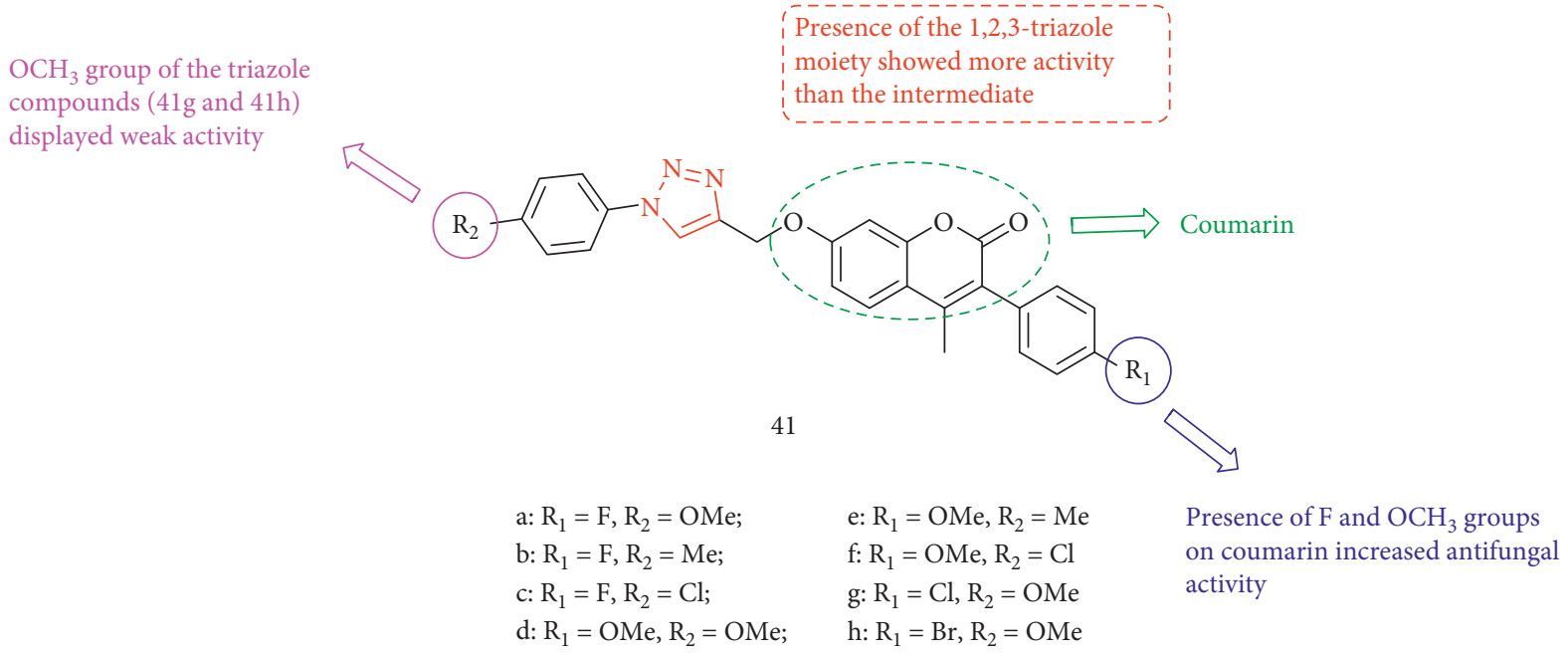

FIGURE 4: Chemical structure coumarin-based 1,2,3-triazole compounds.

The results of anti-fungal activities disclosed that $\mathrm{OCH}_{3}$ and $\mathrm{Cl}$ substituted coumarins $42 \mathrm{a}$ and $42 \mathrm{~b}$ ) were realy active against yeast strains.

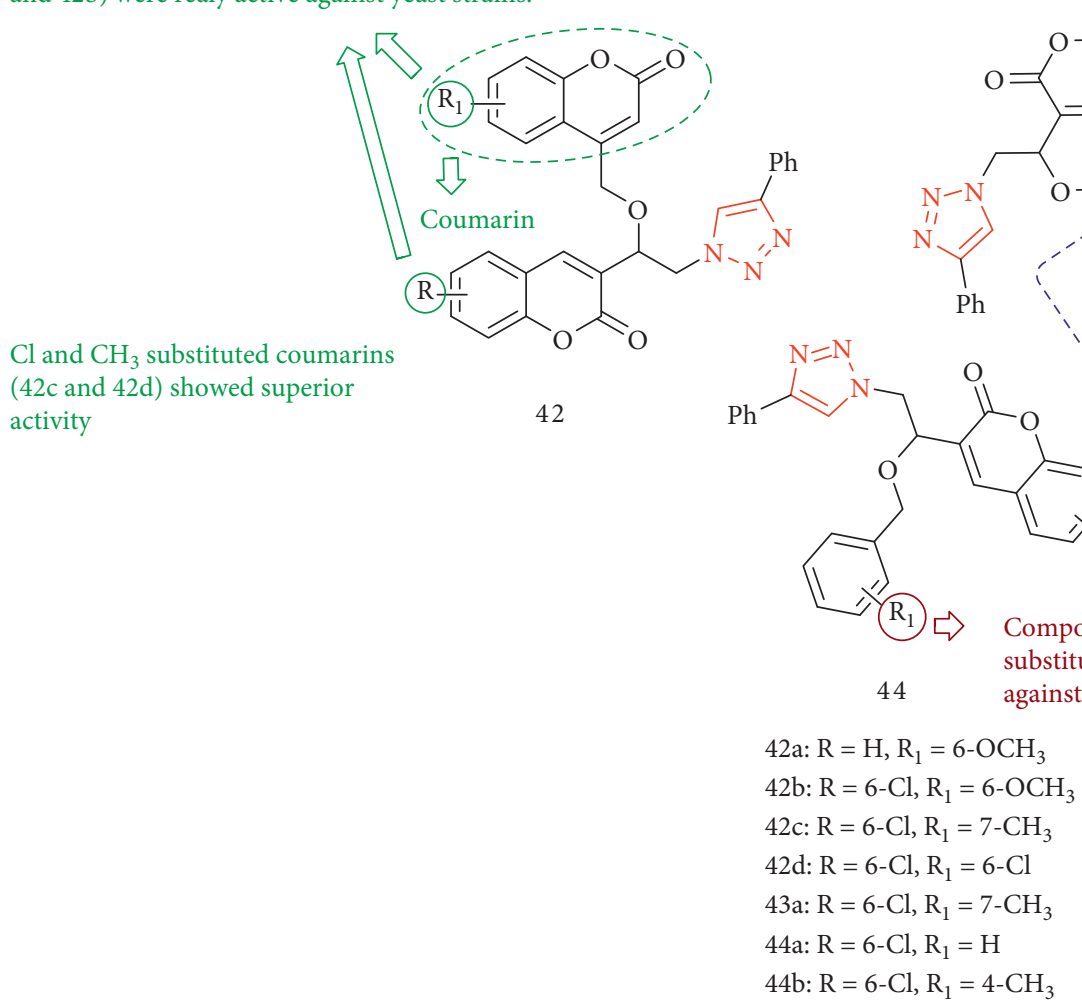

$\mathrm{Cl}$ substituted coumarin with $\unlhd \mathrm{CH}_{3}$ substituted quinolinone (43a) was found to extremely i) active against filamentous strain A.niger and yeast fungi<smiles>CCCCCC=C1C=CCCC1</smiles><smiles>[C]1C=CC=CC=C1</smiles>

43

Figure 5: Chemical structure of coumarin, quinolinone-linked 1,2,3-triazoles.

compounds $\mathbf{5 8 g}$ and $\mathbf{5 8 h}$ revealed significant activity among all synthesized triazoles [79].

\subsubsection{1,2,3-Triazole-Amide Hybrids. González-Calderón} et al. [80] used a one-pot method to synthesize new benzylic 1,2,3-triazole-4-carboxamides with passable yields. As shown in Figure 15, the sequence of compounds was evaluated for antifungal activity in vitro toward four filamentary fungi and four Candida species. Compounds 59b and 59c were the most impressive fungal factors (of all the trial compounds) against $R$. oryzae, even better than the standard medicine $(\mathrm{MIC}=0.017 \mu \mathrm{mol} / \mathrm{mL}$ for $59 \mathrm{~b}$ and $59 \mathrm{c}$; $\mathrm{MIC}=0.14 \mu \mathrm{mol} / \mathrm{mL}$ for Itraconazole). The SAR for compounds 59b and 59c showed that the 4-phenyl-4-carboxamide triazole was accountable for the antifungal result, 
Almost all of the synthesized compounds are more active against the fungi strain C. lunata as compared to reference medicines Miconazole and Amphotericin B.

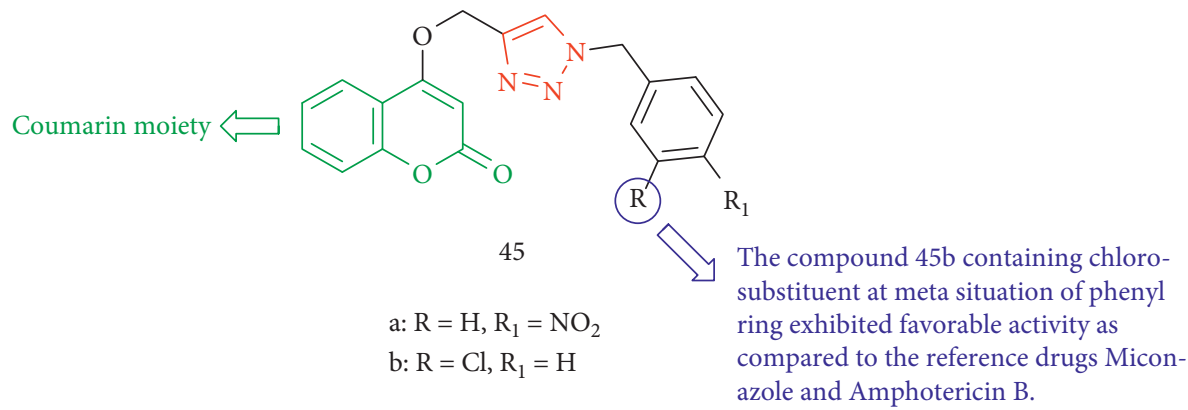

FIGURE 6: Chemical structure of novel coumarin incorporated triazoles.

Most of the compounds were inactive against the fungal strain A. niger, A. flavus and C. neoformans

Ethyl-2-oxo-7-(prop-2-yn-1-yloxy) $-2 \mathrm{H}$-chromene-3-carboxylate

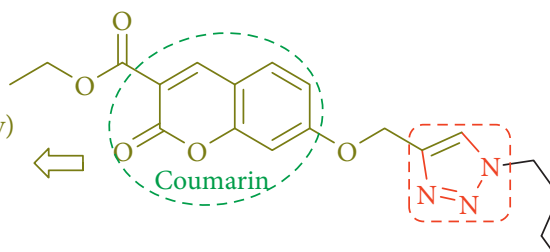

$=$

$\mathrm{R}_{3}$

Compounds with (chloro-group at para, meta and ortho), and 46e with MIC amounts $25 \mu \mathrm{g} / \mathrm{mL}$ displayed equal power for fungal strain $C$. albicans compared to the Miconazole.

$$
\begin{array}{ll}
46 & \begin{array}{l}
\text { Compound } 46 \mathrm{~d} \text { containing fluoro-group } \\
\text { at para situation of phenyl ring has been } \\
\text { showed good stopper of } \mathrm{C} \text {. albicans }
\end{array} \\
\text { a: } \mathrm{R}_{1}=\mathrm{H}, \mathrm{R}_{2}=\mathrm{H}, \mathrm{R}_{3}=\mathrm{Cl} & \text { with MIC amounts } 12.5 \mu \mathrm{g} / \mathrm{mL} \text { and double } \\
\text { b: } \mathrm{R}_{1}=\mathrm{H}, \mathrm{R}_{2}=\mathrm{Cl}, \mathrm{R}_{3}=\mathrm{H} & \text { active as compared to the Miconazole } \\
\text { c: } \mathrm{R}_{1}=\mathrm{Cl}, \mathrm{R}_{2}=\mathrm{H}, \mathrm{R}_{3}=\mathrm{H} & \text { and similar to Fluconazole. } \\
\text { d: } \mathrm{R}_{1}=\mathrm{H}, \mathrm{R}_{2}=\mathrm{H}, \mathrm{R}_{3}=\mathrm{F} & \\
\text { e: } \mathrm{R}_{1}=\mathrm{H}, \mathrm{R}_{2}=\mathrm{H}, \mathrm{R}_{3}=\mathrm{H} &
\end{array}
$$

FIgURE 7: Chemical structure of 1,2,3-triazole incorporated coumarin derivatives.

The compounds $48 \mathrm{a}$ and $48 \mathrm{~b}$ dis- played antifungal activity against C.albicans MTCC 854 and Issatchenkia hanoiensis MTCC 4755 at MIC amount of $7.1 \mu \mathrm{M}$ and $6.5 \mu \mathrm{M}$ in order that is smaller than the reference drug.<smiles>[R3]c1c(-c2ccccc2)cc(Br)c2oc(=O)c(-c3csc(N/N=C/c4ccc(OC/C=C/c5ccc(C(C)(C)C)cc5)cc4)n3)cc12</smiles>

$\mathrm{H}_{3} \mathrm{C}$<smiles>COc1ccc(-n2cccn2)cc1</smiles>

$$
\begin{aligned}
& \text { 48a: } \mathrm{R}_{1}=\mathrm{R}_{2}=\mathrm{R}_{3}=\mathrm{H} \\
& \text { 48b: } \mathrm{R}_{1}=\mathrm{H}_{2} \mathrm{R}_{2}=\mathrm{R}_{3}=\mathrm{C}_{4} \mathrm{H}_{4} \\
& \text { 48c: } \mathrm{R}_{1}=\mathrm{OCH}_{3}, \mathrm{R}_{2}=\mathrm{R}_{3}=\mathrm{H} \\
& \text { 48d: } \mathrm{R}_{1}=\mathrm{OCH}_{3}, \mathrm{R}_{2}=\mathrm{Br}, \mathrm{R}_{3}=\mathrm{H} \\
& \text { 48e: } \mathrm{R}_{1}=\mathrm{R}_{2}=\mathrm{NO}_{2}, \mathrm{R}_{3}=\mathrm{H}
\end{aligned}
$$

The compound 48d (6-bromo-8-methoxycoumarinyl; MIC, $5.9 \mu \mathrm{M}$ ) was found to be a very strong hybrid of the examed sequence against most of the Candida spp when compared to Miconazole (MIC,18.7 $\mu \mathrm{M}$ ).

FIgURE 8: Chemical structure of synthesis of 1,2,3-triazole-thiazole hybrids. 
The triazoles carrying monomethoxy-substituted phenyl ring, showed moderate to most activity excluding $(49 a, 49 b, 49 c)$.

$\mathrm{OCH}_{3}$ group of these triazoles, except 49d decreased the antifungal activity against all tested fungi
2,3,4,6-tetra-O-acetyl-bD-glucopyranosyl azide

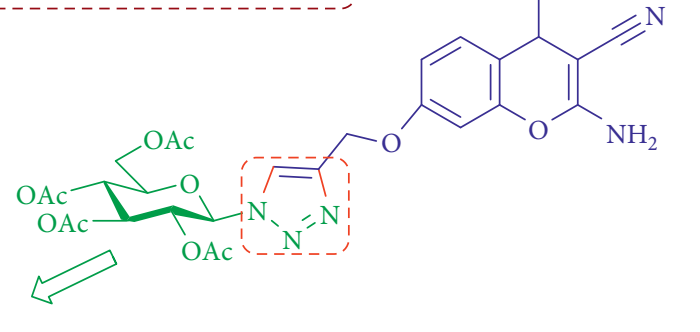

49

$$
\begin{aligned}
& \text { a: } \mathrm{R}=4-\mathrm{OMe} ; \mathrm{e}: \mathrm{R}=4-\mathrm{NO}_{2} \\
& \text { b: } \mathrm{R}=3-\mathrm{OMe} ; \mathrm{f}: \mathrm{R}=4-\mathrm{Cl} \\
& \text { c: } \mathrm{R}=2-\mathrm{OMe} ; \mathrm{g}: \mathrm{R}=4-\mathrm{Br} \\
& \mathrm{d}: \mathrm{R}=3 \text {, 4-dimethoxy }
\end{aligned}
$$

Figure 9: Chemical structure of novel $1 \mathrm{H}-1,2,3$-triazole-tethered $4 \mathrm{H}$ chromene-D-glucose conjugates.

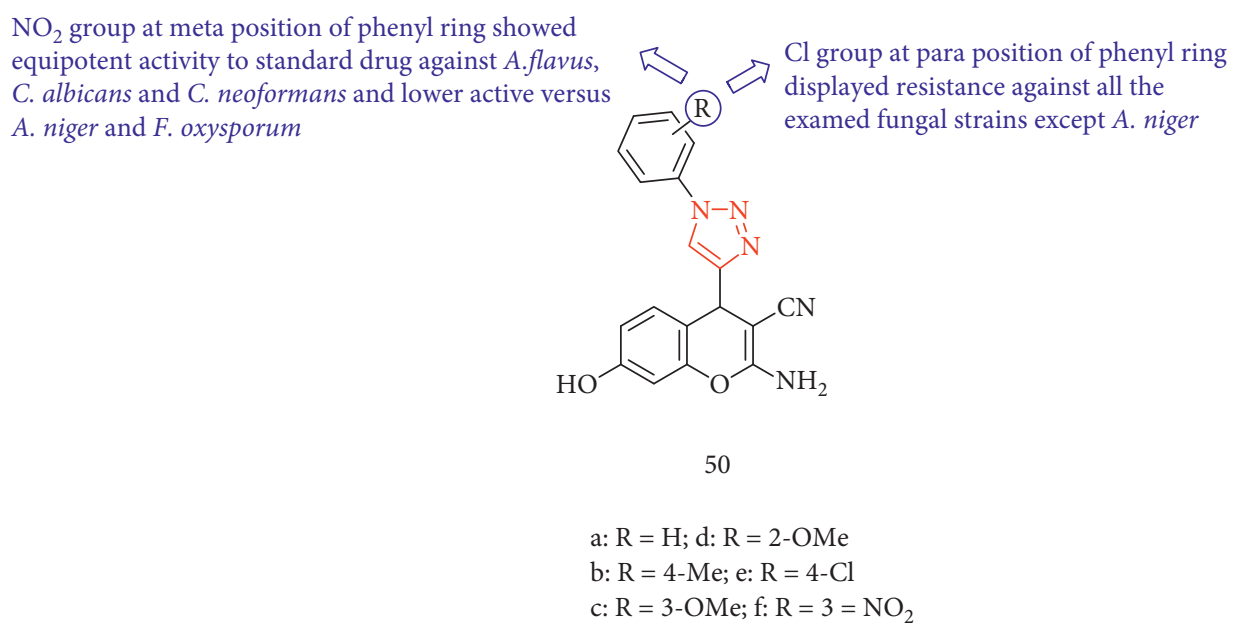

FIGURE 10: Chemical structure of novel triazole-chromene conjugates.

while neither the electron-wealthy ring (including piperonyl in 59c) nor the electron-needy ring (substituted with 2,6-dichloro to form $\mathbf{5 9 b}$ ) was related. Compounds with the largest functional groups in their structure exhibit lower activity than standard drug, indicating the need for a modest substituent in positions 1 and 5 of triazole to interact positively with the active site of the fungus.

A new class of $N$-Boc L-Leucine-connected 1,2,3-triazoles were synthesized and evaluated the fungicidal activity against A. niger and Candida albicans fungus strains using an MIC value of $0.0102 \mu \mathrm{mol} / \mathrm{mL}$. In case of both fungal strains, compounds 60a and 60b had approximately comparable activity with Fluconazole. Compounds 60a and 60c found a remarkable activity as compared to Fluconazole in the case of C. albicans (Figure 16) [81].

Kaushik et al. [82] reported a novel library of 1,2,3triazoles bridged with amine-amide functionalities from $N$-substituted (prop-2-yn-1-yl)amines and sodium azide and 2-bromo- $N$-arylacetamides by copper(I)-catalyzed. Antifungal assessment of recent derivatives was carried out against Aspergillus niger and Candida albicans. All compounds of synthesized 1,2,3-triazoles showed modest to good antifungal activity against fungi strains. Compounds 61a-f displayed good activity against C. albicans, while in case of $A$. niger, compounds $61 \mathrm{~b}, 61 \mathrm{c}$, and $61 \mathrm{~g}$ displayed significant activity (Figure 17).

The use of $\left[\mathrm{Et}_{3} \mathrm{NH}\right][\mathrm{OAc}]$ as a mediator in the performance of ultrasonic irradiation via click chemistry resulted in a simple, very impressive, and greener method for the preparation of novel 1,4-disubstituted-1,2,3-triazoles with high yields. These compounds were assessed in vitro for antifungal activity against five different fungus species: Aspergillus niger, Aspergillus flavus, Fusarium oxysporum, Cryptococcus neoformans, and Candida albicans. Some compounds have the same or greater power compared to the reference drug (Miconazole) (Figure 18) [83]. 
<smiles>[R]c1cc2c(=O)c(O)c(-c3ccc(F)cc3)oc2c([R])c1[R]</smiles>

Compound 51a with dichloro replacement and compound 51b with $\mathrm{Cl}, \mathrm{CH}_{3}$ substituent showed that the compounds with more electron donating groups are accountable for the increased activity of the compounds.

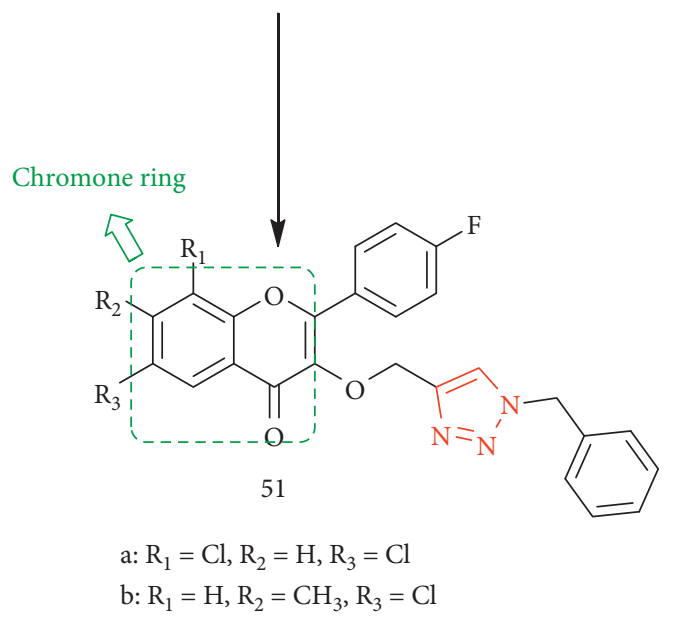

FIGURE 11: Chemical structure of novel chromone-based 1,2,3-triazoles.<smiles>[R]c1cccc(-n2cc(COc3ccc(/C=C/C(=O)c4c(O)cc(OC)cc4OC)cc3OC)nn2)c1</smiles>

Existence of chloro group in phenyl ring of one triazole unit chalcones exhibited powerful antifungal property, while difluoro compounds increased antifungal activity in two triazole connected chalcones.

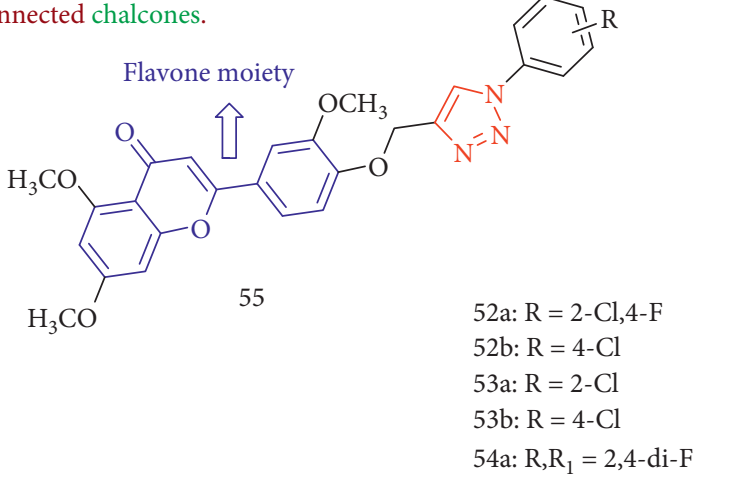

$55 \mathrm{a}: \mathrm{R}=2-\mathrm{Cl}, 4-\mathrm{F}$ $55 \mathrm{~b}: \mathrm{R}=3-\mathrm{Cl}, 4-\mathrm{F}$ $55 \mathrm{c}: \mathrm{R}=4-\mathrm{Cl}$ 56a: $\mathrm{R}, \mathrm{R}_{1}=2-\mathrm{Cl}, 4-\mathrm{F}$ 56b: $\mathrm{R}_{1} \mathrm{R}_{1}=2-\mathrm{Cl}$<smiles>[R]c1ccc(-n2cc(COc3ccc(-c4cc(=O)c5c(OC)cc(OC)cc5o4)cc3OCc3cn(-c4ccc([R])cc4)nn3)nn2)cc1</smiles>

The flavone compounds having difluoro substituted phenyl rings were found to be slow versus antifungal and also antibacterial activity.

FiguRE 12: Chemical structure of newer 1,2,3-triazole-linked chalcone and flavone hybrid compounds.

Aryloxy-linked dimeric 1,2,3-triazoles from azides and bis(prop-2-yn-1-yloxy)benzene were synthesized by Deshmukh et al. [84] using a $\mathrm{Cu}(\mathrm{I})$-catalyzed click chemistry approach with good to excellent yields.
All of the compounds were tested for antifungal activity against five different fungal strains: Cryptococcus neoformans, Fusarium oxysporum, Aspargillus flavus, Aspargillus niger, and Candida albicans, and Miconazole 


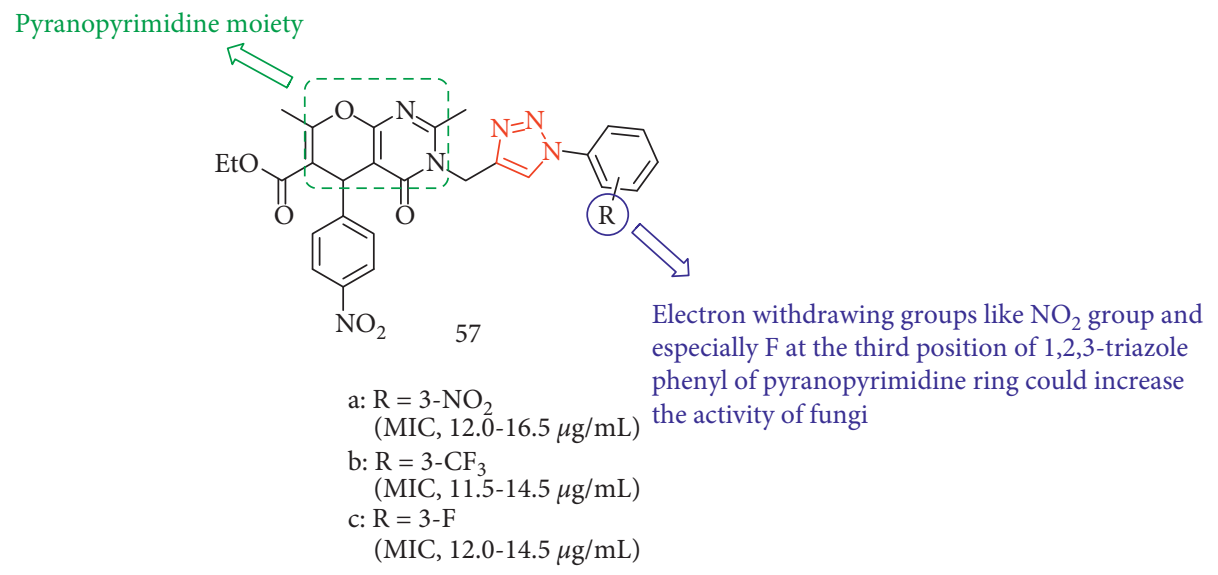

FIGURE 13: Chemical structure of pyrano-[2,3-d]-pyrimidine-attached 1,2,3-triazole derivatives.

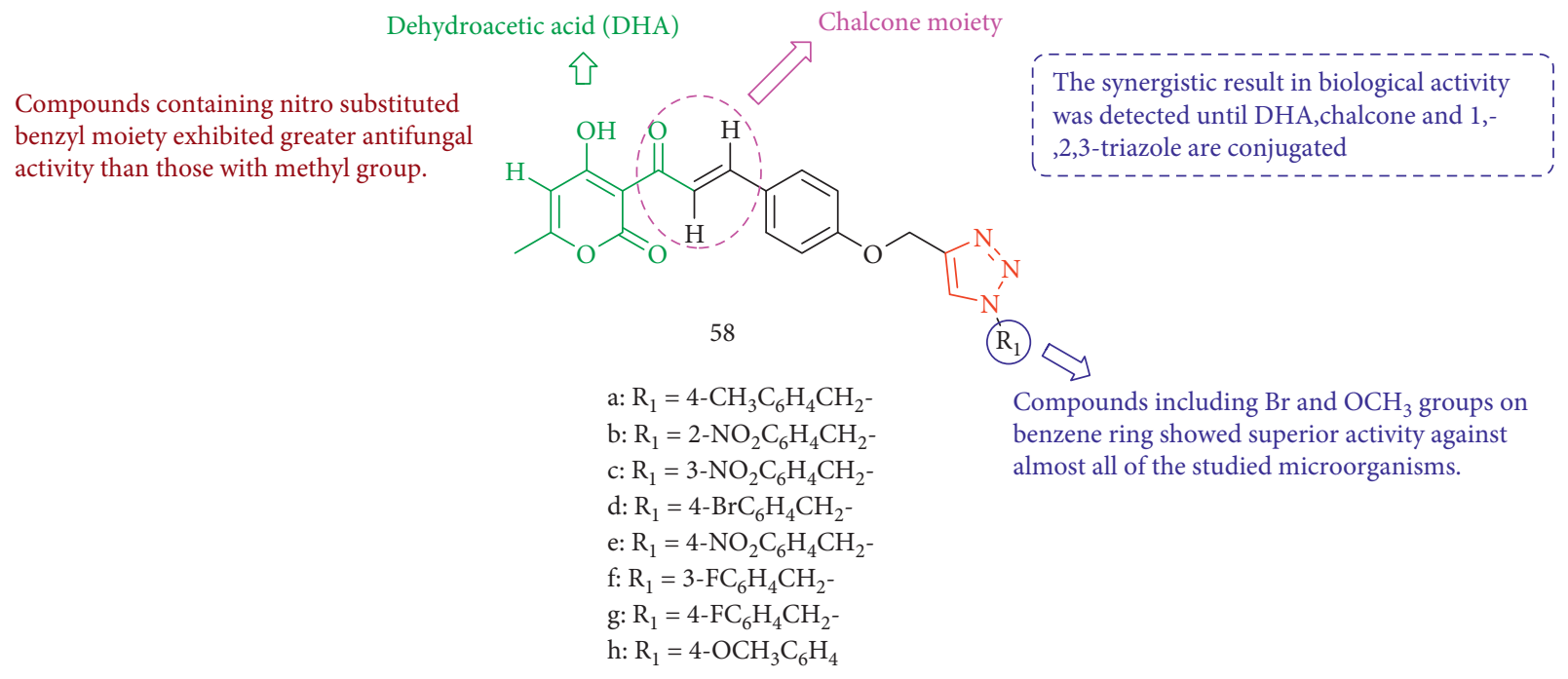

FIGURE 14: Chemical structure of dehydroacetic acid-chalcone-1,2,3-triazole hybrids.

The therapy with $59 \mathrm{~d}$ and $59 \mathrm{e}$ led to a very restricted affect on A. fumigatus.

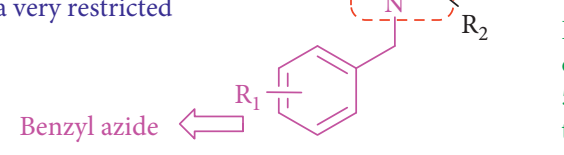

59
There was no structure-activity relationship for the yeast growth inhibition of $C$. albicans compled by the active compounds.

Little ethers as substituents meliorated the outcomes obtained, as proofed by the information for $59 \mathrm{a}$ and $59 \mathrm{c}$. Other serious facet is the size of the structure.

$$
\begin{aligned}
& \text { a: } \mathrm{R}_{1}=2 \text {, 3-dimethoxy, } \mathrm{R}_{2}=1,1^{\prime} \text {-biphenyl } \\
& \text { b: } \mathrm{R}_{1}=2 \text {, 6-dichloro, } \mathrm{R}_{2}=\text { phenyl } \\
& \text { c: } \mathrm{R}_{1}=1,3 \text {-dioxol, } \mathrm{R}_{2}=\text { phenyl } \\
& \text { d: } \mathrm{R}_{1}=2,6 \text {-dichloro, } \mathrm{R}_{2}=p \text {-tolyl } \\
& \text { e: } \mathrm{R}_{1}=1,3 \text {-dioxol, } \mathrm{R}_{2}=p \text {-tolyl }
\end{aligned}
$$

FIGURE 15: Chemical structure of novel benzylic 1,2,3-triazole-4-carboxamides.

is utilized as standard medicine. Most of the compounds showed moderate-to-great antifungal activity (Figure 19).
Yan et al. [85] synthesized 42 carboxamide derivatives, including a 1,2,3-triazole ring, and demonstrated antifungal activity against nine phytopathogens at $50 \mu \mathrm{g} / \mathrm{mL}$ boscalid as 


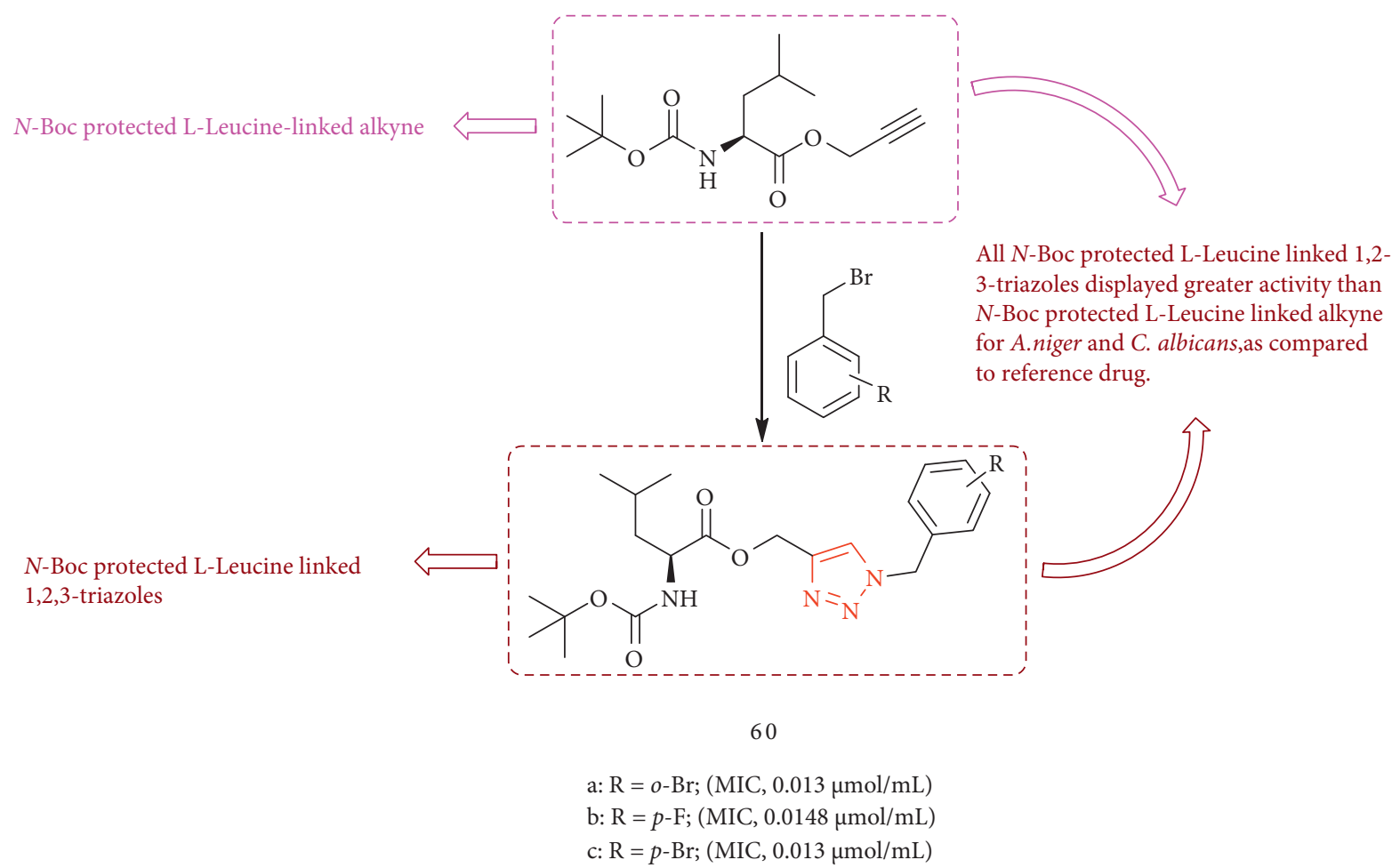

Figure 16: Chemical structure N-Boc-protected Leucine-linked 1,4-disubstituted 1,2,3-triazole.

The results showed that compounds having naphthyl moiety revealed premier activity in comparison to phenyl moiety.

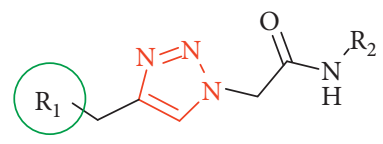

61
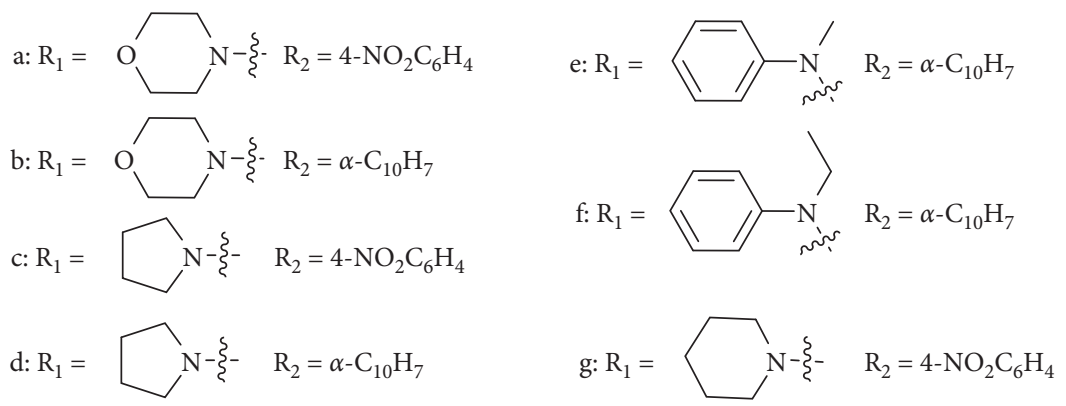

Figure 17: Chemical structure of amine-amide-linked 1,4-disubstituted 1,2,3-triazoles.

the positive control. The target compounds in sequence A displayed more extraordinary inhibitory activities against G. graminsis, S. sclerotiorum, B. cinerea, and $R$. cerealis compared to other fungus strains. In sequence $B$, compounds showed fewer antifungal activities than series A. Compound 65A3-1 revealed remarkable antifungal activity against Sclerotinia sclerotiorum, Botrytis cinerea, Rhizoctonia cerealis, and Gaeumannomyces graminsis, and it was chosen as the best compound for further investigation. When $R$ of the benzene was monosubstituted, the inhibitory rate of 65A1-1 $(p-\mathrm{Cl})$ was preferred over 65A1-2 $(p-\mathrm{F})$ and 65A1-3 $\left(p-\mathrm{OCH}_{3}\right)$, while $\mathrm{R}$ of the benzene was disubstituted; the activity of $65 \mathrm{Al}-\mathbf{4}(3,4-\mathrm{di}-\mathrm{Cl})$ was superior to those of 65A1-5 (3-Cl-4-F) and 65A1-6 (4-Cl-3- $\left.\mathrm{OCH}_{3}\right)$ (Figure 20).
Brahmi et al. [86] explored a novel sequence of semicarbazone-triazole hybrid derivatives with condensation among the commercial semicarbazide hydrochloride and heterocyclic aldehydes. The in vitro antifungal activities were examined against two fungus strains (Fusarium oxysporum and Fusarium phyllophilum) and showed the greatest inhibitory antifungal activity that was created for compound 66c against $F$. oxysporum in comparison to the standard drug. The ortho-methoxy substitution in the aryl ring (66e) is more acceptable for activity than the para-methoxy substituent (66d) because of the structure's fixation by intramolecular $\mathrm{H}$-bonds. The following antifungal activity levels were observed: $66 \mathrm{c}>\mathbf{6 6} \mathbf{e}>\mathbf{6 6 d}$ against $F$. oxysporum. 66a and 66b had low-to-moderate activity (Figure 21). 


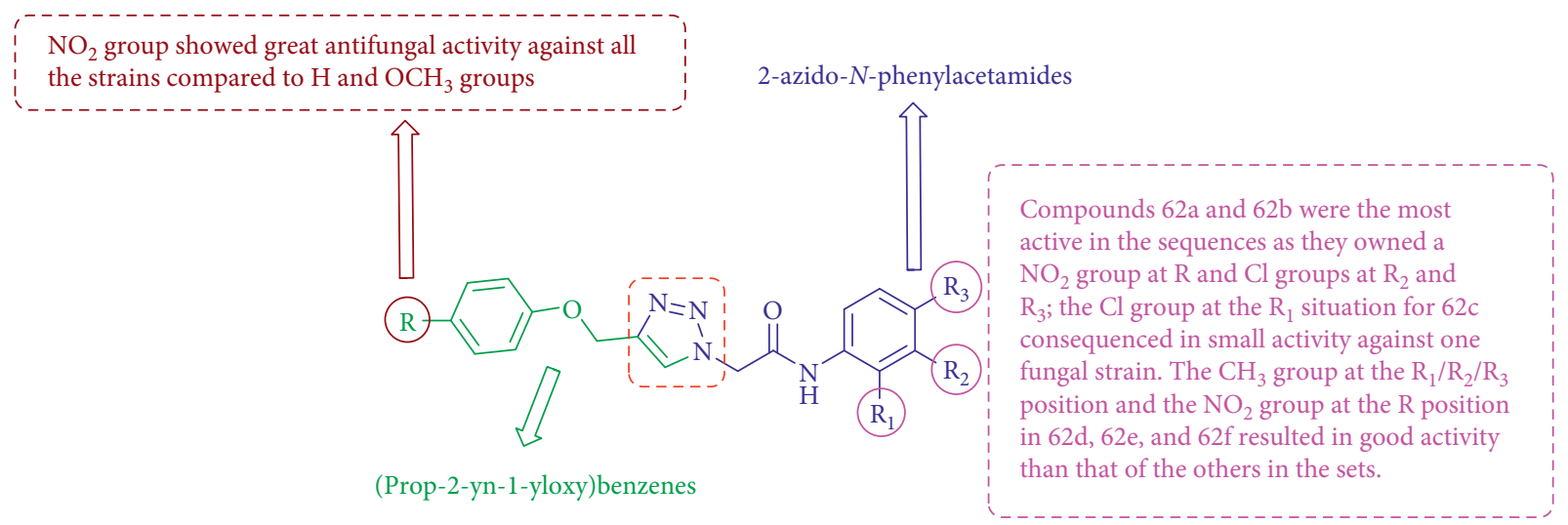

62

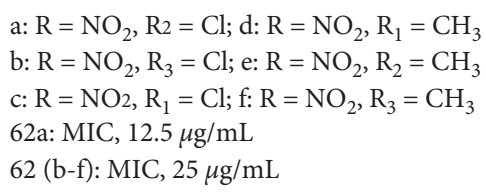

FIGURE 18: Chemical structure of new N-phenylacetamide-incorporated 1,2,3-triazoles.

1,3-bis (prop-2-yn-1-yloxy)benzene
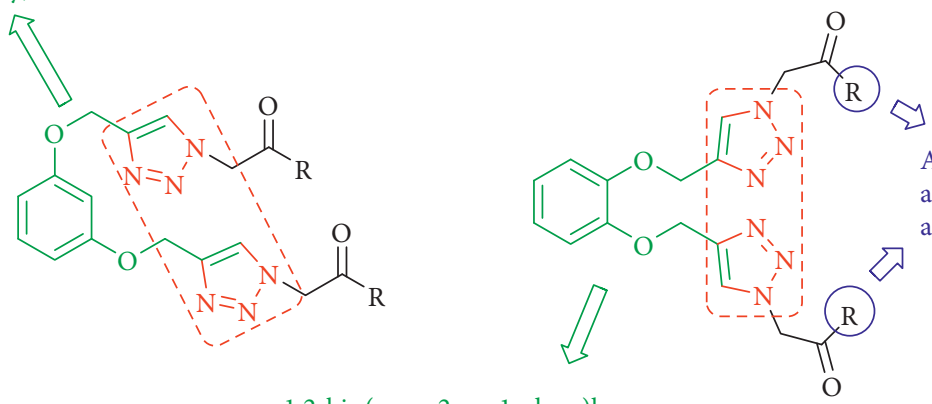

Among all compounds, $64 \mathrm{f}$ and and $64 \mathrm{~g}$ exhibited the greatest antifungal activity.

1,2-bis (prop-2-yn-1-yloxy)benzene

63

64

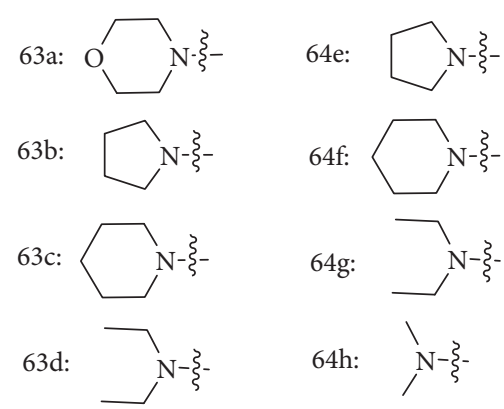

Figure 19: Chemical structure of new aryloxy-linked substituted dimeric 1,2,3-triazoles.

Kaushik and Luxmi [87] examined a collection of 25 amides linked to 1,4-disubstituted 1,2,3-triazoles. The antifungal activity of two fungus strains was also studied using a serial dilution approach. Fluconazole was employed as a conventional treatment, and compounds $67 \mathbf{a}$ and $67 \mathbf{b}$ showed moderate intense activity (Figure 22$)$.

Kaushik and Luxmi [88] synthesized 2-(4-(hydroxyalkyl)-1H-1,2,3-triazol-1-yl)- $N$-substituted propanamides using $\mathrm{Cu}(\mathrm{I})$ catalyzed reaction of 2 -azido- $N$-substituted propanamide and terminal alkynes. Furthermore, the antifungal activity of these triazoles was examined in vitro against two fungal strains (A. niger and $C$. albicans), with Fluconazole serving as a reference drug. Compounds 68a-c revealed powerful fungicidal activity against $C$. albicans and displayed good activity against $A$. niger (Figure 23).

Amide-ester-connected 1,4-disubstituted 1,2,3-triazoles were synthesized by employing Copper(I)-catalyzed 1,3dipolar cycloaddition of 2-azido- $N$-substituted acetamides and benzoic acid prop-2-ynyl esters. All of the compounds were evaluated for antifungal activity against two different 
65A1-4 (3,4-di-Cl), 65A2-1 and 65A3-1

exhibited the most principal antifungal

activities between compounds in sequence A.

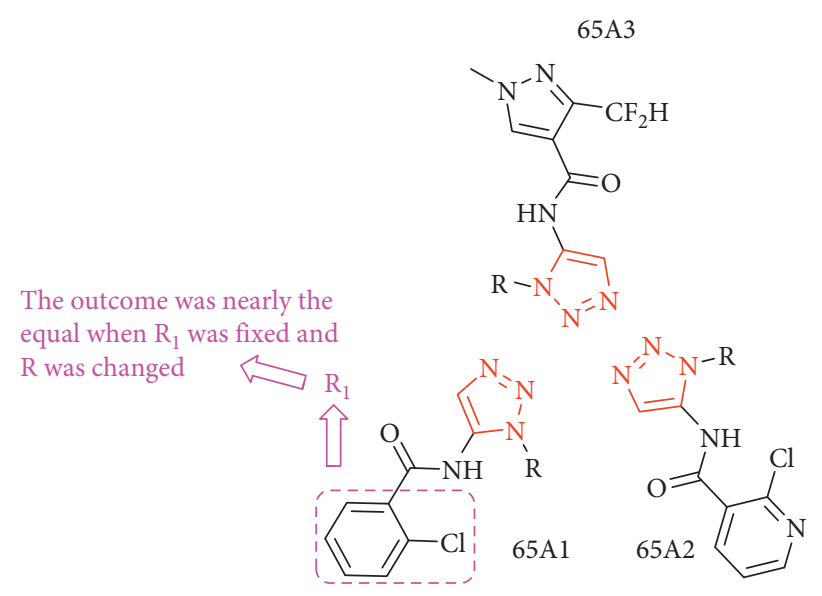

Antifungal activities of series B $<$ series A

Compounds (B1-1-B1-3) displayed the most antifungal activities in sequence $B$.

$\sum$<smiles>O=C(Br)Nc1ccccc1-n1cc(-c2ccc(Br)cc2)nn1</smiles>

65

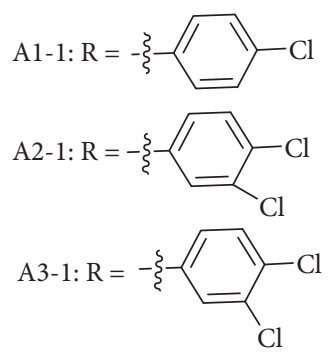

$\mathrm{B} 1-1: \mathrm{R}=$<smiles>Cc1ccccc1Cl</smiles>

Benzene ring substituted at the 4-position of 1,2,3-triazole showed higher activity than benzo ring and aliphatic chain.

$\mathrm{B} 1-2: \mathrm{R}=$<smiles>Cc1cccnc1Cl</smiles><smiles>Cc1cn(C)nc1C(C)(C)C</smiles>

FIgURE 20: Chemical structure of carboxamide derivatives containing 1,2,3-triazole ring.

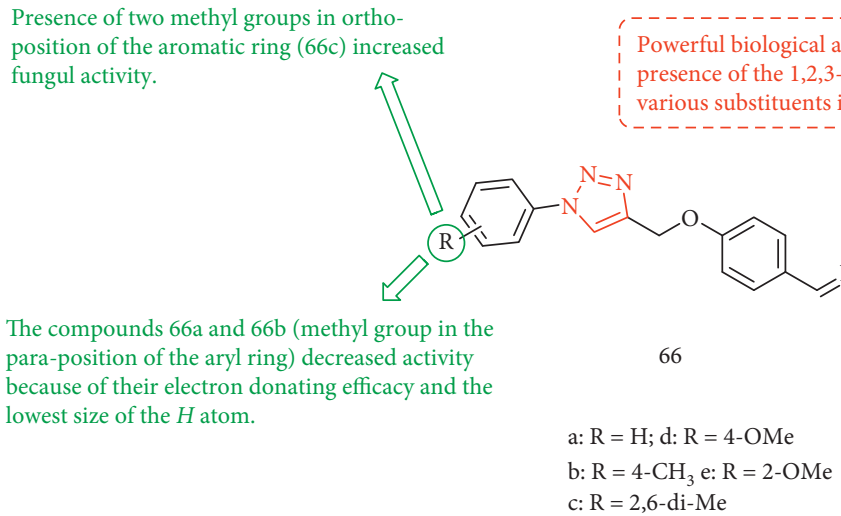

FIgURe 21: Chemical structure of new series of semicarbazone-triazole hybrid derivatives.

fungus strains, Aspergillus niger and Candida albicans. The antifungal activity results revealed that most of the synthesized compounds exhibited moderate-to-good antifungal efficacy against the named fungus strains. Compound $69 \mathrm{e}$ including $R_{2}=$ electron-donating group and $R_{1}=p-\mathrm{Br}-$ $\mathrm{C}_{6} \mathrm{H}_{4}$ - had good antifungal activity against $A$. niger. $R_{1}$ and $R_{2}$ containing an electron-donating group, like methyl on both the benzoate and amino phenyl moieties (69i), showed good fungicidal activity against C. albicans (Figure 24) [89].
Wang et al. [90] synthesized and tested novel hydrazide derivatives of 1,2,3-triazole for fungicidal activity against S. sclerotiorum, F. graminearum, M. oryzae, and R. solani. The findings revealed that all of the target compounds have notable antifungal activity. Compound 70b showed the most potent antiphytopathogenic activity, with $\mathrm{EC}_{50}$ values of $0.18,0.35,0.37$, and $2.25 \mu \mathrm{g} / \mathrm{mL}$ against the four fungi, respectively. Owing to the lower cost of fluorosubstituted aniline compared to chlorine-substituted aniline, $\mathbf{7 0 b}$ was 


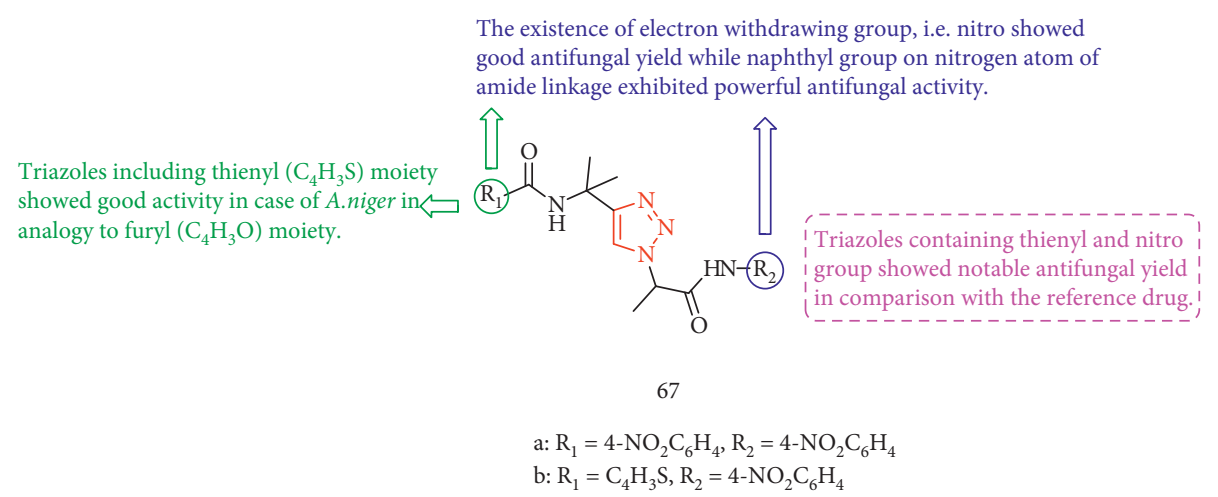

FIgURE 22: Chemical structure of 1,4-disubstituted 1,2,3-triazoles.

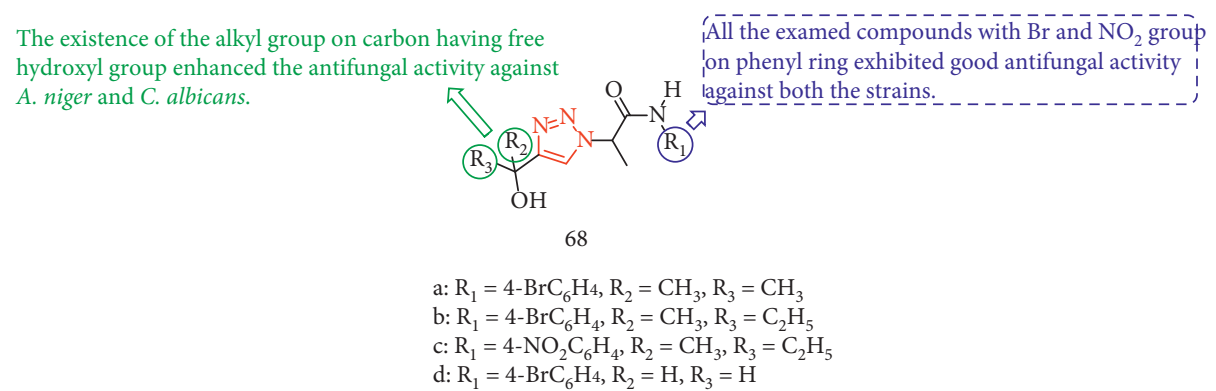

FIgURE 23: Chemical structure of amide-linked 1,4-disubstituted 1,2,3-triazoles.

$\mathrm{R}_{2}=$ electron withdrawing group, like nitro and $\mathrm{R}_{1}=p$-methoxyphenyl (69f), $p$-flourophenyl (69g), and naphthyl (69h) revealed as strong fungicidal agents.

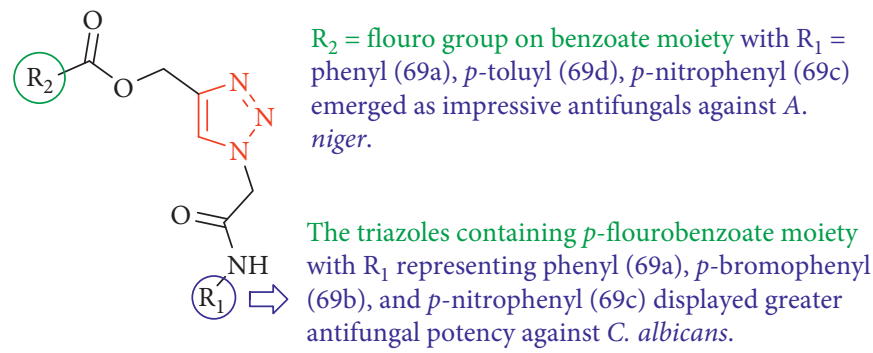

69

$$
\begin{aligned}
& \text { a: } \mathrm{R}_{1}=\mathrm{C}_{6} \mathrm{H}_{5^{-}}, \mathrm{R}_{2}=p-\mathrm{F}_{-} \mathrm{C}_{6} \mathrm{H}_{4^{-}} \\
& \text {b: } \mathrm{R}_{1}=p-\mathrm{Br}^{-} \mathrm{C}_{6} \mathrm{H}_{4}-\mathrm{R}_{2}=p-\mathrm{F}_{-} \mathrm{C}_{6} \mathrm{H}_{4}- \\
& \text { c: } \mathrm{R}_{1}=p-\mathrm{NO}_{2}-\mathrm{C}_{6} \mathrm{H}_{4}-, \mathrm{R}_{2}=p-\mathrm{F}_{-} \mathrm{C}_{6} \mathrm{H}_{4}- \\
& \mathrm{d}: \mathrm{R}_{1}=p-\mathrm{CH}_{3}-\mathrm{C}_{6} \mathrm{H}_{4^{-}}, \mathrm{R}_{2}=p-\mathrm{F}_{-} \mathrm{C}_{6} \mathrm{H}_{4^{-}} \\
& \text {e: } \mathrm{R}_{1}=p-\mathrm{Br}-\mathrm{C}_{6} \mathrm{H}_{4^{-}}, \mathrm{R}_{2}=p-\mathrm{CH} 3-\mathrm{C}_{6} \mathrm{H}_{4^{-}} \\
& \text {f: } \mathrm{R}_{1}=p-\mathrm{CH}_{3} \mathrm{O}-\mathrm{C}_{6} \mathrm{H}_{4}-, \mathrm{R}_{2}=p-\mathrm{NO}_{2}-\mathrm{C}_{6} \mathrm{H}_{4}- \\
& \text { g: } \mathrm{R}_{1}=p-\mathrm{F}_{-} \mathrm{C}_{6} \mathrm{H}_{4^{-}}, \mathrm{R}_{2}=p-\mathrm{NO}_{2}-\mathrm{C}_{6} \mathrm{H}_{4^{-}} \\
& \text {h: } \mathrm{R}_{1}=\alpha \text {-Naphthyl, } \mathrm{R}_{2}=p-\mathrm{NO}_{2}-\mathrm{C}_{6} \mathrm{H}_{4} \text { - } \\
& \text { i: } \mathrm{R}_{1}=p-\mathrm{CH}_{3}-\mathrm{C}_{6} \mathrm{H}_{4^{-}}, \mathrm{R}_{2}=p-\mathrm{CH}_{3}-\mathrm{C}_{6} \mathrm{H}_{4^{-}}
\end{aligned}
$$

Figure 24: Chemical structure of amide-ester-linked 1,4-disubstituted 1,2,3-triazoles.

chosen to experiment antifungal property in vivo despite the equal antifungal activity produced by other compounds. The EC50 values displayed that an electron-withdrawing group outperformed an electron-donating group for $R_{2}$ (Figure 25).

Saidugari et al. [91] synthesized new 1,2,3-triazolehydrazone derivatives with a 3,4-dimethoxy pyridine ring core. Different benzohydrazides and 2-(chloromethyl)-3,4dimethoxypyridine 1,4-ethynylbenzaldehyde were produced using these compounds. They were tested for fungal stains such as Aspergillus niger and Candida albicans (Figure 26).

A series of 5-nitrofuran-triazoles were synthesized with appropriate structural corrections of the formerly reported 
Halogen substituents of $R_{1}$ at the ortho situation and halogen substituents of $R_{2}$ at the para position (70b, 70c, 70d and 70e) created the optimal combinations.

\footnotetext{
Antifungal activity experiments showed that 70 a performed better than $71 \mathrm{a}$ and $72 \mathrm{a}$
}<smiles>[R]c1ccc(C(=O)N/N=C/C2=NC=N2)cc1</smiles><smiles>CN(N)c1ccc(Br)cc1</smiles>

71<smiles>[R]c1ccccc1-n1cc(P)nn1</smiles>

$\downarrow$<smiles>[R]c1cccc(CO)c1</smiles><smiles>[R1]c1cccc(-n2cc(C=NC)nn2)c1</smiles>

Acylhydrazone derivatives

Oxime ether derivatives<smiles>[R]c1cccc(NNC(=O)c2cn(-c3ccccc3[R])nn2)c1</smiles>

Hydrazide derivatives

$$
\begin{aligned}
& \text { 70a: } \mathrm{R}_{1}=2-\mathrm{Cl}, \mathrm{R}_{2}=\mathrm{H} \\
& \text { 70b: } \mathrm{R}_{1}=2-\mathrm{Cl}, \mathrm{R}_{2}=4-\mathrm{Cl} \\
& \text { 70c: } \mathrm{R}_{1}=2-\mathrm{Cl}, \mathrm{R}_{2}=4-\mathrm{F} \\
& \text { 70d: } \mathrm{R}_{1}=2-\mathrm{F}, \mathrm{R}_{2}=4-\mathrm{Cl} \\
& \text { 70e: } \mathrm{R}_{1}=2-\mathrm{F}, \mathrm{R}_{2}=4-\mathrm{F} \\
& \text { 71a: } \mathrm{R}_{1}=2-\mathrm{Cl}, \mathrm{R}_{2}=\mathrm{H} \\
& \text { 72a: } \mathrm{R}_{1}=2-\mathrm{Cl}, \mathrm{R}_{2}=\mathrm{H}
\end{aligned}
$$

FIgURE 25: Chemical structure of 1,2,3-triazole hydrazide derivatives exhibiting antiphytopathogenic activity.

$$
\text { Compounds 73a-c and 73d displayed very good anti-fungal activity. }
$$

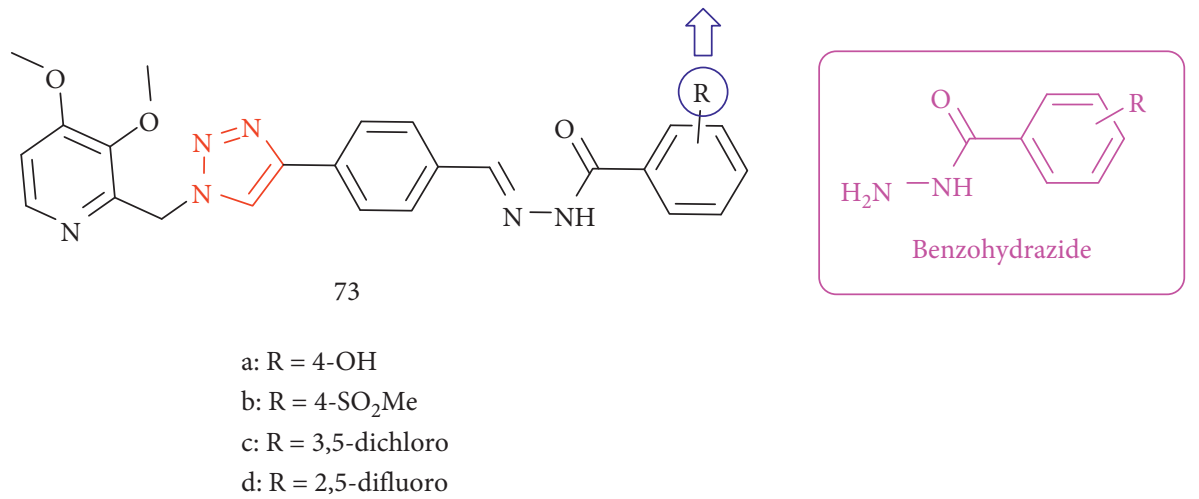

FIGURE 26: Chemical structure of novel 1,2,3-triazole-carbohydrazide derivatives.

counterparts, and they were evaluated to examine 14 various fungal strains and were shown to have great antifungal activities. In comparison to one or more fungal strains examined, all compounds were comparable with Miconazole and showed good effectiveness against other equivalents. Compound 74a displayed twofold better antifungal activity $(\mathrm{MIC}=3.9 \mu \mathrm{g} / \mathrm{mL})$ compared to Miconazole (MIC $=7.8 \mu \mathrm{g} / \mathrm{mL}$ ) against $C$. parapsilosis and C. albicans (Figure 27) [92].
2.4.3. 1,2,3-Triazole-Sugar Hybrids. Tan et al. [93] used CuAAC and methylation to synthesize a new cationic chitosan derivative with 1,2,3-triazolium and pyridinium groups. The antifungal capabilities of all compounds were evaluated to study three plant-threatening fungi by hypha measurement in vitro. The research presented that $N$ methylation of pyridine and 1,2,3-triazole may successfully increase the antifungal properties of the synthesized chitosan derivatives. The results exhibited that chitosan 


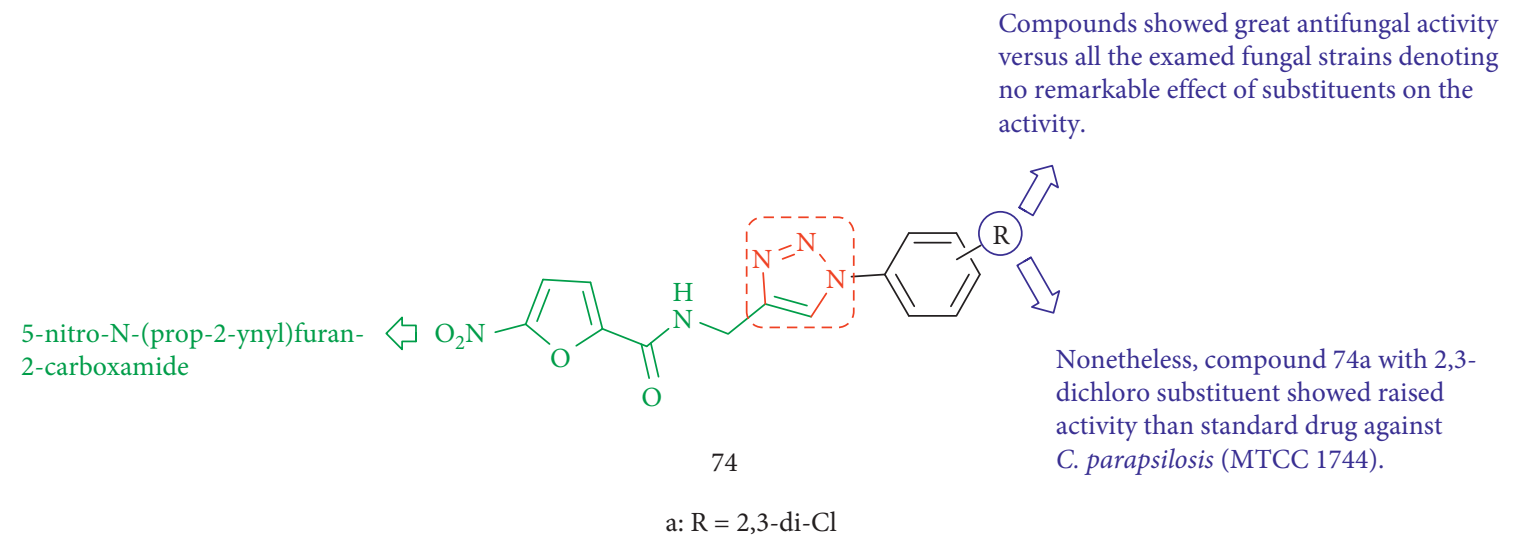

FIGURE 27: Chemical structure of 5-nitrofuran-triazole conjugates.

derivative containing 1,2,3-triazolium and pyridinium increased antifungal activity as compared with chitosan and chitosan derivations bearing 1,2,3-triazole and pyridine. All of the synthesized compounds displayed superior ability of inhibiting the growth of the examined phytopathogenic fungi than chitosan (Figure 28).

Li et al. [94] used click chemistry to design and synthesize reclaimed chitosan containing a 1,2,3-triazole scaffold with a different alcohol chain. To improve the antifungal activity of chitosan derivatives, molecules of varied lengths were used as functional dendrons. All of the derivatives showed great activity against the examed fungi ( $P$. asparagi and C. lagenarium). The inhibitory indices of six chitosan derivatives 77 were greater than those of unmodified chitosan and quaternary ammonium chitosan $\mathbf{7 6}$ at the identical concentration. The results revealed that the triazolyl group linked to the synthesized chitosan derivatives contributed significantly to antifungal action, hence increasing their antifungal activity (Figure 29).

Tan et al. [95] synthesized the 1,2,3-triazolium-functionalized starch derivative, and the efficacy of quaternization of the 1,2,3-triazole section with benzyl bromide on the antifungal screen of the starch derivative was evaluated by looking at the percentage inhibition of mycelial growth. These derivations displayed notable reclaimed antifungal behavior than starch derivative bearing 1,2,3-triazole and starch. Electrostatic and hydrophobic interactions may have a greater antifungal activity tangency than hydrogen bond interactions and higher inhibitory indices of 1,2,3-triazolium-functionalized starch derivatives compared with starch derivative containing 1,2,3-triazole (Figure 30).

A novel group of inulin derivatives with 1,2,3-triazoliumcharged parts by associating "click reaction" with impressive 1,2,3-triazole quaternization were synthesized. As shown in Figure 31, the antifungal tests revealed that compounds containing triazolium $\mathbf{8 0}$ inhibited the growth of tested phytopathogens more effectively than inulin derivatives, including triazoles 79. However, 1,2,3-triazolium exhibited a higher cationic charge, which was affected more by the interactions with anionic fragments in the fungal cell wall [96].

Tan et al. [97] suggested a direct synthetic approach to novel starch derivatives with 1,2,3-triazolium- and pyridinium-charged units by linking $\mathrm{CuAAC}$ with impressive alkylation of pyridine and 1,2,3-triazole. Fungicidal activity against three plant-threatening fungi (Watermelon fusarium, Phomopsis asparagi, and Colletotrichum lagenarium) was estimated in vitro by hypha measurement. The antifungal activity of synthesized starch derivatives having 1,2,3-triazolium and pyridinium was higher than that of starch derivatives with 1,2,3-triazole and pyridine, implying that the alkylation of 1,2,3-triazole and pyridine was remarkable for raised antifungal activity (Figure 32).

Based on the pioneer starch compounds $N$-alkylated with 1,2,3-triazole and iodomethane, four novel 1,2,3-triazolium-functionalized starch derivatives were synthesized (CuAAC). The antifungal activities of compounds against Fusarium oxysporum, Watermelon fusarium, and Colletotrichum lagenarium were tested in vitro by hypha measurement. C. lagenarium is the most sensitive pathogenic fungus yeast to the examined compounds. The inhibitory indices of all cases increase with increasing concentration $(P<0.05)$ with $1.0 \mathrm{mg} / \mathrm{mL}$ exhibiting the greatest antifungal activity. Following a one-step alkylation with iodomethane, 1,2,3-triazolium-functionalized starch derivatives exhibit massively increased antifungal property with inhibitory indices of up to $60 \%$ at $1.0 \mathrm{mg} / \mathrm{mL}(P<0.05)$, compared with 1,2,3-triazole-functionalized starch derivatives with inhibitory indices of less than $10 \%(P<0.05)$. In general, the length of the alkyl groups was an effective determinant of 1,2,3triazolium-functionalized starch derivative antifungal activity (Figure 33) [98].

Li et al. [99] investigated three new chitosan derivatives, including 1,2,3-triazole with or without halogen. Their antifungal activity toward three kinds of phytopathogens was evaluated via hyphal mensuration in vitro. The inhibitory effects and water solubility of the synthesized chitosan derivatives were significantly superior to chitosan. CTCTS and BTCTS, which include halogens at the polymer's edge, inhibited the development of the examined phytopathogens more impressively, with inhibitory indices ranging from 81 to $93 \%$ at $1.0 \mathrm{mg} / \mathrm{mL}$ (Figure 34 ).

2.4.4. 1,2,3-Triazoles-Pyrazole, Imidazole, and Benzimidazole Hybrids. Among the heterocycles containing nitrogen, imidazole, pyrazole, and triazole have many biological, 


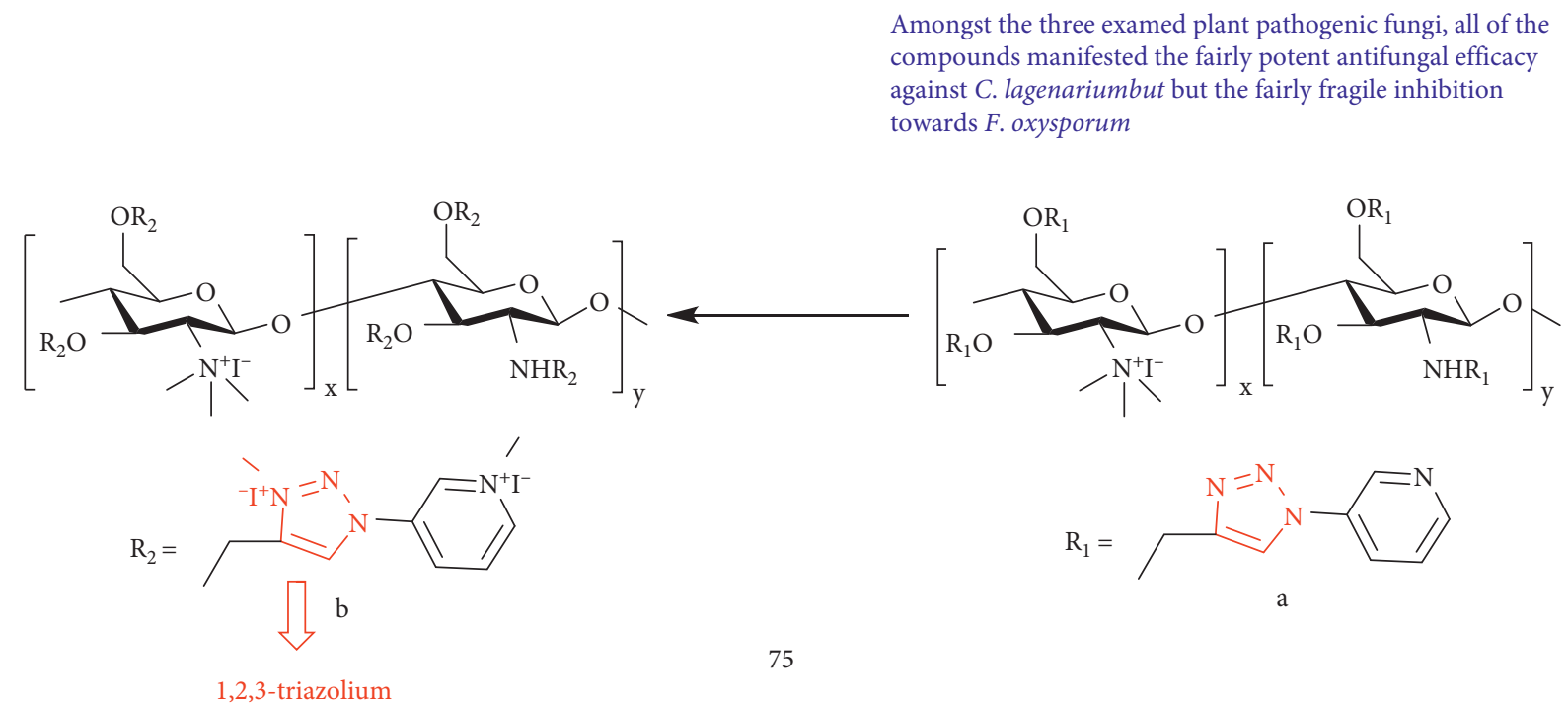

FIGURE 28: Chemical structure of novel cationic chitosan derivations bearing 1,2,3-triazolium and pyridinium.

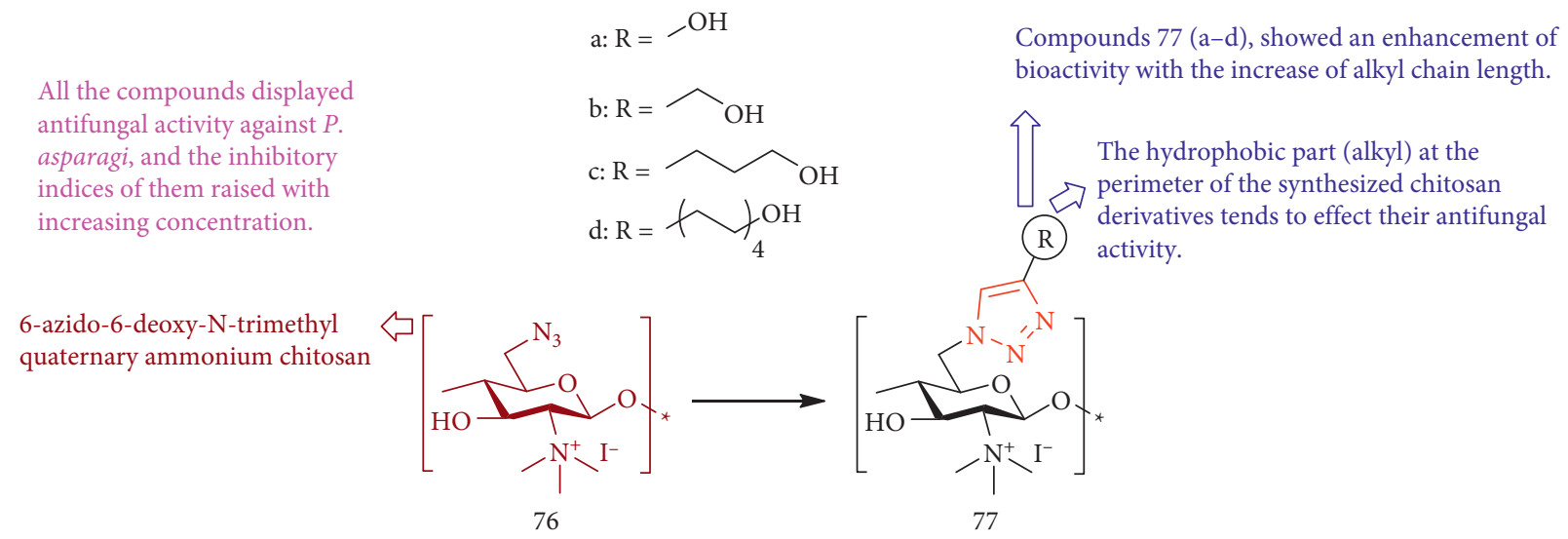

FIGURE 29: Chemical structure of novel triazolyl-functionalized chitosan derivatives with different chain lengths of aliphatic alcohol substituent.

The outcomes displayed that quaternization of 1,2,3-triazole with benzyl bromide could impressively increase antifungal activity of the synthesized starch derivatives. 1,2,3-triazolium-functionalized starch derivative had excellent antifungal activity, especially the best inhibitory indicator of 1,2,3-triazolium-functionalized starch derivative against Colletotrichum lagenarium.

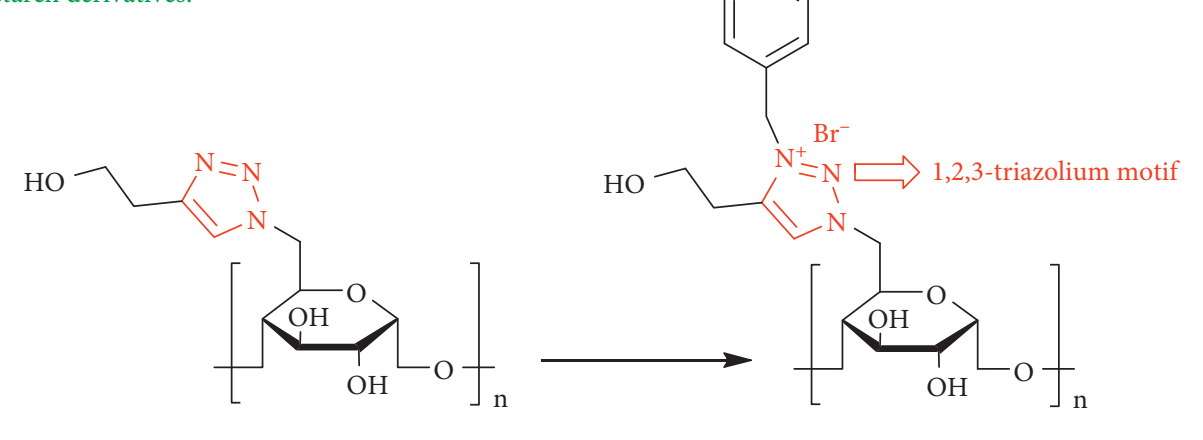

Figure 30: Chemical structure of novel 1,2,3-triazolium-functionalized starch derivative. 


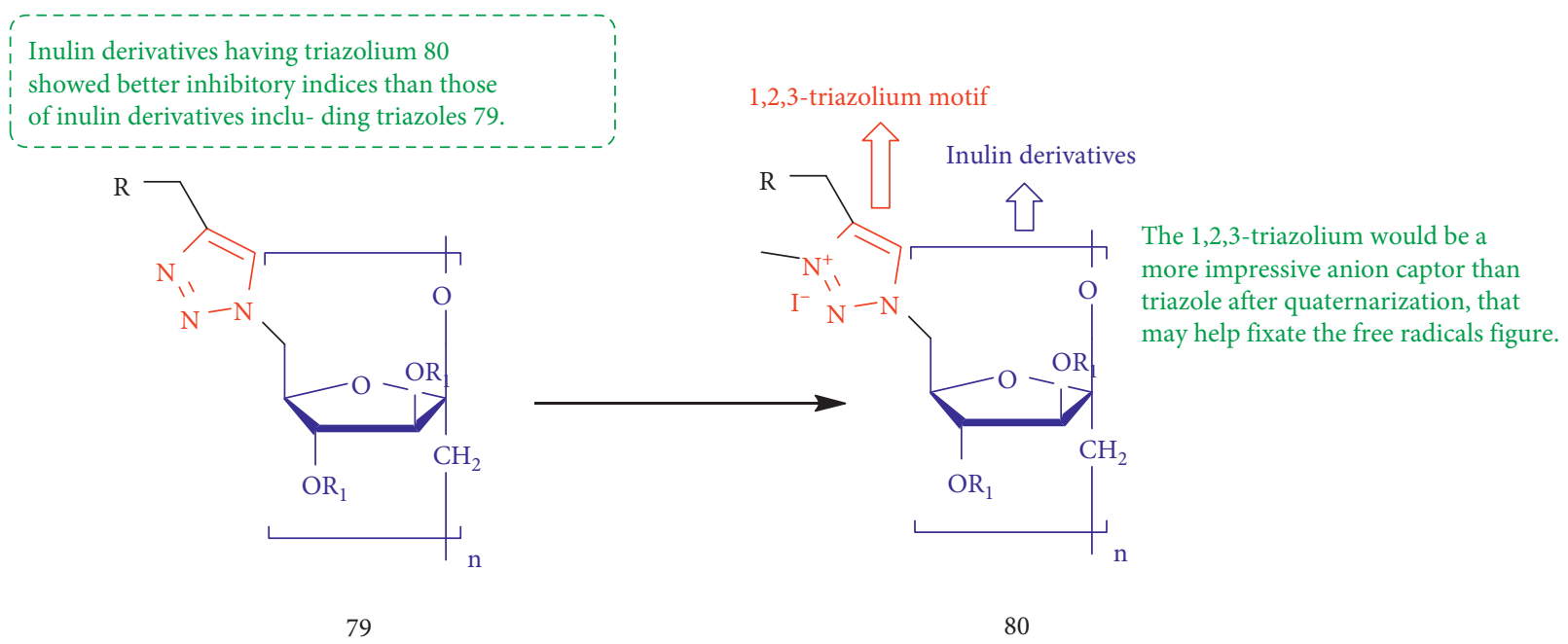

Figure 31: Chemical structure of inulin derivatives possessing 1,2,3-triazolium charged units.

The antifungal examination results showed that all the compounds reveal antifungal activity against $P$. asparagi, and the antifungal activity of starch derivatives is concentration-affiliate.

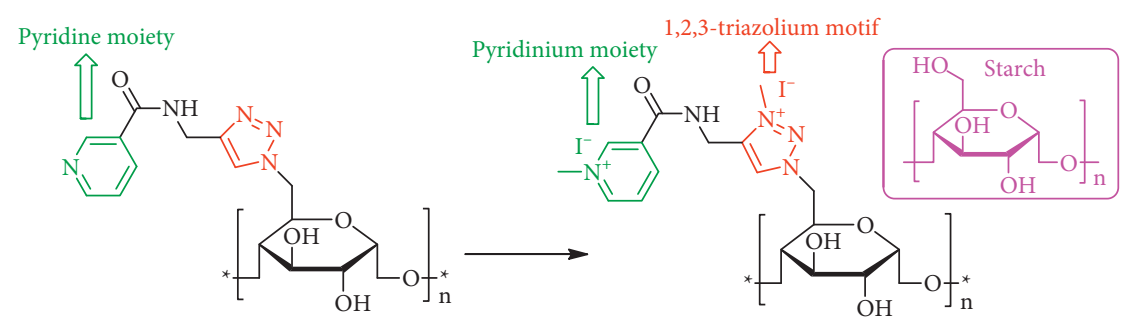

81

Antifungal activity respectively: share of $1,2,3$-triazolium and pyridinium groups $>$ share of 1,2,3-triazole and pyridine groups $>$ starch

FIgURE 32: Chemical structure of novel starch derivative bearing 1,2,3-triazolium and pyridinium.

The results showed that increasing the length of the alkyl chain on the 1,2,3-triazolium rings reduced the antifungal activity of starch derivatives $(\mathrm{P}<0.05)$ against all the fungi strains and the antifungal activity increased respectively: $83 a>83 b>83 c>83 d>82 a \sim 82 d>$ starch.
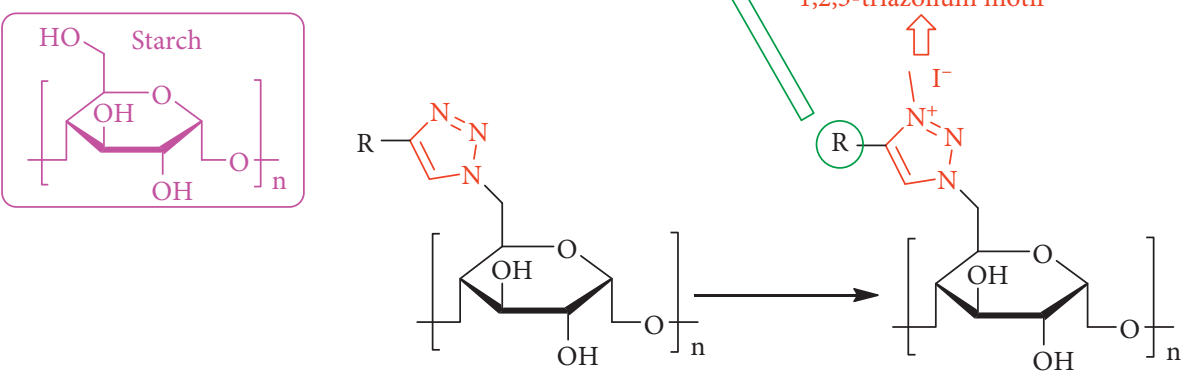

82
$\mathrm{a}: \mathrm{R}=\widehat{\mathrm{OH}}$
b: $\mathrm{R}=\curvearrowright \mathrm{OH}$
$\mathrm{c}: \mathrm{R}=\overbrace{\mathrm{OH}}$
$\mathrm{d}: \mathrm{R}=>\mathrm{OH}$

Antifungal activity respectively: 1,2,3-triazolium- functionalized starch

derivatives $>$ starch derivatives bearing 1,2,3-triazole $>$ starch

FIgURE 33: Chemical structure of novel 1,2,3-triazolium-functionalized starch derivatives. 


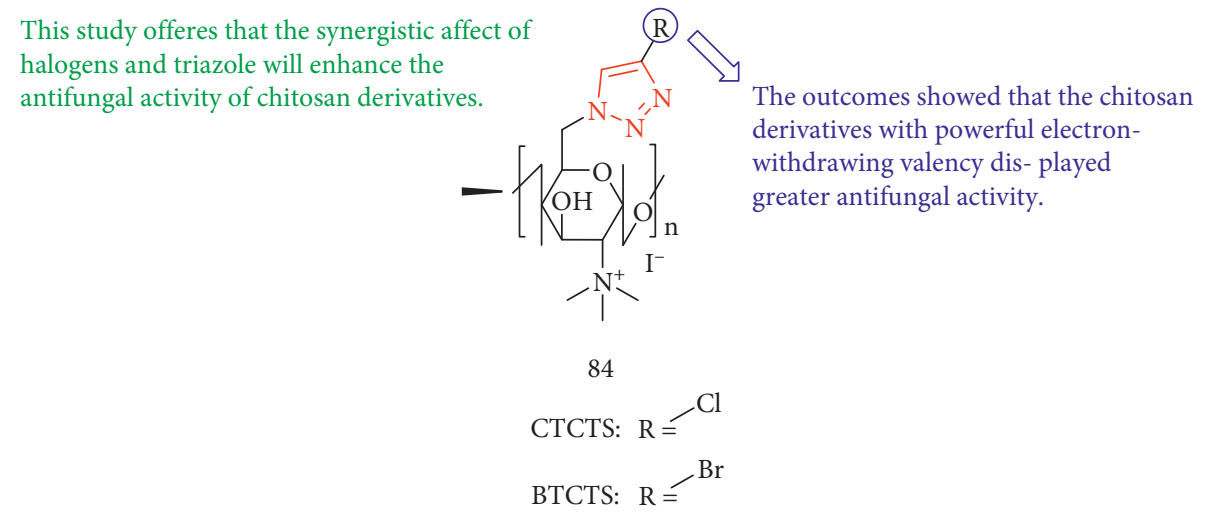

FIGURE 34: Chemical structure of water-soluble chitosan derivatives with halogeno-1,2,3-triazole.

agrochemical, chemical, and medicinal characteristics. A set of eighteen imidazole amide-linked 1,2,3-triazole hybrids (Figure 35) were synthesized, and their antifungal activities against $C$. albicans and $A$. niger were examined. The derivative, 85e $(\mathrm{MIC}=0.0064 \mu \mathrm{mol} / \mathrm{ml})$, was approximately twice active compared to Fluconazole (MIC $=0.0102 \mu \mathrm{mol} /$ $\mathrm{ml})$ against $A$. niger. Six hybrids (85a-f) ( $\mathrm{MIC}=0.0246-0.0282 \mu \mathrm{mol} / \mathrm{mL}$ ) were found to have remarkable influence on C. albicans. The research showed that triazole derivatives with $\mathrm{OMe}$ and $\mathrm{Cl}$ groups at the anilide ring had better antifungal activity than $\mathrm{NO}_{2}$. Among the synthesized compounds, most of the methyl derivatives in the pyrazole ring had higher activity than the $\boldsymbol{H}$ analogs. In general, these compounds have been shown to be more effective against $A$. niger than against Candida albicans [100].

Nalawade et al. [101] demonstrated the formation of a series of 1-substituted benzyl-4-[1-phenyl-3-(4-methyl-2aryl-1,3-thiazol-5-yl)-1H-pyrazol-4-yl]-1H-1,2,3-triazole. Almost most of the compounds showed good-to-high antifungal activity toward $R$. glutinis and A. niger. The antifungal activity suggests that these compounds can be preferred for improved optimization and spread, since they have the potential for behaving against fungal infections (Figure 36).

Khare et al. [102] synthesized new 1,2,3-triazolyl pyrano [2,3-c]pyrazole derivatives in high yield using $\mathrm{NaHCO}_{3}$ as a catalyst under ultrasonic irradiation. The observations showed that the antifungal activity was different from the substituent present on an aromatic unit of 1,2,3-triazolyl pyrano[2,3-c]pyrazole. Compound 87e revealed high antifungal activity, and it was more potent than Miconazole against $C$. albicans with $\mathrm{MIC}=12.5 \mu \mathrm{g} / \mathrm{mL}$; moreover, only this compound displayed equivalent activity against $A$. niger with $\mathrm{MIC}=25 \mu \mathrm{g} / \mathrm{mL}$ (Figure 37).

Bhat et al. [103] explained the synthesis of a new sequence of 1,2,3-triazolyl pyrazole derivatives, as well as antifungal investigations on the synthesized compounds against A. flavus, C. keratinophilum, and C. albicans. When compared to other fungal species, C. albicans was the most vulnerable. A. flavus and C. keratinophilum responded differently to each organic compound. Compounds 88a and $\mathbf{8 8 b}$ exhibited significant activity compared to the reference drug Fluconazole. The SAR also revealed the existence of multi-electron-withdrawing, liphophilic, and electronegative groups on phenyl rings, such as fluorine, chlorine, nitro, and trifluoromethyl, and electron-donating groups like quinyl and phthalazinyl, which may be more useful than the less substituted or unsubstituted groups on phenyl rings (Figure 38).

Sindhu et al. [104] reported a new molecule sequence of pyridinone, 1,2,3-triazoles, and pyrazole. Two yeast strains, Saccharomyces cerevisiae and Candida albicans, were studied in vitro for fungicidal activity. As it is shown in Figure 39, all compounds had excellent antifungal activity, with MICs ranging from 64 to $256 \mu \mathrm{g} / \mathrm{mL}$ for C. albicans and from 64 to $256 \mu \mathrm{g} / \mathrm{mL}$ for S. cerevisiae. Compounds $\mathbf{8 9 b}$ and 89a displayed MIC values of $64 \mu \mathrm{g} / \mathrm{mL}$ against $S$. cerevisiae, which were lower than the reference Amphotericin B (APT-B).

Dubovis et al. [105] designed and developed a novel and fundamental method for synthesizing 1-(1H-imidazole-4yl)-1H-1,2,3-triazoles. As shown in Figure 40, antifungal screening of these compounds on a variety of phytopathogenic fungus has been explored. A significant alteration of the triazole ring of the halogen-substituted aromatic remainders displayed an enhancement of fungicidal activity in the final compounds. Compound $\mathbf{9 0 a}$ was substantially more active than its nonsubstituted or alkyl-substituted counterparts.

Seven miconazole analogs, including 1,4,5-tri and 1,5disubstituted triazole moieties, were developed and synthesized by azide-enolate 1,3-dipolar cycloaddition. The antifungal properties of these compounds were screened in vitro for three different Candida spp. as yeast samples and four penicillate fungi: Rhizopus oryzae, Mucor hiemalis, Trichosporon cutaneum, and Aspergillus fumigatus. Compound $91 \mathrm{~b}$ was shown to be better than or equivalent to Itraconazole in its antifungal activity against the filamentous fungi $R$. oryzae, M. hiemalis, and T. cutaneum. When compared to the reference drug ( $\mathrm{MIC}=0.25 \mathrm{~g} / \mathrm{mL}$ ), compound 91c inhibited A. fumigatus growth only little (MIC $0.5 \mu \mathrm{g} / \mathrm{mL}$ ) (Figure 41) [106].

Rezki [107] described the synthesis and antimicrobial evaluation of new polyheterocyclic molecules based on the benzimidazole core of 1,2,3-triazole and 1,2,4-triazoles. As shown in Figure 42, triazoles 92a-c gave the most potent 


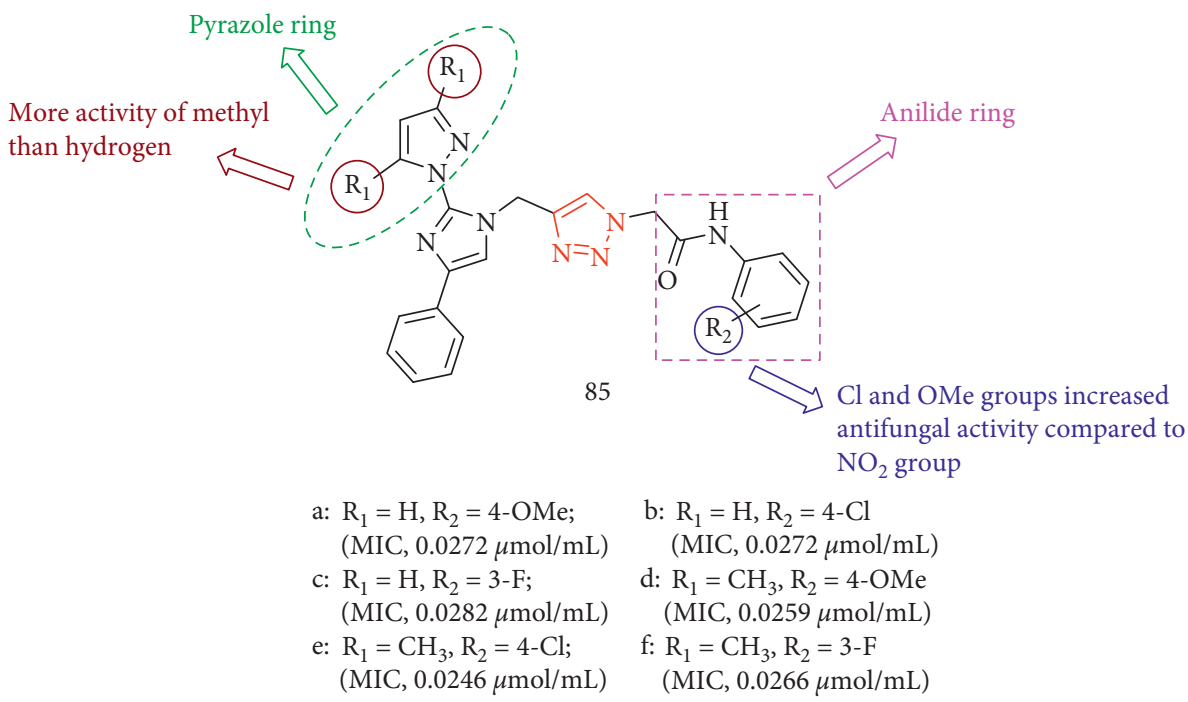

FIgURE 35: Chemical structure of pyrazole-imidazole-triazole hybrids.

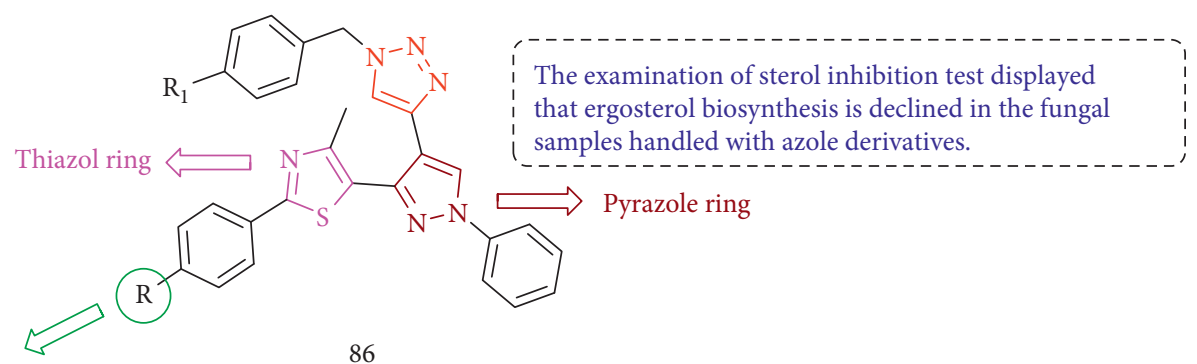

All compounds excluding compound 86e, all 2-(4-fluorophenyl)-4-methylthiazole substituted compounds described similar activity against A. niger with attentive to reference drug Ravuconazole.

$$
\begin{aligned}
& \mathrm{a}: \mathrm{R}=\mathrm{F}, \mathrm{R}_{1}=\mathrm{H} \\
& \mathrm{b}: \mathrm{R}=\mathrm{F}, \mathrm{R}_{1}=\mathrm{CH}_{3} \\
& \mathrm{c}: \mathrm{R}=\mathrm{F}, \mathrm{R}_{1}=\mathrm{F} \\
& \mathrm{d}: \mathrm{R}=\mathrm{F}, \mathrm{R}_{1}=\mathrm{Cl} \\
& \mathrm{e}: \mathrm{R}=\mathrm{F}, \mathrm{R}_{1}=\mathrm{Br}
\end{aligned}
$$

FIGURE 36: Chemical structure of new thiazolyl-pyrazolyl-1,2,3-triazole derivatives.

The compounds $87 \mathrm{a}, 87 \mathrm{~b}, 87 \mathrm{c}, 87 \mathrm{~d}$, and $87 \mathrm{e}$ exhibited high antifungal activity with lower $\mathrm{MIC} \leq 25 \mu \mathrm{g} / \mathrm{mL}$.

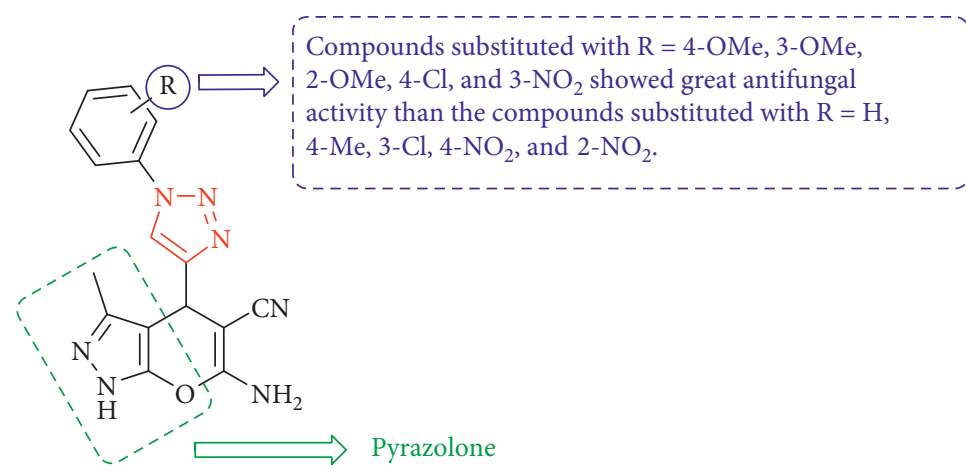

FIGURE 37: Chemical structure of new 1,2,3-triazolyl pyrano[2,3-c]pyrazole derivatives. 


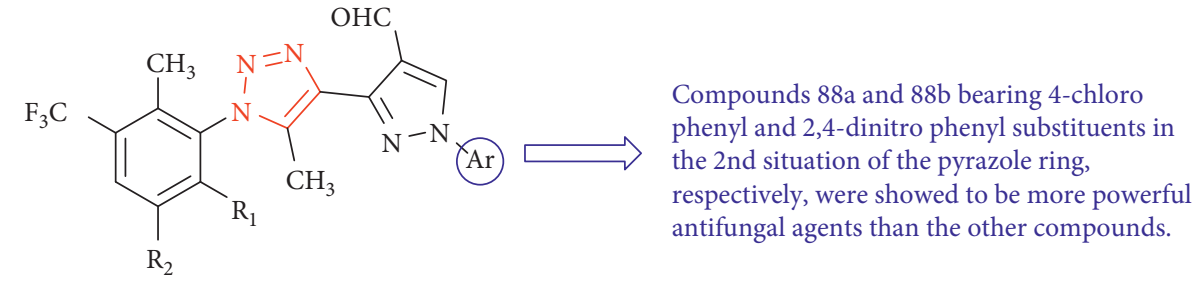

88

a: $\mathrm{R}_{1}, \mathrm{R}_{2}=\mathrm{H} ; \mathrm{Ar}=4$-Cl-phenyl

b: $\mathrm{R}_{1}, \mathrm{R}_{2}=\mathrm{H} ; \mathrm{Ar}=2$, 4-Dinitro phenyl

FIGURE 38: Chemical structure of new 1,2,3-triazolyl pyrazole derivatives.

Compound 89a exhibited greatest activity against C. albicans with MIC value of $64 \mu \mathrm{g} / \mathrm{mL}$ and Also was most active against $S$. cerevisiae with MIC value of $64 \mu \mathrm{g} / \mathrm{mL}$

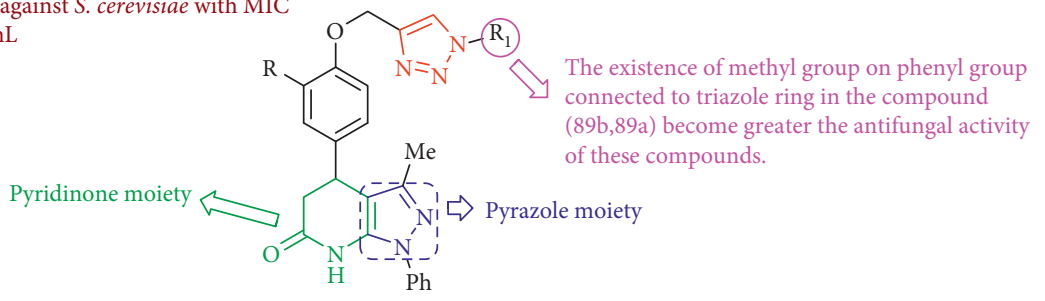

89

$$
\begin{aligned}
& \text { a: } \mathrm{R}=\mathrm{OMe}, \mathrm{R}_{1}=4-\mathrm{MeC}_{6} \mathrm{H}_{4} \\
& \mathrm{~b}: \mathrm{R}=\mathrm{H}, \mathrm{R}_{1}=4-\mathrm{MeC}_{6} \mathrm{H}_{4}
\end{aligned}
$$

FIgURE 39: Chemical structure of some functionalized 1H-1,2,3-triazole tethered pyrazolo[3,4-b]pyridin-6(7H)-ones.

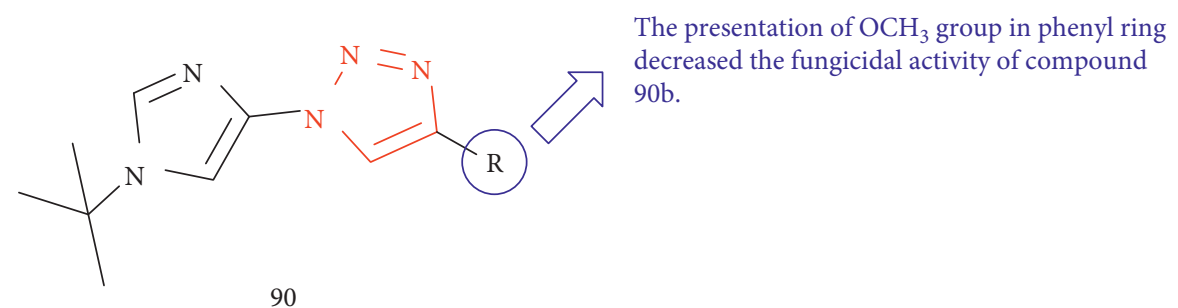

90

$$
\begin{aligned}
& \text { a: } \mathrm{R}=\mathrm{H} \\
& \text { b: } \mathrm{R}=\mathrm{OCH}_{3}
\end{aligned}
$$

Figure 40: Chemical structure of substituted 1-(1H-imidazole-4-yl)-1H-1,2,3-triazoles.

Compounds 91a, 91b and 91c displayed good activity against

C. albicans and C. tropicalis (MIC $0.03-0.06 \mu \mathrm{g} / \mathrm{mL}$ ) as

compared to standard drug (Itraconazole, MIC $0.03 \mu \mathrm{g} / \mathrm{mL}$ ).

1-(2-Azido-2-(2,4-dichlorophenyl) ethyl)-1H-imidazole

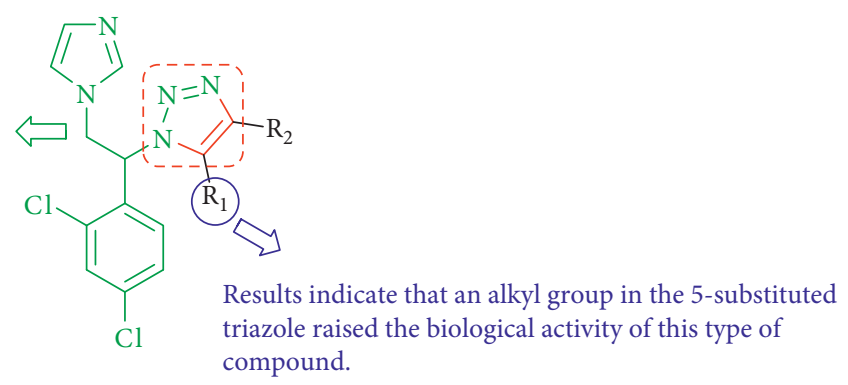

91

$$
\begin{aligned}
& \text { a: } \mathrm{R}_{1}=\mathrm{Ph}, \mathrm{R}_{2}=\mathrm{COPh} \\
& \text { b: } \mathrm{R}_{1}=\mathrm{CH}_{3}\left(\mathrm{CH}_{2}\right)_{4^{-}}, \mathrm{R}_{2}=\mathrm{SO}_{2} \mathrm{Ph} \\
& \text { c: } \mathrm{R}_{1}=\mathrm{CH}_{3}\left(\mathrm{CH}_{2}\right)_{3} \mathrm{C}\left(\mathrm{CH}_{3}\right)_{2^{-}}, \mathrm{R}_{2}=\mathrm{H}
\end{aligned}
$$

FIGURE 41: Chemical structure of novel triazole-based miconazole analogs. 


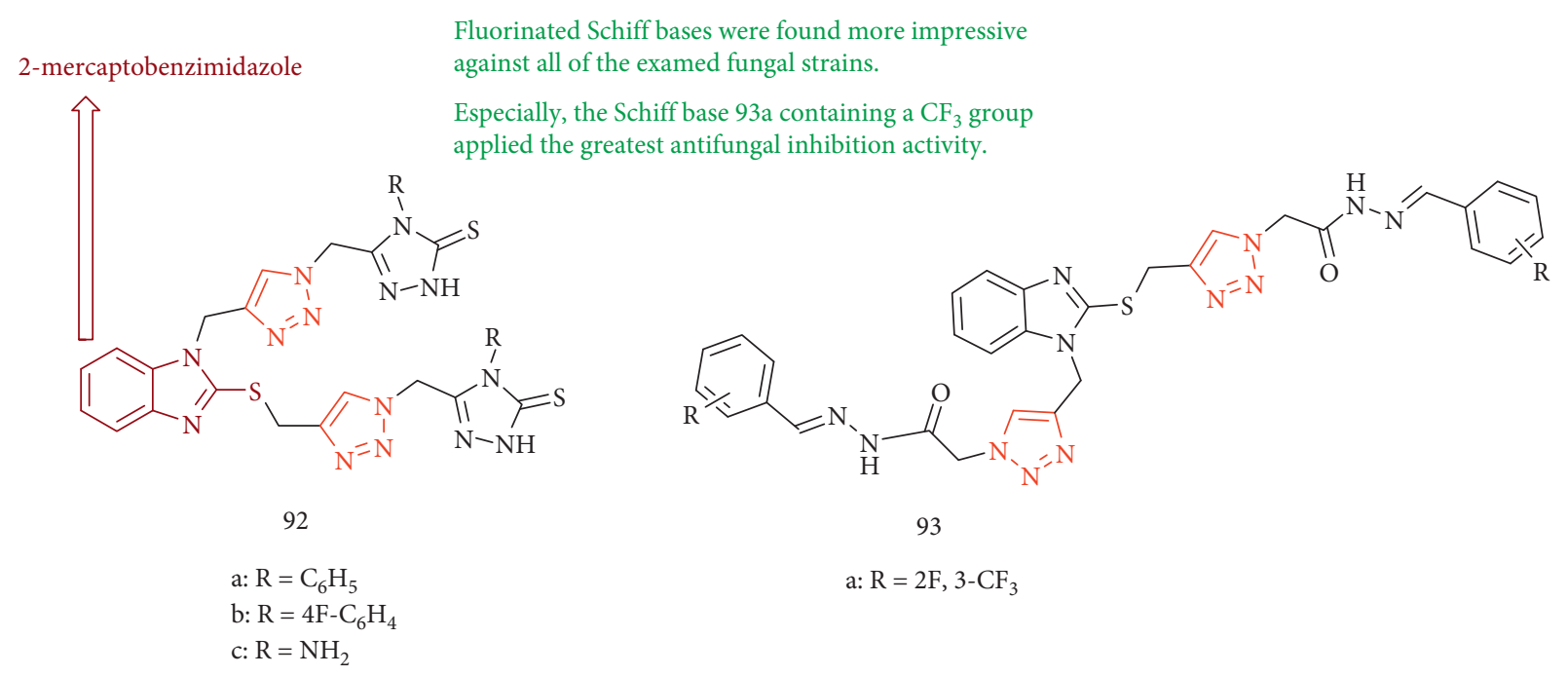

FIGURE 42: Chemical structure of new polyheterocyclic molecules by clubbing the benzimidazole reliance.

inhibition toward all of the tested fungal strains that were more powerful than the standard drug Fluconazole.

2.4.5. 1,2,3-Triazole Core with 1,2,4-Triazoles. The click reaction of aromatic azides with various benzo-fused $N$ heteroaromatic alkynes resulted in the synthesis of 1,4-disubstituted 1,2,3-triazoles with benzo-fused $N$-heteroaromatic scaffolds. As it is shown in Figure 43, all of the synthesized compounds were screened for antifungal behavior toward two fungi (Aspergillus niger and Candida albicans). All of the compounds revealed modest-to-good antifungal activity toward the examined fungal strains. Compounds 95a $\quad\left(\mathrm{MIC}=2.15 \mu \mathrm{mol} / \mathrm{cm}^{3} \times 10^{-2}\right), \quad$ 95b $\left(\mathrm{MIC}=2.05 \mu \mathrm{mol} / \mathrm{cm}^{3} \times 10^{-2}\right)$, and 96b $(\mathrm{MIC}=1.63 \mu \mathrm{mol} /$ $\mathrm{cm}^{3} \times 10^{-2}$ ) displayed nearly twofold antifungal activity against $A$. niger as compared to the reference drug. Some of the compounds, like $95 \mathrm{~b}\left(\mathrm{MIC}=2.05 \mu \mathrm{mol} / \mathrm{cm}^{3} \times 10^{-2}\right)$ and 96a $\left(\mathrm{MIC}=1.77 \mu \mathrm{mol} / \mathrm{cm}^{3} \times 10^{-2}\right)$, showed antifungal effect comparable to standard drug against C. albicans [108].

2.4.6. 1,2,3-Triazloe-Indole and Oxindole Hybrids. Xu et al. [109] explored a class of new 1,4-disubstituted 1,2,3-triazoles with an indole ring using $\mathrm{CuCl}_{2} / \mathrm{Zn}$-catalyzed Huisgen cycloaddition. The fungicidal activities of all the collected compounds against cotton physalospora pathogens (CPP) and Colletotrichum capsici pathogens (CCP) were evaluated, and the results displayed that these compounds, mainly 99a and 99f, exhibited remarkable inhibitory effects for fungi. Compounds revealed greater activity toward CCP than toward CPP (Figure 44).

Soltani Rad et al. [110] described a new class of fungicidal compounds known as 1,2,3-triazolyl $\beta$-hydroxy alkyl/carbazole hybrid molecules. The 'Click' Huisgen cycloaddition reaction was carried out in the present of copper-doped silica cuprous sulfate. Compound 101a demonstrated strong antifungal activity against all fungal studies (Candida albicans (ATCC 10231), Aspergillus niger (ATCC 16404), Candida krusei (ATCC 6258), and Trichophyton rubrum
(PTCC5143)) compared with Fluconazole and Clotrimazole as standard drugs. From the SAR viewpoint, since all of the studied compounds differ only in side chains, the differences in antifungal activity are ascribed to these changes (Figure 45).

Huo et al. [111] reported two series of new aryl-1,2,3triazole- $\beta$-carboline hybrids, and their antifungal activities were appraised in vitro against phytopathogenic species containing Fusarium oxysporum, R. solani, Botrytis cinerea Pers., sunflower sclerotinia rot, and rape sclerotinia rot using a $50 \mu \mathrm{g} / \mathrm{mL}$ mycelia growth inhibition test. In vitro, none of the target compounds displayed antifungal activity, with an inhibition rate of less than $20 \%$ against $F$. oxysporum (Figure 46).

5-Fluoroindoline-2,3-dione-1-aryl-1H-triazole-4-yl methyl hybrid molecules were synthesized in aqueous conditions using a well-known CuAAC reaction applying Cell-CuI-NPs as a novel heterogeneous catalyst [112]. All synthesized compounds were analyzed against two fungal pathogens of Candida Albicans and Aspergillus niger and then Fluconazole $(\mathrm{MIC}=0.0051-0.0102 \mu \mathrm{mol} / \mathrm{mL})$ drug was applied. All synthesized compounds showed moderate-to-high antifungal activity (Figure 47).

Sakly et al. [113] investigated a wide range of novel functionalized spirooxindole-pyrrolidine and spirooxindole-pyrrolizidine-connected 1,2,3-triazole conjugates. The compounds were examined in vitro for antifungal and antibacterial activity using the agar dilution procedure and showed appropriate activity. Compounds 106a and 107a were similarly potent against $C$. albicans as griseofulvin (Figure 48).

Aouad [114] reported the discovery of new isatin-1,2,3triazoles attached by morpholines, piperazines, or piperidines through a methylene or acetyl linkage and tested for antifungal activity against a panel of pathogenic fungal strains. Antimicrobial activity ensured the association of the action on the nature of the cyclic secondary amine added to the 1,2,3-triazole ring. The isatin-1,2,3-triazole hybrids including a piperazine unit were found to be the most active of 
<smiles>Cn1cc(Cn2nnc3ccccc32)nn1</smiles><smiles>c1ccc2c(c1)ncn2Cc1c[nH]nn1</smiles>

(R)

Displacement of benzyl group with phthalimide$\mathrm{NCH}_{2}$ group at $\mathrm{N}_{1}$ situation of triazole ring of compound (96c) containing carbazolyl section raised the antifungal effect against $\mathrm{A}$. niger.

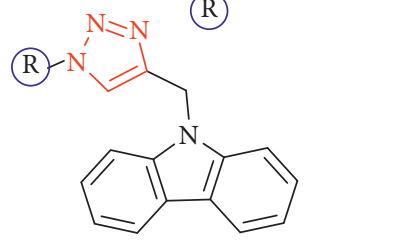

96

95a: $\mathrm{R}=\mathrm{C}_{6} \mathrm{H}_{5} \mathrm{CH}_{2}$ 95b: $\mathrm{R}=\mathrm{C}_{6} \mathrm{H}_{5} \mathrm{CH}_{2} \mathrm{CH}_{2}$ $95 \mathrm{c}: \mathrm{R}=\mathrm{C}_{6} \mathrm{H}_{4}(\mathrm{CO})_{2} \mathrm{NCH}_{2}$ 96a: $\mathrm{R}=\mathrm{C}_{6} \mathrm{H}_{5} \mathrm{CH}_{2} \mathrm{CH}_{2}$ 96b: $\mathrm{R}=4-\mathrm{NO}_{2} \mathrm{C}_{6} \mathrm{H}_{4} \mathrm{CH}_{2}$
The outcomes legibly showed that the existence of electron withdrawing groups on phenyl ring increased the antifungal activity of synthesized compounds against A.niger.

Presence of electron donating groups on phenyl ring raised the antifungal activity of synthesized triazoles against C. albicans.

Figure 43: Chemical structure of 1,4-disubstituted 1,2,3-triazoles containing benzo-fused N-heteroaromatic moieties.

Most of the examed compounds showed modest to great activity against the two tested fungi at $20 \mu \mathrm{g} / \mathrm{mL}$

99a: $\mathrm{R}_{1}=\mathrm{H}, \mathrm{R}_{2}=\mathrm{CH}_{3}, \mathrm{R}_{3}=\mathrm{H}$

99b: $\mathrm{R}_{1}=\mathrm{H}, \mathrm{R}_{2}=\mathrm{HR}_{3}=\mathrm{NO}_{2}$

99c: $\mathrm{R}_{1}=\mathrm{H}, \mathrm{R}_{2}=\mathrm{OCH}_{3}, \mathrm{R}_{3}=\mathrm{H}$

99d: $\mathrm{R}_{1}=\mathrm{OC}_{2} \mathrm{H}_{5}, \mathrm{R}_{2}=\mathrm{H}, \mathrm{R}_{3}=\mathrm{H}$

99e: $\mathrm{R}_{1}=\mathrm{H}, \mathrm{R}_{2}=\mathrm{H}, \mathrm{R}_{3}=\mathrm{H}$

99f: $\mathrm{R}_{1}=\mathrm{CH}_{3}, \mathrm{R}_{2}=\mathrm{H}, \mathrm{R}_{3}=\mathrm{H}$<smiles>Cn1ccc2ccccc21</smiles>

Amongst the recent compounds, likely because of the powerful electron withdrawing potency of the para-nitro substituent, 99b had nearly no activity.

Indole moiety<smiles>CCCn1ccc2ccccc21</smiles>

7<smiles>[R]c1ccc(-c2cn[nH]n2)cc1[R]</smiles><smiles>[C]1=CC=C1</smiles>

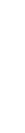




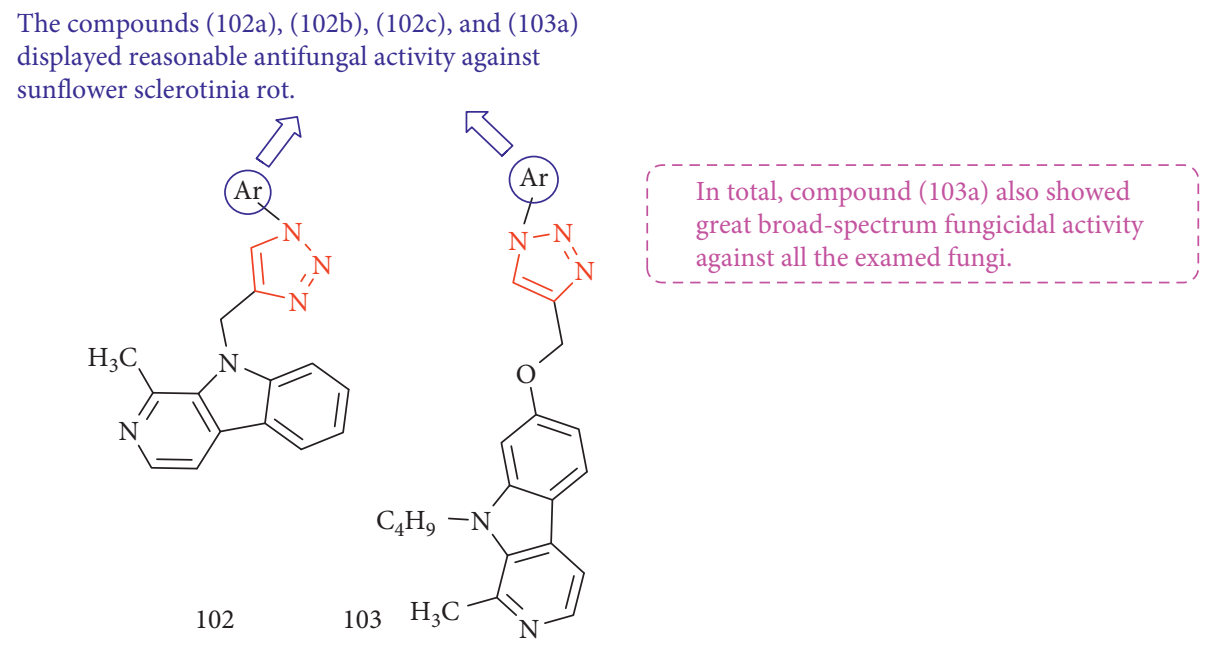

102a: $\mathrm{Ar}=$ phenyl; 102c: $\mathrm{Ar}=3,4,5$-trifluorophenyl

102b: Ar = 4-trifluoromethylphenyl; 103a: $\mathrm{Ar}=3$, 4, 5-trifluorophenyl

Figure 46: Chemical structure of two series of new aryl-1,2,3-triazole- $\beta$-carboline hybrids.

104a, 104b and 105a exhibited higher power than antifungal drug Fluconazole for A. Niger

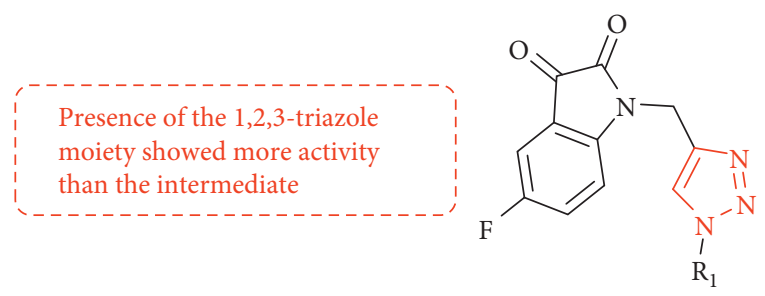

104

104a: $\mathrm{R}_{1}=3-\mathrm{BrC}_{6} \mathrm{H}_{4} \mathrm{CH}_{2}$ (MIC, $0 / 0075 \mu \mathrm{mol} / \mathrm{mL}$ )

104b: $\mathrm{R} 1=4-\mathrm{NO}_{2} \mathrm{C}_{6} \mathrm{H}_{4} \mathrm{CH}_{2}$ (MIC, $0 / 0082 \mu \mathrm{mol} / \mathrm{mL}$ )

$104 \mathrm{c}: \mathrm{R}_{1}=2-\mathrm{CH}_{3} \mathrm{C}_{6} \mathrm{H}_{4} \mathrm{CH}_{2}$ (MIC, $0 / 0090 \mu \mathrm{mol} / \mathrm{mL}$ )

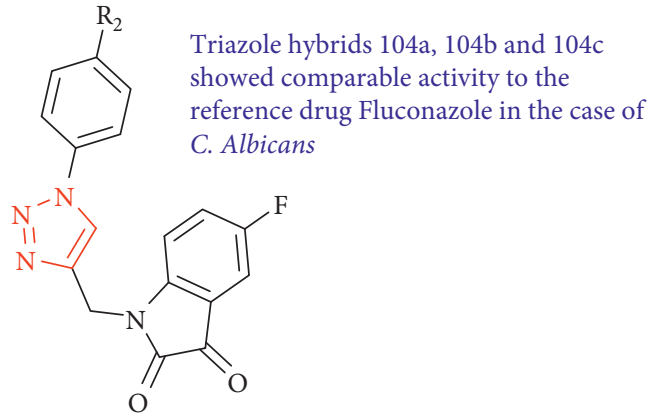

105

FIGURE 47: Chemical structure of 5-fluoroindoline-2,3-dione-triazoles derivatives.

the examined compounds (108a-c). Compounds with a piperazine moiety $(\mathbf{1 0 9 a}-\mathbf{c})$ displayed the biggest antifungal inhibition activity (Figure 49).

Shaikh et al. [115] described novel triazole-based isatin derivatives that were evaluated for biological activity using click chemistry. The 1,2,3-triazole-based isatin compounds showed good-to-moderate activity against all five human pathogenic fungal strains tested. The activity of $110 \mathrm{~b}$ and $110 \mathrm{c}$ with chlorogroup at meta and ortho situations in the phenyl ring displayed strong activity as compared with the standard drug against Fusarium oxysporum. Compound 110a with nitro-group at para position in the phenyl ring displayed equal activity against the fungicidal strain Candida albicans as compared with the reference medicine Miconazole (Figure 50).

2.4.7. 1,2,3-Triazole-Quinoline Hybrids. Nesaragi et al. [116] described a new sequence of quinolin-3-yl-methyl-1,2,3triazolyl-1,2,4-triazol-3(4H)-ones synthesized via click chemistry as a final tactic in which azides with final alkynes were tested for antifungal properties against four various pathogenic fungi (C. albicans, A. flavus, A. fumigatus, and A. niger). Fluconazole was employed as a standard drug. The antifungal results of synthesized derivatives announced favorable activity. According to the in silico and in vitro studies, these additional quinolines triazoles may acquire the arbitrary structural prerequisites for secondary synthesis of novel restorative components (Figure 51).

Shaikh et al. [117] investigated the biological activity of tetrazoloquinoline derivatives based on 1,4-disubstituted 1,2,3-triazole (Figure 52). All of the synthesized 1,4-disubstituted 1,2,3-triazole-based tetrazoloquinoline derivatives displayed good-to-moderate activity toward C. albicans, $P$. chrysogenum, C. lunata, A. niger, A. flavus, and C. neoformans strains. Compounds $113 \mathbf{a}-\mathbf{c}$ revealed four times the activity against $C$. albicans strain compared to the standard medicine Miconazole and Amphotericin B and twice the activity compared to Fluconazole. 


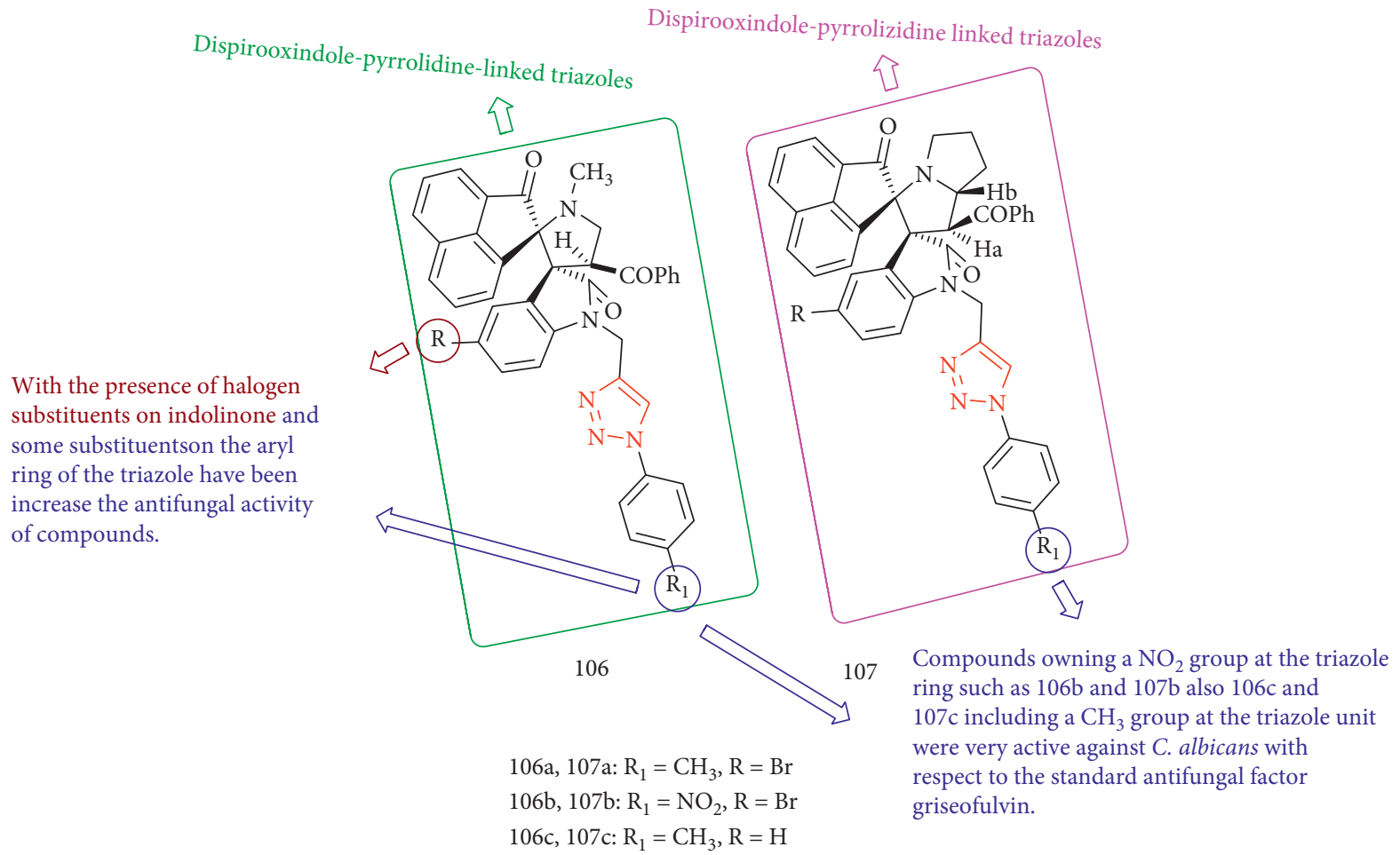

FIGURE 48: Chemical structure of novel spirooxindole-pyrrolidine/pyrrolizidine-linked 1,2,3-triazole conjugates.

Propargylated isatin moiety<smiles></smiles><smiles>[CH]N(C)CCC(=O)N1CCN(C(=O)Cn2cc(CN3C(=O)C(=O)c4ccccc43)nn2)CC1</smiles>

The existence of the acetyl group among the indole and the 1,2,3-triazole moieties plays a notable role in increasing antifungal activity.
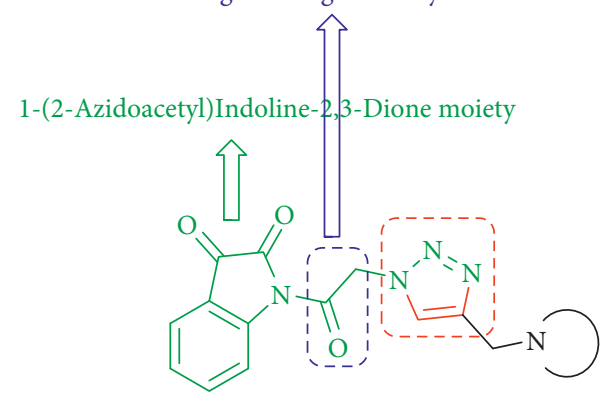

109<smiles>[C+]N1CCC(=[SH]N2CCN(C)CC2)CC1</smiles>

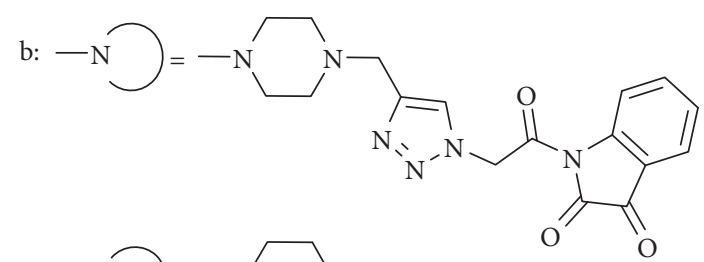<smiles>CC1CN(Cc2cn(CC(=O)N3C(=O)C(=O)c4ccccc43)nn2)CCN1C=C1CCN(C)CC1</smiles>

FIGURE 49: Chemical structure of novel isatin-1,2,3-triazoles with piperidine, morpholine, or piperazine moieties. 
Aafter presentation of 1,2,3-triazole ring on isatin, it gave notable antifungal property.

Compounds 110d and 111a containing nitro- substituentat meta situation of phenyl ring displayed favorable activity as compared with the Miconazole.
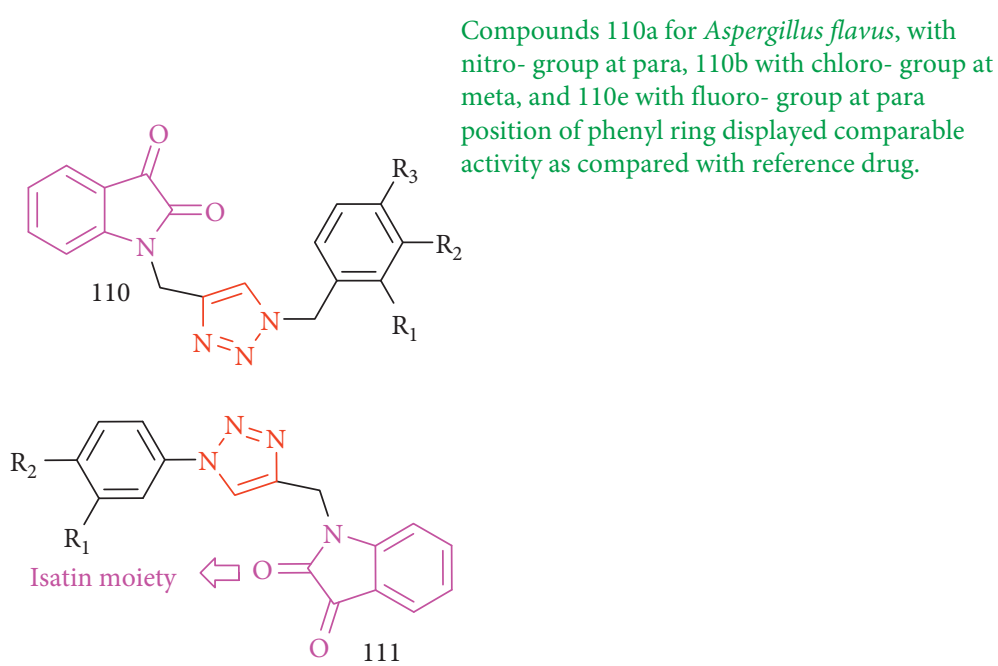

110a: $\mathrm{R}_{1}=\mathrm{H}, \mathrm{R}_{2}=\mathrm{H}, \mathrm{R}_{3}=\mathrm{NO}_{2}$

110b: $\mathrm{R}_{1}=\mathrm{H}, \mathrm{R}_{2}=\mathrm{Cl}, \mathrm{R}_{3}=\mathrm{H}$

110c: $\mathrm{R}_{1}=\mathrm{Cl}, \mathrm{R}_{2}=\mathrm{H}, \mathrm{R}_{3}=\mathrm{H}$

110d: $\mathrm{R}_{1}=\mathrm{H}, \mathrm{R}_{2}=\mathrm{NO}_{2}, \mathrm{R}_{3}=\mathrm{H}$

110e: $\mathrm{R}_{1}=\mathrm{H}, \mathrm{R}_{2}=\mathrm{H}, \mathrm{R}_{3}=\mathrm{F}$

111a: $\mathrm{R}_{1}=\mathrm{NO}_{2}, \mathrm{R}_{2}=\mathrm{H}$

FIGURE 50: Chemical structure of novel triazole-incorporated isatin derivatives as antifungal agents.

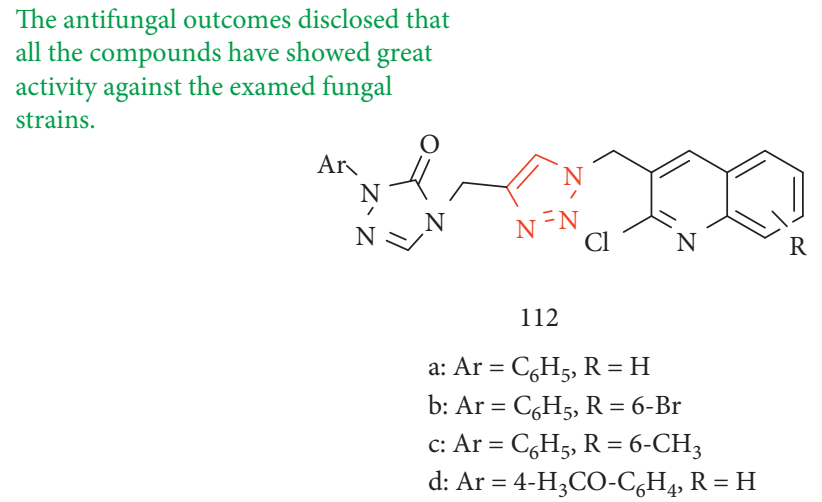

FIGURE 51: The chemical structure of quinoline-appended triazoles as potent antitubercular and antifungal agents.

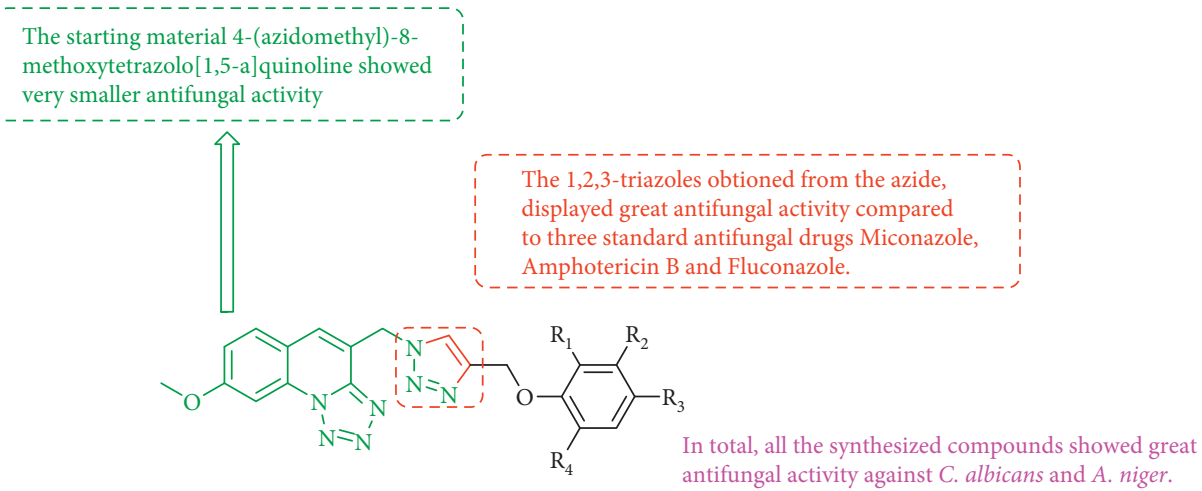

113

$$
\begin{aligned}
& \text { a: } \mathrm{R}_{1}=\mathrm{H}, \mathrm{R}_{2}=\mathrm{H}, \mathrm{R}_{3}=\mathrm{Cl}, \mathrm{R}_{4}=\mathrm{H} \\
& \text { b: } \mathrm{R}_{1}=\mathrm{H}, \mathrm{R}_{2}=\mathrm{CH}_{3}, \mathrm{R}_{3}=\mathrm{Cl}, \mathrm{R}_{4}=\mathrm{H} \\
& \text { c: } \mathrm{R}_{1}=\mathrm{Cl}, \mathrm{R}_{2}=\mathrm{H}, \mathrm{R}_{3}=\mathrm{Cl}, \mathrm{R}_{4}=\mathrm{Cl} \\
& 113 \mathrm{a}, 113 \mathrm{~b}, 113 \mathrm{c}(\mathrm{MIC}, 4 \mu \mathrm{mol} / \mathrm{mL})
\end{aligned}
$$

FIGURE 52: Chemical structure of tetrazoloquinoline-1,2,3-triazole derivatives. 
Irfan et al. [118] reported the synthesis of 1,2,3-triazole derivatives that were evaluated on three various fungal strains, C. glabrata ATCC 90030, Candida tropicalis ATCC 750, and Candida albicans ATCC 90028, and the findings were compared with the reference drug (Fluconazole). The results of anticandidal activity were obtained from three various Candida strains. They showed that compound 114a outperformed Fluconazole with $\mathrm{IC}_{50}$ values of $12.022 \mu \mathrm{g} / \mathrm{mL}$ against Candida glabrata, $0.044 \mu \mathrm{g} / \mathrm{mL}$ against Candida albicans, and $3.60 \mu \mathrm{g} / \mathrm{mL}$ against Candida tropicalis. Also, compounds 114a and 114b exhibited $<5 \%$ hemolysis at their $\mathrm{IC}_{50}$ values, demonstrating the nontoxic treatment of these inhibitors (Figure 53).

2.4.8. bis-Triazole Derivatives. Novel series of bis-1,2,3- and 1,2,4-triazoles as potential antimicrobial agents were synthesized by Bitla et al. [119] also, and all of them screened for their antifungal effect against Saccharomyces cerevisiae and Aspergillus niger. The majority of the synthesized compounds displayed favorable antifungal activity with the zone of inhibition $(1.5-8.2 \mathrm{~mm})$. The studies showed that (115a-d) compounds displayed an impressive antifungal effect among all the other synthesized compounds (Figure 54).

The click reaction catalyzed by $\mathrm{Cu}(\mathrm{I})$ used a class of $1,2,3-$ triazole containing oxime products under both conventional and microwave irradiation conditions. The compounds were evaluated against two fungi (Aspergillus flavus and Aspergillus niger) using Nystatin as a standard medicine. Compounds 116a and 116b showed a better zone of inhibition, whereas compounds $\mathbf{1 1 6} \mathbf{c}-\mathbf{f}$ exhibited a similar zone of inhibition comparable to the standard drug against the tested fungal strains (Figure 55) [120].

A new class of 1,3-bis-(1,2,3-triazole-1-yl)-propan-2-ol derivatives were synthesized using various alkynes and 1aryl-1,3-diazidopropan-2-ol derivatives, with the critical step including click reaction. When compared to Itraconazole and Fluconazole (MIC $=2.56$ and $1.28 \mu \mathrm{g} / \mathrm{mL}$, respectively), almost all of the synthesized compounds displayed great activity against Candida spp. strains in $0.04-0.5 \mu \mathrm{g} / \mathrm{mL}$ concentration ranges. The effect of cyclopropyl groups and fluorine atom in molecule 117a suggested a great selectivity in this compound to inhibit these type of Candida strains (Figure 56) [121].

A new class of 1,2,4-triazole thione derivatives including substituted piperazine portions and 1,2,3-triazole were described by Wang et al. [122]. The results of the bioassay showed that several compounds have significant fungicidal activity toward a variety of plant fungi at $50 \mu \mathrm{g} / \mathrm{mL}$. In most cases, trifluoromethyl-including triazole thione derivatives displayed desirable fungicidal activities that could be due to the great effects (like hydrophobicity and permeability) of the trifluoromethyl group reported on the parent structure (Figure 57).

Pertino et al. [123] synthesized 24 novel triazole derivatives from the abietane diterpenes carnosic acid and carnosol through using click chemistry. The length of the linker and the substituent on the triazole portion differed among compounds. The compounds varied in the length of the linker and the substituent on the triazole section. Antifungal activity was determined against Cryptococcus neoformans (ATCC 32264) and Candida albicans (ATCC 10231). In terms of antifungal action, C. neoformans was the most susceptible fungus, with some compounds inhibiting more than $50 \%$ of its fungal growth at doses as low as concentrations $\leq 250 \mu \mathrm{g} / \mathrm{mL}$. Compound $\mathbf{1 2 3 b}$ containing a $p-\mathrm{Br}-$ benzyl substituent on the triazole ring had the best activity (91\% growth inhibition) at $250 \mu \mathrm{g} / \mathrm{mL}$. In turn, six compounds prevented $50 \% \mathrm{C}$. albicans growth at concentrations further ess than $250 \mu \mathrm{g} / \mathrm{mL}$. When comparing 122a and $122 \mathrm{~b}$ with $122 \mathrm{c}$ and $122 \mathrm{~d}\left(R_{1}: p\right.$-bromobenzyl), the existence of a $\mathrm{Br}$ in the aromatic ring did not shift the activity until the length of the linker was three $\mathrm{CH}_{2}$ units; however, it decreased when the linker possessed two $\mathrm{CH}_{2}$ units. Comparing the activities of $122 \mathrm{a}$ and $122 \mathrm{~b}$ with those of $122 \mathrm{e}$ and 122f, introducing a nitro group in the aromatic ring $\left(R_{1}: p\right.$ nitrobenzyl), the activity of the nitro compounds is lower (Figure 58).

\subsubsection{1,2,3-Triazole Linked to Other Heterocyclic} Pharmacophores. As it is shown in Figure 59, a series of novel derivatives of 1-(4-methyl-2-aryl-1,3-thiazole-5yl)-2-(4-aryl-1,2,3-triazol-1-yl) ethanol were synthesized and their antifungal properties screened in vitro against Candida albicans, Aspergillus niger, Rhodotorula glutinis, and Penicillium chrysogenum. Most of the compounds have moderate-to-good antifungal activity against $A$. niger in comparison to the standard medicine Ravuconazole [124].

Thotla et al. [125] synthesized a new series of Benzo[b] thiophene triazoles with high yields from various azides with propargyl derivatives of benzothiophene, and most of them displayed significant antifungal activity against the fungi tested (Sclerotium rolfsii and Aspergillus niger) (Figure 60).

Costa et al. [126] explained a new route for synthesizing a series of glycerol-derived 4-alkyl-substituted 1,2,3-triazoles using glycerol as the starting substance. Colletotrichum gloeosporioides, a causal factor of papaya anthracnose, were tested for fungicidal activity. All compounds inhibited mycelial development less effectively than the positive control Tebuconazole. Compounds 126a and 126b were the most active (ED50 values below $20 \mathrm{ppm}$ ), with 126b exhibiting the widest power (ED50 10.14 ppm) (Figure 61).

Seventeen new benzoxazole derivatives, containing a 1,2,3-triazole scaffold, were generated in order to discover contemporary bioactive compounds with outstanding antifungal properties. The antifungal activities of the synthesized compounds were screened toward Fusarium verticillium (FV) and Botrytis cinerea (BC), with hymexazol serving as a positive control. The results of the tests showed that compounds 127a-d had good inhibitory effects on fungus. In these compounds, when the benzotriazole and benzoxazole moiety were without substituents at aromatic ring, they revealed the best antifungal activity against $\mathrm{BC}$ (127b). The compounds were more active against BC than against FV (Figure 62) [127]. 
The raised anticandidal activity of compounds $114 \mathrm{a}$ and $114 \mathrm{~b}$ might be happened owing to existence of quinoline ring and free aldehyde group, in order along with 1,2,3 triazole ring in their buildings.

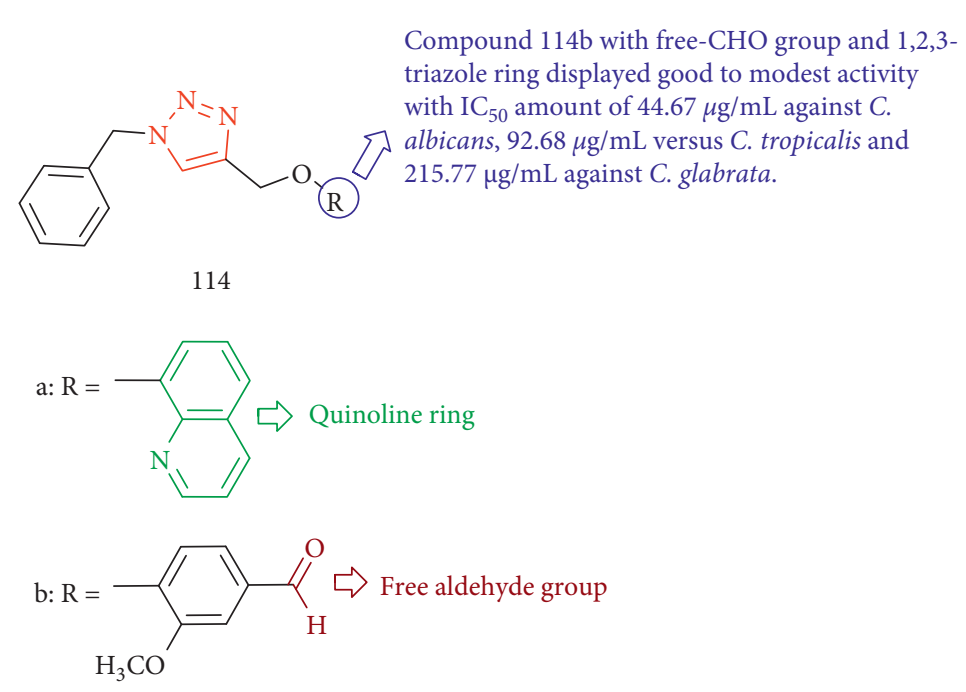

FIGURE 53: Chemical structure of novel 1,2,3-triazole derivatives.<smiles>[R3]n1c(SC2CCCC2)nnc1-c1ccccc1OCc1cn(C)nn1</smiles><smiles>Cc1ccc(Br)c(Br)c1</smiles>

It is marked that $\mathrm{Cl}$ and $\mathrm{Br}$ substitutes at -para and -meta positions of aryl group linked to $-\mathrm{CH}_{2} \mathrm{CO}$ (for example $-\mathrm{R}_{3}$ ) donated very well biological inhibitory activities when only compared with $-\mathrm{CH}_{2} \mathrm{COPh}$ and $-\mathrm{COPh}$ group.

115

$$
\begin{aligned}
& \text { a: } \mathrm{R}=\mathrm{Cl}, \mathrm{R}_{1}=\mathrm{H}, \mathrm{R}_{2}=\mathrm{PhCH}_{2^{-}}, \mathrm{R}_{3}=\mathrm{PhCOCH}_{2^{-}} \\
& \text {b: } \mathrm{R}=\mathrm{Cl}, \mathrm{R}_{1}=\mathrm{H}, \mathrm{R}_{2}=\mathrm{PhCH}_{2^{-}}, \mathrm{R}_{3}=\mathrm{PhCO}- \\
& \text { c: } \mathrm{R}=\mathrm{H}, \mathrm{R}_{1}=\mathrm{H}, \mathrm{R}_{2}=\mathrm{PhCH}_{2^{-}}, \mathrm{R}_{3}=p-\mathrm{BrPhCOCH}_{2^{-}} \\
& \text {d: } \mathrm{R}=\mathrm{H}, \mathrm{R}_{1}=\mathrm{H}, \mathrm{R}_{2}=\mathrm{PhCH}_{2^{-}}, \mathrm{R}_{3}=m-\mathrm{BrPhCOCH}_{2^{-}}
\end{aligned}
$$

FIgURE 54: Structure of bis-(1,2,3- and 1,2,4)-triazole derivatives as potential antimicrobial and antifungal agents.

$$
\begin{aligned}
& \text { a: } \mathrm{R}_{1}=\mathrm{OCH}_{3}, \mathrm{R}_{2}=\mathrm{OCH}_{3} \\
& \text { b: } \mathrm{R}_{1}=\mathrm{OCH}_{3}, \mathrm{R}_{2}=\mathrm{C}_{4} \mathrm{H}_{9} \\
& \text { c: } \mathrm{R}_{1}=\mathrm{CH}_{3}, \mathrm{R}_{2}=\mathrm{OCH}_{3} \\
& \text { d: } \mathrm{R}_{1}=\mathrm{OCH}_{3}, \mathrm{R}_{2}=\mathrm{CH}_{3} \\
& \text { e: } \mathrm{R}_{1}=\mathrm{OCH}_{3}, \mathrm{R}_{2}=\mathrm{Br} \\
& \text { f: } \mathrm{R}_{1}=\mathrm{H}, \mathrm{R}_{2}=\mathrm{OCH}_{3}
\end{aligned}
$$

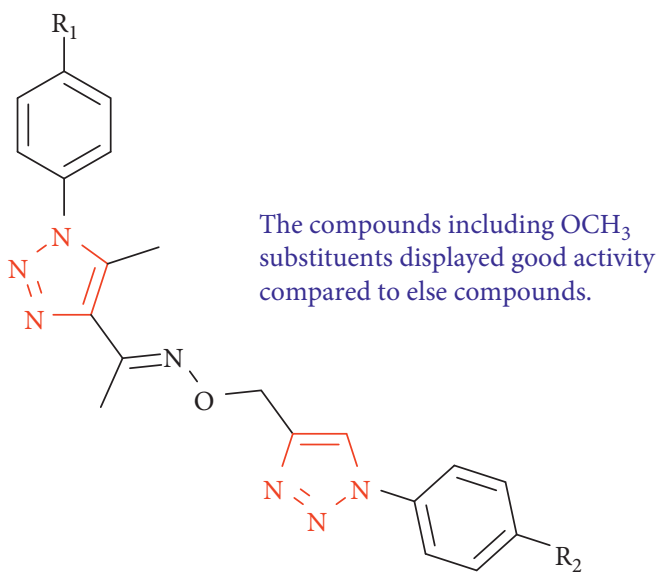

116

Figure 55: Chemical structure of some new 1,2,3-triazole derivatives. 
Compound 117a displays an inhibitory efficasy on strains of Candida albicans and Candida krusei under $0.0075 \mu \mathrm{g} / \mathrm{mLwhilst}$ antifungal properties against other Candida strains is alike, and in some instances, less (Candida glabrata, Candida tropicalis, $\mathrm{MIC}=2.56 \mu \mathrm{g} / \mathrm{mL}$ ).

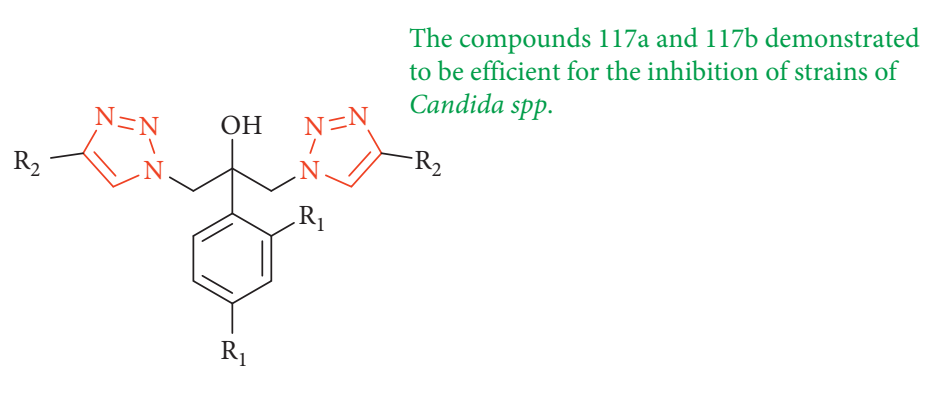

117

a: $\mathrm{R}_{1}=\mathrm{F}, \mathrm{R}_{2}=$ Cyclopropyl

b: $\mathrm{R}_{1}=\mathrm{OCH}_{3}, \mathrm{R}_{2}=$ Cyclopropyl

Figure 56: Chemical structure of 1,3-bis-(1,2,3-triazol-1-yl)-propan-2-ol derivatives.

The activity of most compounds, whereas $\mathrm{R}$ was
firmed as $\mathrm{H}$, showed the tendency $\mathrm{Ph}>\mathrm{Py}$, and
4-methylpyrimidyl $>4,6$-dimethylpyrimidyl in the
aryl group of piperazine 4-situation.

119a exhibited wide fungal activity.
When $\mathrm{R}$ was firmed as $\mathrm{F}$, displayed the tendency benzyl > 2,4-dichlorobenzyl, $\mathrm{Ph} \approx \mathrm{Py}$, and 4-methylpyrimidyl $>4,6$ dimethylpyrimidyl in the class of piperazine 4-situation.<smiles>[R1]c1ccc(CN2CCN(Cn3nc([R3])n(/N=C/c4cnn(-c5ccccc5)n4)c3=S)CC2)c([R7])c1</smiles><smiles>[R2]C1=CC([R2])=[Y](C2CCN(Cn3nc(C)n(/N=C/c4cnn(-c5ccccc5)n4)c3=S)CCN2)C([R1])[X]1</smiles>

119a: $\mathrm{R}=\mathrm{F}, \mathrm{R} 1=\mathrm{H}, \mathrm{R} 2=\mathrm{CH} 3, \mathrm{X}=\mathrm{Y}=\mathrm{N}$.

FIgURE 57: Chemical structure of novel 1,2,4-triazole thione derivatives containing 1,2,3-triazole and substituted piperazine moieties.

Straight and adaptive azide-enolate $(3+2)$ cycloaddition was used to synthesize modern oxazolidin-2-oneconnected-1,2,3-triazole derivatives. As it can be seen in Figure 63, the sequence of compounds was tested for fungicidal activity toward four penicillate fungi as well as six yeast species of Candida spp., and Itraconazole used as the reference antifungal drug. Compounds 128a-c showed higher activity against C. glabrata (MICs of 0.12 , 0.25 , and $0.12 \mu \mathrm{g} / \mathrm{mL}$, respectively) than Itraconazole $(\mathrm{MIC}=1 \mu \mathrm{g} / \mathrm{ml})$. The activity of compound 128a $(\mathrm{MIC}=2 \mu \mathrm{g} / \mathrm{mL})$ against Trichosporon cutaneum was better than that of Itraconazole (MIC $=8 \mu \mathrm{g} / \mathrm{mL}$ ), while compound 128c showed a great antimycotic activity in Mucor hiemalis (MIC $=2 \mu \mathrm{g} / \mathrm{mL}$ versus $4 \mu \mathrm{g} / \mathrm{mL}$ for Itraconazole) [128].
González-Calderón et al. [129] reported the first synthesis of a new kind of compound, using $1^{\prime}$-homo- $N$-1,2,3-triazolebicyclic carbonucleosides 129a and $\mathbf{1 2 9 b}$ that exhibited good activity against some of the yeast strains examined (Figure 64).

The new benzofuran-triazole hybrids were generated using click reaction. The antifungal effect of goal compounds toward five strains of pathogenic fungi was assessed using the microdilution broth technique. The results showed that the lead compounds were active in a moderate-to-acceptable range. Some compounds only have a mild antifungal activity against Candida albicans and Rhodotorula rubra. With the exception of compounds 130a and 130b, most of the compounds displayed antifungal activity against Cryptococcus neoformans in concentrations ranging from 32 to $128 \mu \mathrm{g} / \mathrm{mL}$. The primary SARs were supported by the 
The outcomes showed some selectivity for the various fungi and that the assignment of the lactone is serious for the effect.<smiles>[R]Oc1c(C(C)C)cc2c(c1O[R])[C@]1(C(=O)OC)CCCC(C)(C)[C@H]1CC2</smiles>

For compound 121a and 121b the $\gamma$-lactone emerges to be significant for activity.

122

Compounds 121a, 121b, 122b and 123a, that displayed the best activities against C. albicans, containing the following usual properties:

1: the linker to the diterpene part included three $\mathrm{CH}_{2}$ units. 2: in the triazole rings, $R_{1}$ was either a methyl phenyl sulfide (compounds 121a and 123a) or a benzyl (compounds $121 \mathrm{~b}$ and 122b);

3: the activity was nearly the identicalfor the four compounds 4: when $\mathrm{R}_{1}$ connected to the triazole ring was $p$-bromobenzyl or $p$-nitrobenzyl, the equivalent derivatives were passive.

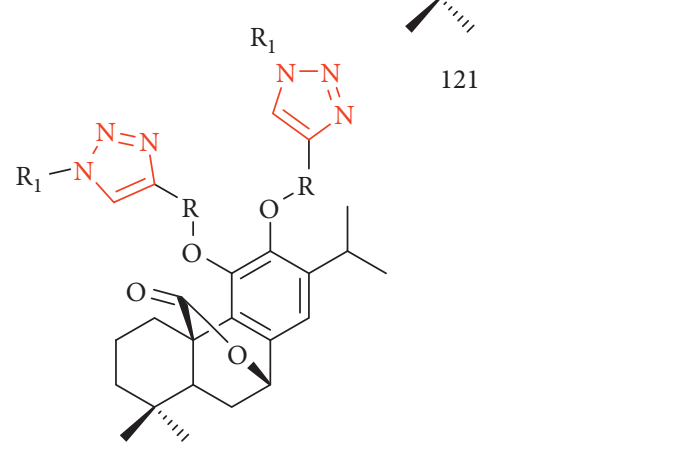<smiles>[R]Oc1c(C(C)C)cc2c3c1OC(=O)[C@]31CCCC(C)(C)[C@@H]1CC2</smiles>

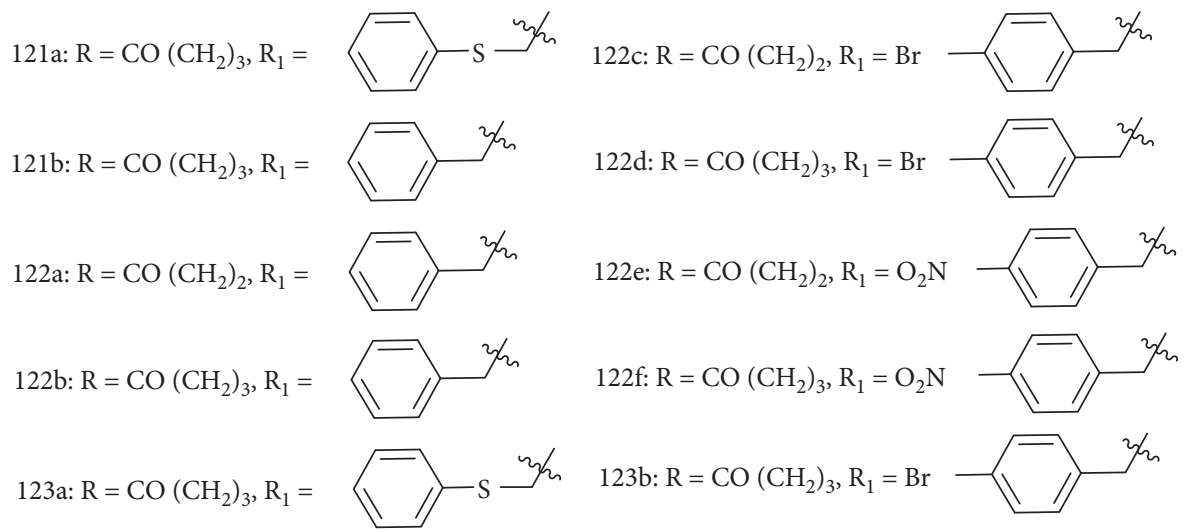

Figure 58: Chemical structure of 1,2,3-triazole-substituted carnosic acid and carnosol derivatives.

excellent bioactivities of $130 \mathrm{f}$ and $130 \mathrm{~g}$ among all the goal compounds (Figure 65) [130].

2.4.10. Miscellaneous 1,2,3-Triazole Hybrids. Yadav et al. [131] synthesized novel fluorinated-chalcone-1,2,3-triazoles. The antimicrobial assessment revealed that most of the compounds displayed unusual activity. When 1,2,3-triazole and chalcone were added to the antimicrobial screening results, the activity increased. Compound 131c containing $p$ nitro group displayed superior power against $A$. niger and C. albicans with MIC value of $0.0032 \mathrm{mmol} / \mathrm{mL}$ compared to Fluconazole $(\mathrm{MIC}=0.0102 \mathrm{mmol} / \mathrm{mL})$. Compound $\mathbf{1 3 1 b}$ with a bromine group demonstrated comparable activity to the standard with MIC values of $0.0054 \mathrm{mmol} / \mathrm{mL}$ against
C. albicans. Compounds having nitro and methoxy groups on the benzene ring displayed better activity against most of the microorganisms tested (Figure 66).

A sequence of 4-((1-benzyl/phenyl-1H-1,2,3-triazole-4-yl) methoxy) benzaldehyde derivatives were generated in high yield. All compounds were examined for fungicidal activity against Aspergillus niger and Candida albicans in vitro. The majority of the compounds demonstrated good-to-outstanding antifungal activity. Compounds 132a and 132b were more potent against $A$. niger with MIC value of $0.0084 \mu \mathrm{M} / \mathrm{mL}$ compared to Fluconazole $(\mathrm{MIC}=0.0102 \mu \mathrm{M} /$ $\mathrm{mL}$ ) (Figure 67) [132].

Jiang et al. [133] explored a series of new paeonol derivatives linked to a 1,2,3-triazole moiety for obtaining modern bioactive compounds with remarkable fungicidal 


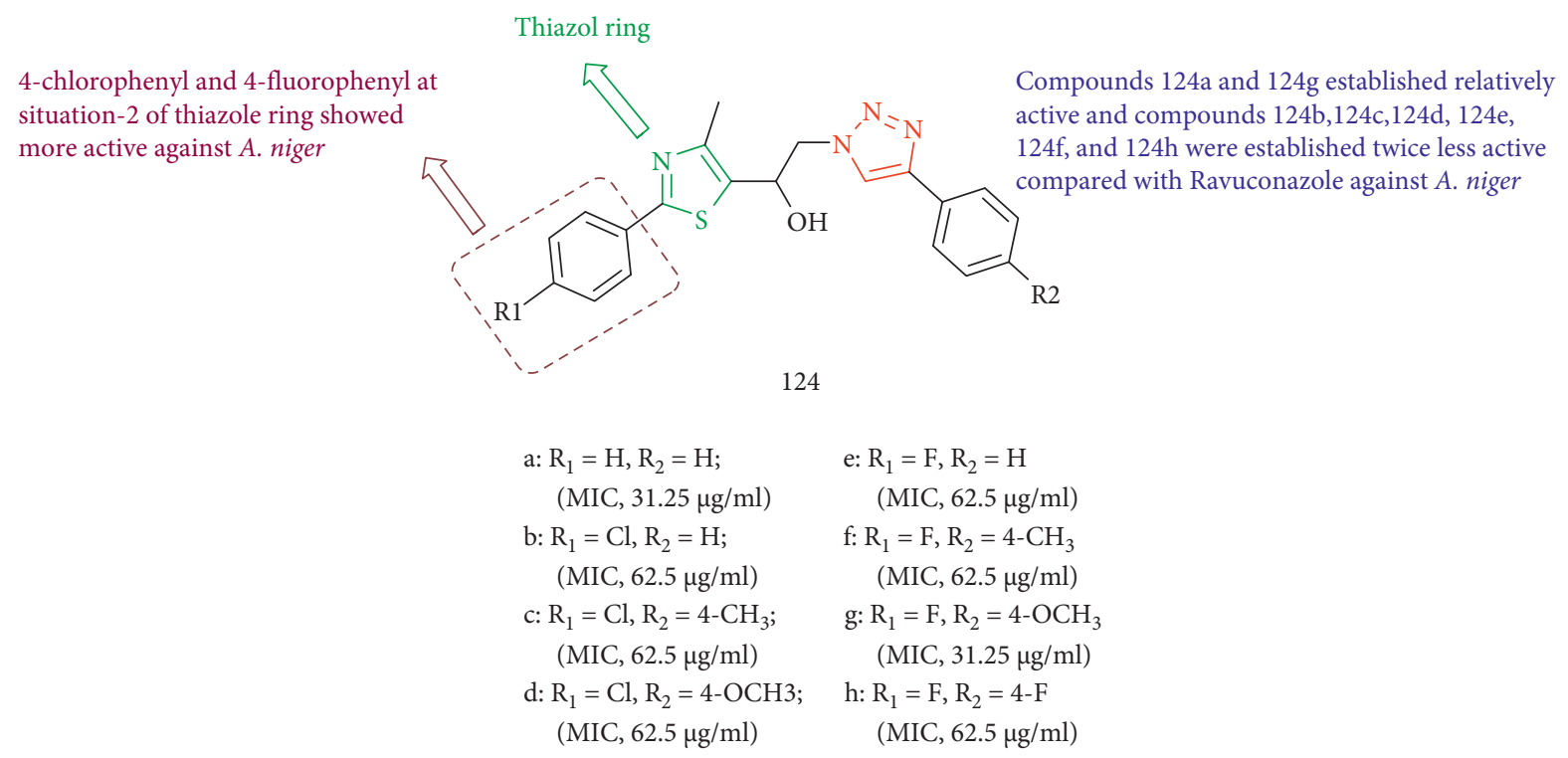

FIGURE 59: Chemical structure of 1-(4-methyl-2-aryl-1,3-thiazol-5-yl)-2-(4-aryl-1,2,3-triazol-1-yl)ethanol.

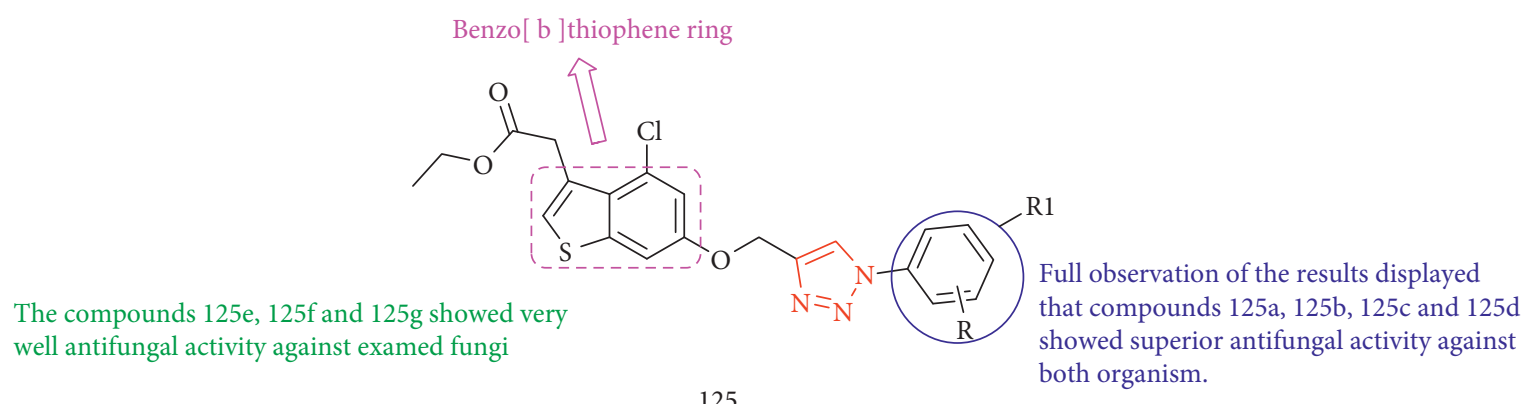

$$
\begin{aligned}
& \text { a: } \mathrm{R}=4-\mathrm{COCH}_{3} ; \mathrm{b}: \mathrm{R}=4-\mathrm{OH} \\
& \mathrm{c}: \mathrm{R}=\mathrm{Cl} ; \mathrm{d}: \mathrm{R} 1=\text { cyclohexyl } \\
& \text { e: } \mathrm{R}=4-\mathrm{NO}_{2} ; \mathrm{f}: \mathrm{R}=3-\mathrm{Me} \\
& \mathrm{g}: \mathrm{R}=3-\mathrm{OMe}^{-}
\end{aligned}
$$

Figure 60: Chemical structure of benzo[b]thiophenes-1,2,3-triazole derivatives.

All compounds presented large yield (comparable to the industrial fungicide tebuconazole) in inhibiting C. gloeosporioides sporulation and all compounds dis- played a lower output inhibiting mycelial growth than the positive control Tebuconazole.
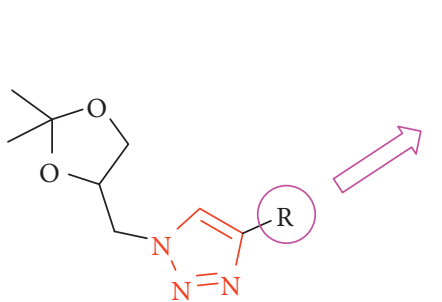

These 4-alkyl-substituted triazoles might show a framework to be explored for the growth of novel fungicidal agents.

$$
\begin{aligned}
& \text { a: } \mathrm{R}=\mathrm{CH}_{3}\left[\mathrm{CH}_{2}\right] 4 \mathrm{CH}_{2^{-}} \\
& \text {b: } \mathrm{R}=\mathrm{CH}_{3}\left[\mathrm{CH}_{2}\right] 8 \mathrm{CH}_{2^{-}}
\end{aligned}
$$

FIgURE 61: Chemical structure of glycerol triazolic derivatives. 


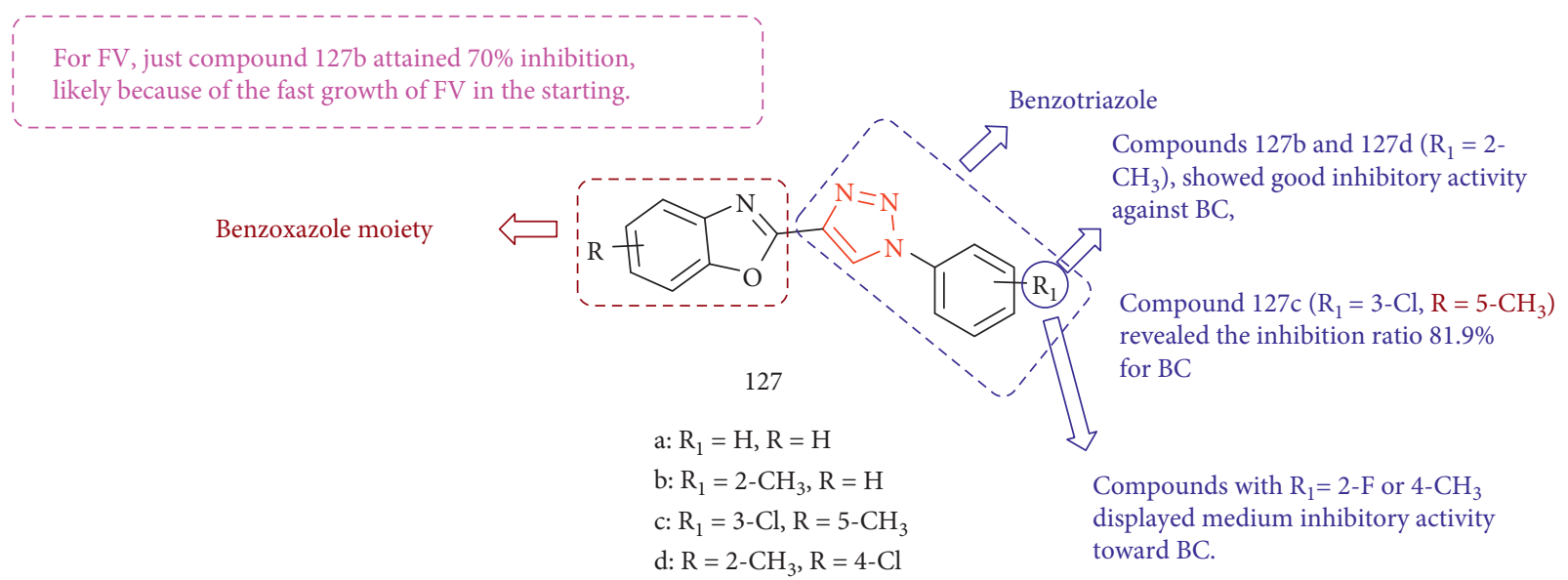

Figure 62: Chemical structure of novel benzoxazole derivatives containing a 1,2,3-triazole moiety.

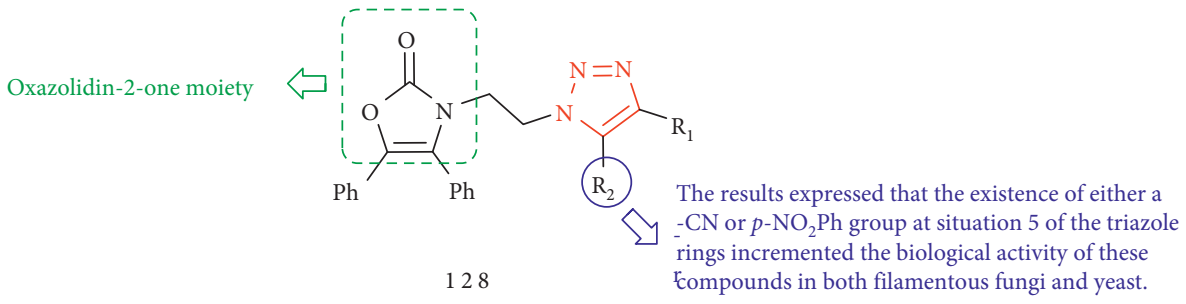

$$
\begin{aligned}
& \text { a: } \mathrm{R}_{1}=\mathrm{SO}_{2}-p-\mathrm{TOI}, \mathrm{R}_{2}=m-\mathrm{NO}_{2} \mathrm{Ph} \\
& \text { b: } \mathrm{R}_{1}=\mathrm{SO}_{2} \mathrm{Ph}, \mathrm{R}_{2}=\text { Pentyl } \\
& \text { c: } \mathrm{R}_{1}=\mathrm{CN}, \mathrm{R}_{2}=\mathrm{Ph}
\end{aligned}
$$

FIGURE 63: Chemical structure of oxazolidin-2-one-linked-1,2,3-triazoles.

Compounds 129a and 129b displayed good activity in some of the yeast strains, containing C. utilis, C. lipolytica, C. glabrata and C. famata.

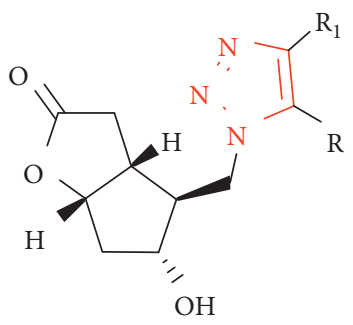

129

$$
\begin{aligned}
& \text { a: } \mathrm{R}=\mathrm{Me}, \mathrm{R}_{1}=\mathrm{COMe} \\
& \text { b: } \mathrm{R}=\mathrm{Ph}, \mathrm{R}_{1}=\mathrm{COPh}
\end{aligned}
$$

FIGURE 64: Chemical structure of $1^{\prime}$-homo-N-1,2,3-triazole-bicyclic carbonucleosides.

activity using $\mathrm{Cu}(\mathrm{OAc})_{2} \cdot \mathrm{H}_{2} \mathrm{O}$ /sodium ascorbate as a catalyst and under mild conditions. The antifungal properties of all the target compounds were assessed in vitro against two plant pathogenic fungi: Rhizoctonia cerealis and Colletotrichum capsici. The outcomes of antifungal activities showed that several of the compounds had acceptable activity in vitro against the examined fungi at $20 \mu \mathrm{g} / \mathrm{mL}$ (Figure 68).

He et al. [134] investigated the activity of 5-iodo-1,4disubstituted-1,2,3-triazole compounds that were evaluated to study their Escherichia coli PDHc-E1 and fungicidal activity. Compound $\mathbf{1 3 5 b}$ had the most inhibitory activity $\left(\mathrm{IC}_{50}=4.21 \pm 0.11 \mu \mathrm{M}\right)$ and was shown to be an aggressive PDHc-E inhibitor. Fungicidal activity findings exhibited that compounds 135a-c had almost good activity against Botrytis cinerea and Rhizoctonia solani even at $12.5 \mu \mathrm{g} / \mathrm{mL}$. The SAR resolution showed that the 4-situation in the benzene ring significantly influenced the antifungal effect and inhibitory strength against E. coli PDHc-E1. It exhibited that an acceptable electron-withdrawing substituent in the 4-position of the benzene ring was useful for the binding interaction with the active region of PDHc-E1. The introduction of replacement $R$ in the 4-position of the benzene ring could dramatically raise both enzyme inhibition and antifungal property compared with $R$ in other situations or no substituent on the benzene ring (Figure 69).

Ren et al. [135] described a successful protocol for direct ortho-C-H alkoxylation of 1,4-di-substituted 1,2,3-triazoles utilizing alcohol as the alkoxyl source. Furthermore, alkoxylated products exhibited potent antifungal activity in combating the root-rot disease of Panax notoginseng (Figure 70). 
The substituted groups on the phenyl ring connected to the triazole also had an effect on the activity.

Attenting the antifungal assay outcomes, it can be datumed that the derivatives with a di-fluorine substituted phenyl ring at the benzofuran C-2 side chain are more impressive than the mono fluorine ones (e.g., 130d vs. 130f).

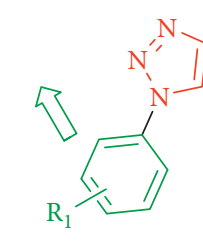

The alkyl-substituted compounds are more powerful than the halogenated derivatives (e.g., 130c vs. 130d)

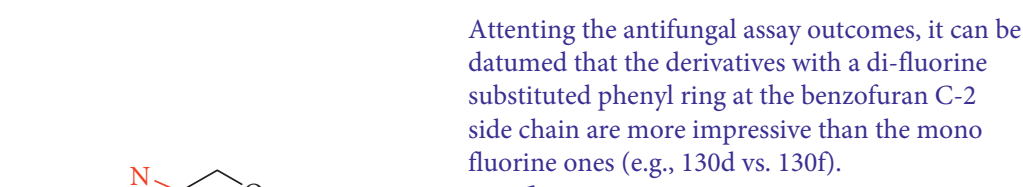

$$
\begin{array}{ll}
\text { and the ortho-substituted derivatives are stronger } & \text { a: } \mathrm{R}=\mathrm{H}, \mathrm{R}_{1}=4-\mathrm{Cl} \\
\text { than the para isomers (e.g., 130e vs. 130d). } & \text { b: } \mathrm{R}=\mathrm{H}, \mathrm{R}_{1}=4-\mathrm{Br} \\
\mathrm{c}: \mathrm{R}=\mathrm{H}, \mathrm{R}_{1}=2-\mathrm{Cl} & \mathrm{d}: \mathrm{R}=\mathrm{H}, \mathrm{R}_{1}=2-\mathrm{CH}_{3} \\
& \text { e: } \mathrm{R}=\mathrm{H}, \mathrm{R}_{1}=4-\mathrm{CH}_{3} \\
\text { f: } \mathrm{R}=\mathrm{F}, \mathrm{R}_{1}=2-\mathrm{CH}_{3} \\
\text { g: } \mathrm{R}=\mathrm{F}, \mathrm{R}_{1}=2,5-\mathrm{di}_{3} \mathrm{CH}_{3}
\end{array}
$$

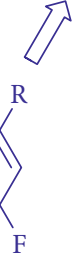

FIGURE 65: Chemical structure of novel benzofuran-triazole hybrids.

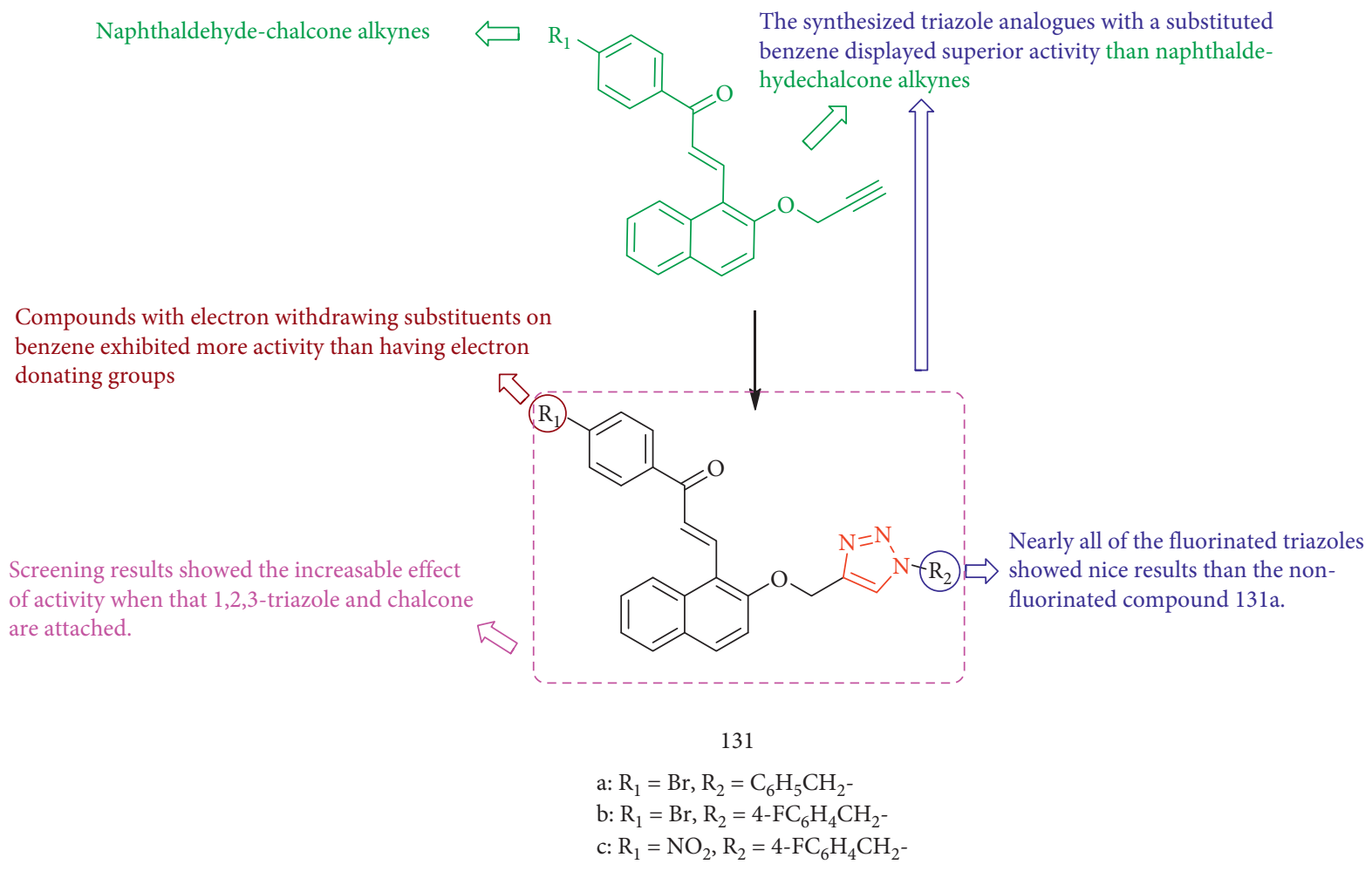

Figure 66: Chemical structure of chalcone-1,2,3-triazole hybrids.

A new 4-(1-phenyl-1-hydroxyethyl)-1-(o-hydroxyphenyl(-1H-1,2,3-triazole was designed by integrating the constructional properties of triazole PITENIN anticancer factors and the azole class of antifungal drugs. Their evaluation of a wide spectrum of human fungal pathogens resulted in the identification of several possible antifungal strains, some of which demonstrated stronger antifungal activity than standard drug against Aspergillus fumigatus, Candida glabrata, Cryptococcus neoformans, and Aspergillus niger. Many of these compounds demonstrated strong antifungal activity against several of the examined pathogen. Compounds 138d and 138e were the most effective against all fungal infections, with MICs ranging from 4 to $32 \mu \mathrm{g} / \mathrm{mL}$. Compounds 138i, 138j, 138f, 138g, and $138 \mathrm{~h}$ displayed very good antifungal activity excluding $A$. niger (MIC $>128 \mu \mathrm{g} / \mathrm{mL}$ ) as shown in Figure 71. Surprisingly, all derivatives exhibited greater activity than Fluconazole against Candida glabrata NCYC 388. In general, dichloro- or bis-trifluoromethyl groups on the scaffold are expected to enhance lipophilicity while simultaneously polarizing the sample molecule [136]. 
$132 \mathrm{c}, 132 \mathrm{~d}$ and $132 \mathrm{e}$ exhibited activity comparable to the standard drug against $A$. niger.

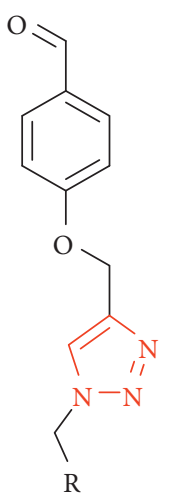

132

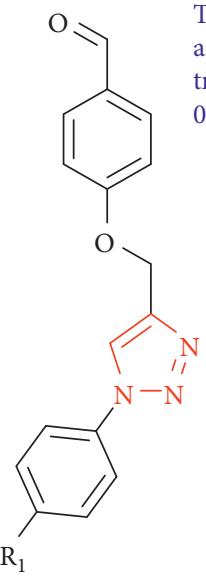

133
The compounds with $\mathrm{Br}$ group (132a, 132b, 132f and 133a) showed greater activity than all other triazoles with MIC amounts in the range 0.0084$0.0087 \mu \mathrm{M} / \mathrm{mL}$ against C. albicans. 132a: $\mathrm{R}=2-\mathrm{Br}-\mathrm{C}_{6} \mathrm{H}_{4}$

132b: $\mathrm{R}=3-\mathrm{Br}-\mathrm{C}_{6} \mathrm{H}_{4}$

132c: $\mathrm{R}=3-\mathrm{F}-\mathrm{C}_{6} \mathrm{H}_{4}$

132d: $\mathrm{R}=4-\mathrm{F}-\mathrm{C}_{6} \mathrm{H}_{4}$

132e: $\mathrm{R}=4$-Pyridinyl

132f: $\mathrm{R}=4-\mathrm{Br}-\mathrm{C}_{6} \mathrm{H}_{4}$

133a: $\mathrm{R}_{1}=4-\mathrm{Br}$

FIGURE 67: Chemical structure of 4-((1-benzyl/phenyl-1H-1,2,3-triazole-4-yl)methoxy)benzaldehyde analogs.

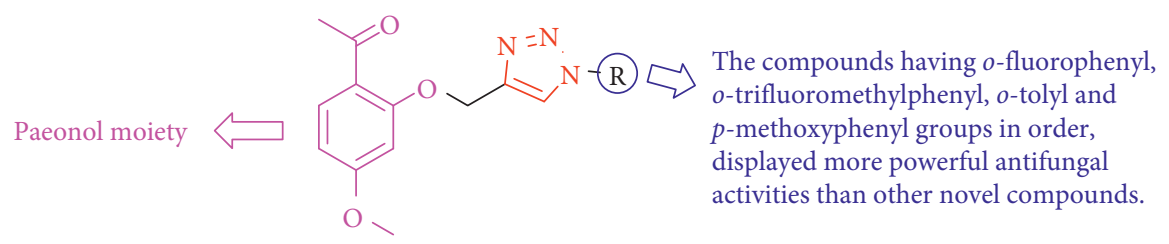

134

FIGURE 68: Chemical structure of novel paeonol derivatives linked with 1,2,3-triazole moiety.

$\mathrm{R}=\left(4-\mathrm{Br}, 3-\mathrm{NO}_{2}, 4-\mathrm{Cl}, 4-\mathrm{F}, 4-\mathrm{CN}\right.$, and $\left.4-\mathrm{OCH}_{3}\right)$ had desirable result on both antifungal activity and enzyme inhibition $\left(\mathrm{IC}_{50}<12 \mu \mathrm{M}\right)$.

\footnotetext{
When $4-\mathrm{CO}_{2}$ Et as $\mathrm{R}$ was presented into the benzene ring, both activities of compound $139 \mathrm{~b}$ notably reduced.

For the di-substituents, $\mathrm{R}=3-\mathrm{CH}_{3}-4-\mathrm{Cl}$ or $\mathrm{R}=2-\mathrm{Cl}-4-\mathrm{NO}_{2}$ was most useful to both antifungal activity and enzyme inhibition.<smiles>C=Cc1cccc(OCc2nnn(Cc3cnc(C)nc3N)c2I)c1</smiles>

135

$$
\begin{array}{ll}
\text { a: } \mathrm{R}=4-\mathrm{CN} & \left.\mathrm{IC}_{50}=8.73 \pm 0.34 \mu \mathrm{M}\right) ;\left(\mathrm{R}=4-\mathrm{Cl}, \mathrm{IC}_{50}=11.86 \pm 1.01 \mu \mathrm{M}\right)> \\
\text { b: } \mathrm{R}=4-\mathrm{Br} & \left(\mathrm{R}=2-\mathrm{Cl}, \mathrm{IC}_{50}=14.83 \pm 0.91 \mu \mathrm{M}\right) .
\end{array}
$$$$
\text { c: } \mathrm{R}=4-\mathrm{Cl}
$$

Comparing the inhibitory power versus E. coli PDHc-E1, $\left(\mathrm{R}=4-\mathrm{Br}, \mathrm{IC}_{50}=4.21 \pm 0.11 \mu \mathrm{M}\right)>\left(\mathrm{R}=2-\mathrm{Br}, \mathrm{IC}_{50}=15.69 \pm\right.$ $0.85 \mu \mathrm{M}) ;\left(\mathrm{R}=4-\mathrm{NO}_{2}, \mathrm{IC}_{50}=5.33 \pm 0.1 \mu \mathrm{M}\right)>\left(\mathrm{R}=2-\mathrm{NO}_{2}\right.$,
}

Figure 69: Chemical structure of the new 5-iodo-1,4-disubstituted-1,2,3-triazole derivatives.

A series of novel strobilurin derivatives with various 1,2,3-triazole side chains were synthesized. As shown in Figure 72, all of the compounds were evaluated in vitro for fungicidal activity against Phytophthora capsici, Alternaria alternate, Gibberella zeae, Sclerotinia sclerotiorum, and Botrytis cinerea, with some displaying medium-to-high fungicidal activity against Alternaria alternate and Phytophthora capsici. Difenoconazole was used as a standard medicine. Amid the goal compounds $\mathrm{X}=\mathrm{Br}$ and $\mathrm{R}=4-\mathrm{OCH}_{3}, \mathrm{R}=4-\mathrm{CH}_{3}$ was preferred for the advancement of antifungal activities, which were surprisingly better than 139e $\left(R=3-\mathrm{NO}_{2}\right)$ and compounds including $(X=\mathrm{Cl})$ with different halogen atoms on the benzene ring displayed comparable inhibition rates against the examined fungi, for example, 139f, 139g, and 139b [137].

Pyta et al. [138] used the click reaction to enhance the antifungal agent gossypol by adding a triazole moiety. The biological assessment of the new gossypol-triazole conjugates, as shown in Figure 73, revealed that the potency of $140 \mathrm{~g}$ and $140 \mathrm{~h}$ compounds containing triazole-benzyloxy portion was equivalent to that of conventional medication against Fusarium oxysporum. Antifungal tests were applied on some plant pathogens that cause serious difficulties in 
<smiles>[R]c1ccc(-n2cc(-c3c(OC)cc([R])cc3OC)nn2)cc1</smiles>

136

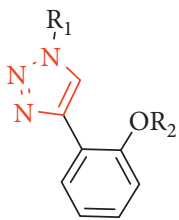

$$
\begin{aligned}
& \text { 136a: } \mathrm{R}_{1}=p-\mathrm{Me}, \mathrm{R}_{2}=\mathrm{H} \quad \text { 137a: } \mathrm{R}_{1}=p-\text { Tol, } \mathrm{R}_{2}=s \mathrm{Bu} \\
& \text { 136b: } \mathrm{R}_{1}=\mathrm{H}, \mathrm{R}_{2}=\mathrm{H} \\
& \text { 136c: } \mathrm{R}_{1}=\mathrm{H}, \mathrm{R}_{2}=\mathrm{Me}
\end{aligned}
$$

Compounds 136a, 136b, 136c, and 137a showed great inhibitory activities forward the three fungal strains including F. oxysporum, F. solani, and C. destrutans and displayed better antifungal activities than commercial agricultural chemical of Propamocarb.

Figure 70: Chemical structure of 1, 4-disubstituted 1,2,3-triazole.

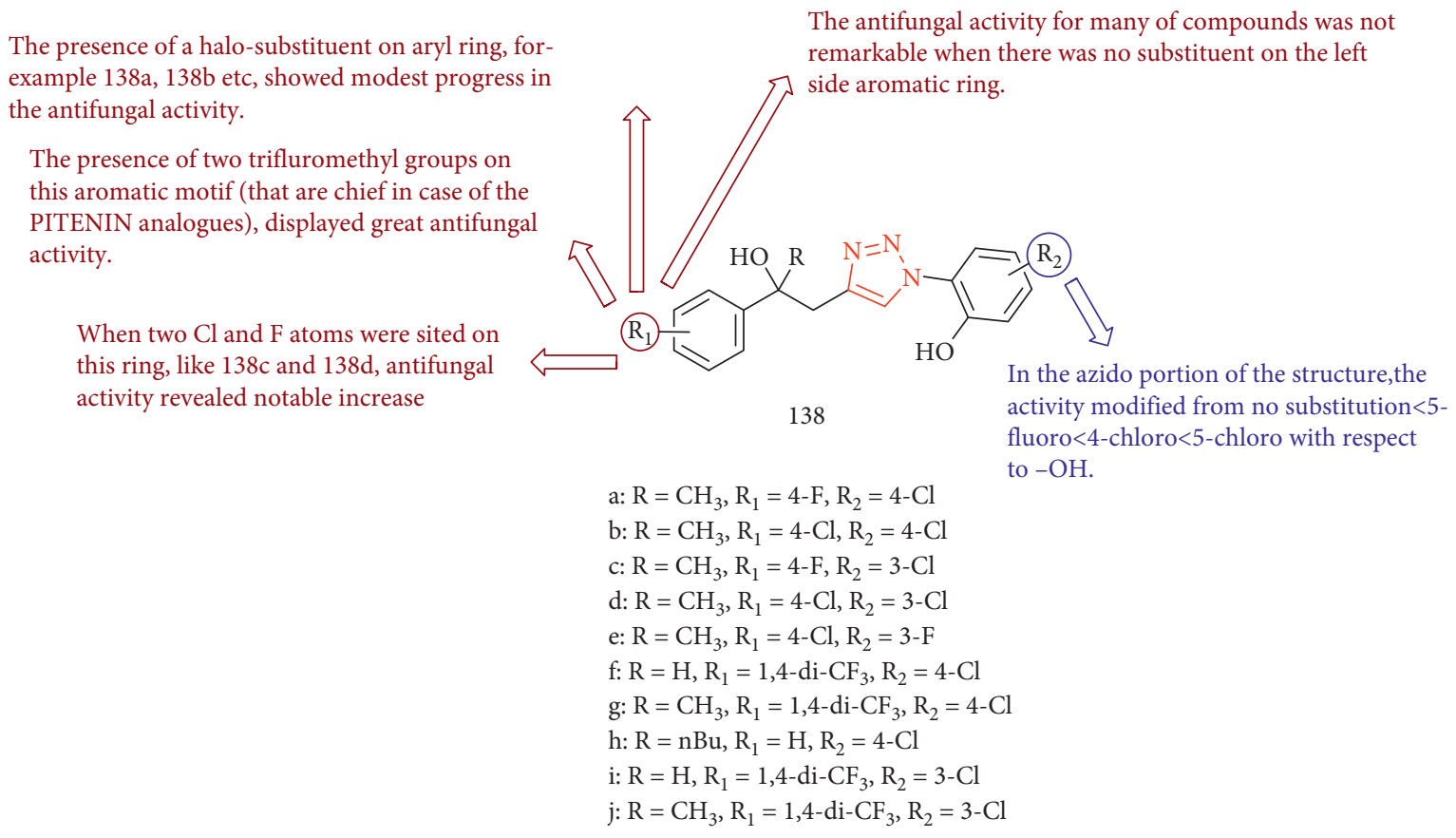

FIGURE 71: Chemical structure of novel 4-(1-phenyl-1-hydroxyethyl)-1-(o-hydroxyphenyl)-1H-1,2,3-triazole.

agriculture. In microbiological investigations, compounds $\mathbf{1 4 0 a - f ,}$ as well as gossypol, were found to be ineffective against Aspergillus brasiliensis.

A new series of 1,2,3-triazole phenylhydrazone derivatives were synthesized, and most of the derivatives displayed vigorous activity against $F$. graminearum, $R$. solani, and S. sclerotiorum. Compounds 141d-f, 142d, 142e, 143d, and $143 \mathrm{e}$ depicted the most excellent antifungal activity against F. graminearum with EC50 values ranging from 0.28 to $1.06 \mathrm{mg} / \mathrm{mL}$. Compound $143 \mathrm{~d}$ showed the biggest and second most inhibitory activity against $R$. solani and S. sclerotiorum with EC50 values of 0.86 and $1.66 \mathrm{mg} / \mathrm{mL}$, respectively. When comparing all compounds with similar halogen substituents, it has an unfavorable effect on antifungal activities, since the methylene group is found among the 1,2,3-triazoles and aromatic rings (Figure 74) [139].
Santos et al. [140] tested nine synthetic 1,2,3-triazole derivatives against four Candida spp. strains of clinical significance like C. tropicalis, C. parapsilosis, C. krusei, and C. albicans. The two compounds displayed antifungal activity containing 144d against C. tropicalis (MIC $>64 \mu \mathrm{g} /$ $\mathrm{mL})$ and $144 \mathrm{~b}$ against $C$. albicans $(\mathrm{MIC}=8 \mu \mathrm{g} / \mathrm{mL})$ with some stereoelectronic properties allied to the activity. When compared to compounds 144a and 144b, the existence of an aldehyde group in place of alcohol in compound 144c was not desirable for antifungal activity, since compound $\mathbf{1 4 4 b}$ with methanol as a substituent showed antifungal activity, while compound $144 \mathrm{c}$ with aldehyde did not (Figure 75).

Structure-based design was used to create a novel derivative of 5-substituted benzotriazole as inhibitors of fungal cytochrome P450 lanosterol 14-a demethylase in response to the demand for new antifungal medicines with better 
The inhibitory rates of $139 \mathrm{~h}\left(\mathrm{R}=3-\mathrm{NO}_{2}\right)$ and $139 \mathrm{~d}$ $\left(\mathrm{R}=4-\mathrm{CH}_{3}\right)$ against $P$. capsici were $69.1 \%$ and $55.5 \%$, and against $A$. alternate were $53.6 \%$ and $69.0 \%$ in series and the inhibition rate of 139 h was $69.1 \%$ against $P$. capsici, that was better than $139 \mathrm{i}\left(\mathrm{R}=\mathrm{OCH}_{2} \mathrm{Ph}\right)$.

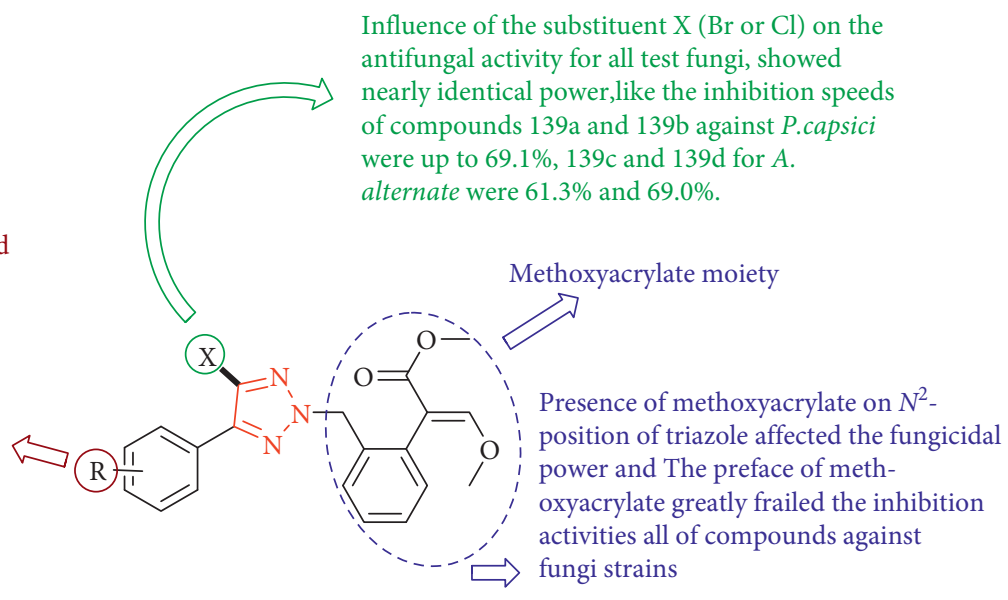

139

$$
\begin{aligned}
& \text { a: } \mathrm{R}=4-\mathrm{F}, \mathrm{X}=\mathrm{Br} ; \mathrm{f}: \mathrm{R}=4-\mathrm{Cl}, \mathrm{X}=\mathrm{Cl} \\
& \text { b: } \mathrm{R}=4-\mathrm{F}, \mathrm{X}=\mathrm{Cl} ; \mathrm{g}: \mathrm{R}=4-\mathrm{Br}, \mathrm{X}=\mathrm{Cl} \\
& \text { c: } \mathrm{R}=4-\mathrm{CH}_{3}, \mathrm{X}=\mathrm{Br} ; \mathrm{h}: \mathrm{R}=3-\mathrm{NO}_{2}, \mathrm{X}=\mathrm{Cl} \\
& \text { d: } \mathrm{R}=4-\mathrm{CH}_{3}, \mathrm{X}=\mathrm{Cl} ; \mathrm{i}: \mathrm{R}=4-\mathrm{OCH}_{2} \mathrm{Ph}, \mathrm{X}=\mathrm{Cl} \\
& \text { e: } \mathrm{R}=3-\mathrm{NO}_{2}, \mathrm{X}=\mathrm{Br}
\end{aligned}
$$

Figure 72: Chemical structure of novel 1,2,3-triazole-functionalized strobilurins.

Presentation of triazole-benzyloxy section to gossypol skeleton amended antifungal activity of compound $140 \mathrm{~g}$, against to its antibacterial power.

The most compelling results were recieved for Fusarium spp.

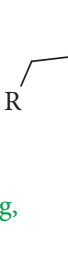

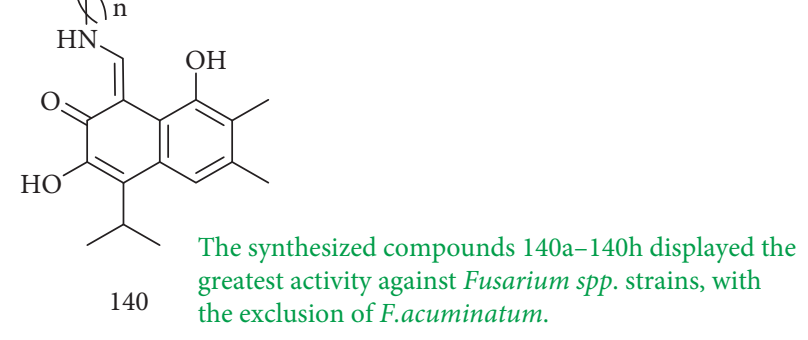

$$
\begin{aligned}
& \text { a: } \mathrm{n}=2 \mathrm{R}=\text { ethyl } \\
& \text { b: } \mathrm{n}=3 \mathrm{R}=\text { ethyl } \\
& \text { c: } \mathrm{n}=2 \mathrm{R}=\mathrm{n} \text {-propyl } \\
& \mathrm{d}: \mathrm{n}=3 \mathrm{R}=\mathrm{n} \text {-propyl } \\
& \text { e: } \mathrm{n}=2 \mathrm{R}=\mathrm{n} \text {-butyl } \\
& \text { f: } \mathrm{n}=3 \mathrm{R}=\mathrm{n} \text {-butyl } \\
& \text { g: } \mathrm{n}=2 \mathrm{R}=\text { benzyloxy } \\
& \text { h: } \mathrm{n}=3 \mathrm{R}=\text { benzyloxy }
\end{aligned}
$$

FIGURE 73: Chemical structure of new gossypol-triazole conjugates including aliphatic chains and benzyloxy groups.

potency and a broader range of activity. The antifungal assessment was performed on the fungus Candida albicans (ATCC 10231). At concentration of $100 \mu \mathrm{g} / \mathrm{mL}$, compounds 145a and 145b displayed larger antifungal activities as compared to the standard drug Fluconazole (Figure 76) [141].

Phosphonates, quinones, and azoles are examples of drugs found in bioactive compounds. In 3-4 steps, a series of phosphonates linked to quinones and azoles with changing carbon chain lengths were prepared to be in high yield. The antifungal activity of these azole derivatives against the phytopathogenic fungus Fusarium graminearum was found to be extremely high in ethyl preserved phosphates. Freebase phosphates have great antifungal training toward Candida albicans and Aspergillus flavus which are human pathogenic fungi. In terms of cytotoxicity and antifungal activity, compound $\mathbf{1 4 6} \mathrm{f}$ is the most active with the smallest cytotoxicity, followed by 146d and 146e (Figure 77) [142]. 
When $\mathrm{n}=0$, comparing the all compounds (141 143), methyl substitution at the $\mathrm{R}_{1}$ or $\mathrm{R}_{2}$ positions has no notable results on antifungal activity, whiles when $\mathrm{n}=1$, methyl substitution seems have an effect on activity, but there is no clear tendency.
All the compounds ( $\mathrm{n}=0$ or $\mathrm{n}=1$ ) with halogen substituents of $R_{3}$ at the para position, particularly for $p-\mathrm{F}$ and $p-\mathrm{Cl}$, display remarkable results and the stronger the electron withdrawing potency of the $\mathrm{R}_{3}$ substituent, the higher the activities.

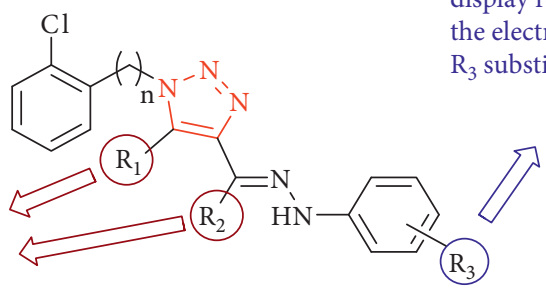

$141-143$

$$
\begin{aligned}
& 141(\mathrm{a}-\mathrm{f}): \mathrm{n}=0, \mathrm{R}_{1}=\mathrm{H}, \mathrm{R}_{2}=\mathrm{CH}_{3}, \mathrm{R}_{3}=-2 \mathrm{~F},-2 \mathrm{Cl},-3 \mathrm{Cl},-4 \mathrm{~F},-4 \mathrm{Cl},-4 \mathrm{Br} \\
& 142(\mathrm{a}-\mathrm{f}): \mathrm{n}=0, \mathrm{R}_{1}=\mathrm{CH}_{3}, \mathrm{R}_{2}=\mathrm{H}, \mathrm{R}_{3}=-2 \mathrm{~F},-2 \mathrm{Cl},-3 \mathrm{Cl},-4 \mathrm{~F},-4 \mathrm{Cl},-4 \mathrm{Br} \\
& 143(\mathrm{a}-\mathrm{f}): \mathrm{n}=0, \mathrm{R}_{1}=\mathrm{CH}_{3}, \mathrm{R}_{2}=\mathrm{CH}_{3}^{-}, \mathrm{R}_{3}=-2 \mathrm{~F},-2 \mathrm{Cl},-3 \mathrm{Cl},-4 \mathrm{~F},-4 \mathrm{Cl},-4 \mathrm{Br}
\end{aligned}
$$

FIGURE 74: Chemical structure of 1,2,3-triazole phenylhydrazones as fungicide candidates.

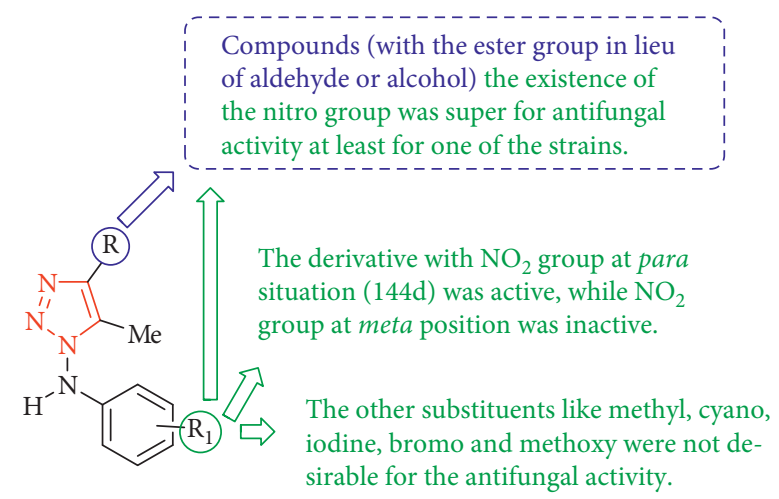

144

$$
\begin{aligned}
& \text { a: } \mathrm{R}=\mathrm{CH}_{3} \mathrm{OH}, \mathrm{R}_{1}=4-\mathrm{Br} \\
& \mathrm{b}: \mathrm{R}=\mathrm{CH}_{3} \mathrm{OH}, \mathrm{R}_{1}=\mathrm{H} \\
& \mathrm{c}: \mathrm{R}=\mathrm{CHO}, \mathrm{R}_{1}=\mathrm{H} \\
& \mathrm{d}: \mathrm{R}=\mathrm{CO}_{2} \mathrm{Et}, \mathrm{R}_{1}=4-\mathrm{NO}_{2}
\end{aligned}
$$

FIGURE 75: Chemical structure of N-substituted-phenylamino-1,2,3-triazole derivatives.

On doing SAR study it was seen that all 5-substituted phenylaminomethyl or phenoxymethyl derivatives of benzotriazole displayed powerful activity against $C$. albicans as compared to Fluconazole.

$$
\text { b: } \mathrm{R}_{1}=\mathrm{H}, \mathrm{R}_{2}=\begin{aligned}
& \text { Hence, 5-substitution with phenylaminomethyl or } \\
& \text { phenoxymethyl side chain is needful for protecting } \\
& \text { the power of benzotriazole derivatives. }
\end{aligned}
$$

FIgURE 76: Chemical structure of benzotriazole derivatives as novel antifungal agents. 


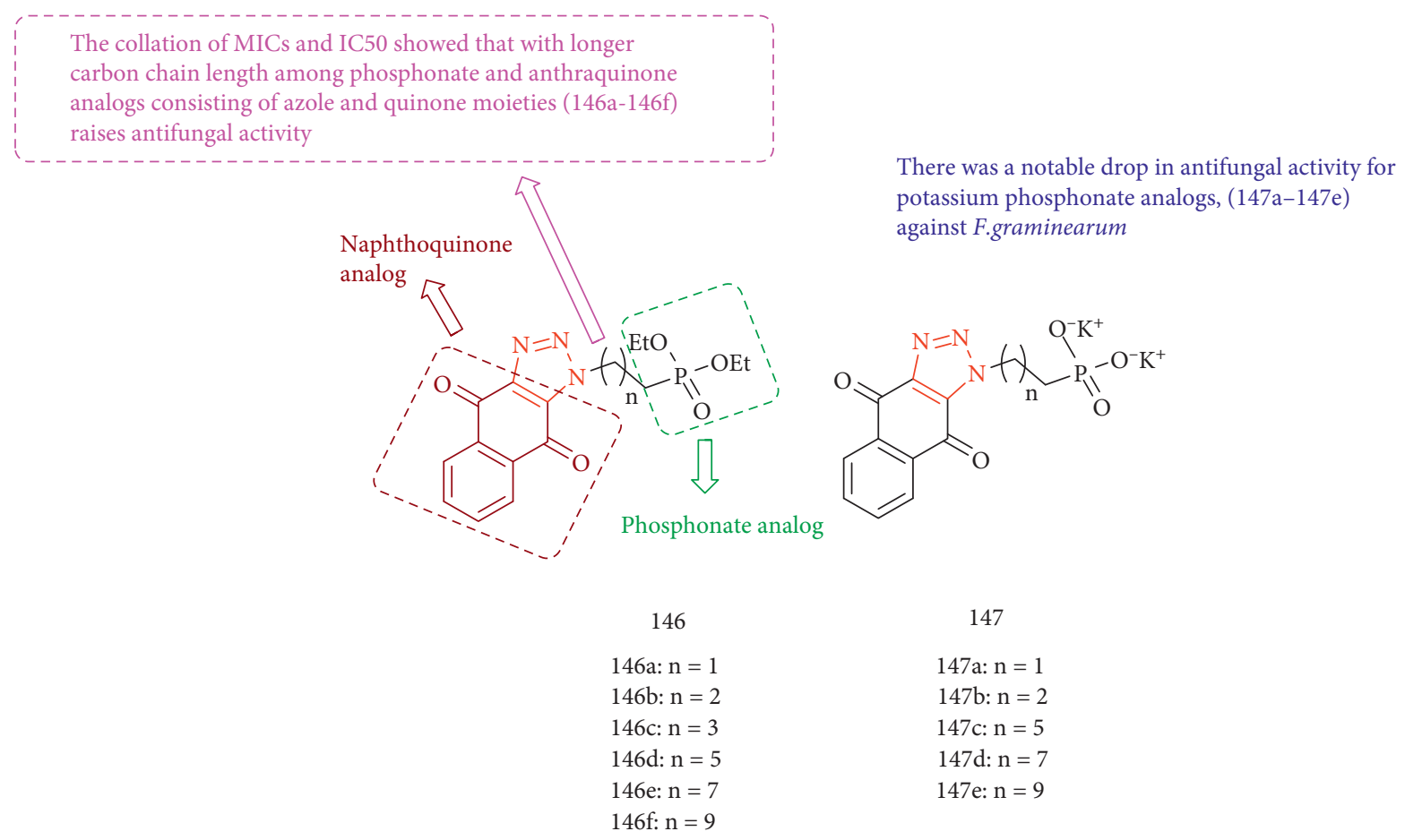

FIGURE 77: Chemical structure of phosphonates conjugated to azoles and quinones with variable carbon chain lengths.

\section{Conclusion}

1,2,3-Triazole-hybrids with broad antifungal activity have garnered worldwide attention. This lead compound will act as a potent drug candidate in the future. The CuAAC reaction for the regioselective synthesis of 1,2,3-triazolehybrids has been proven to be an excellent tool in organic and medicinal chemistry. Fungal infections have a big challenge on the global health system. Fungal infections were the primary cause of death for more than 1.35 million people globally. Treatment of this type of infection is complicated owing to the toxic side effects of antifungal medications; on the other hand, since drug resistance in chemotherapy is one of the most significant hurdles in fungal treatment, the development of novel antifungal agents is critical. The present review explains the recent advantage of 1,2,3-triazole-hybrids as an effective antifungal agent and the mechanism of action and then it evaluates the structure-activity relationship. The versatile synthetic applicability and antifungal activity of these $N$-heterocycles will aid medicinal chemists in organizing, planning, and executing new drugs with higher activity and lower toxicity.

\section{Abbreviations}

AmB:

Amphotericin B

CAI:

Carboxyamidotriazole

CAP:

CCP:

Community-acquired pneumonia

$[\mathrm{Cp} * \mathrm{RuCl}]: \quad$ Pentamethylcyclopentadienyl ruthenium chloride

CPP:
CuAAC:

DFT:

DHA:

DNA:

EC50:

FLC:

HIV-1:

HOMO:

$\mathrm{IC}_{50}$ :

ITC:

LUMO:

MIBK:

MIC:

MRSA:

PITENIN:

RNA:

RT:

RuAAC:

SAR:

SIV:

TBDMS:

TEM- 1 and

SHV-1:

TSAO:

VCZ:
Copper-catalyzed azide alkyne cycloaddition (CuAAC)

The density functional theory

Dehydroacetic acid

Deoxyribonucleic acid

Effective concentration

Fluconazole

Human immunodeficiency virus type 1

Highest occupied molecular orbital

Inhibitory concentration

Itraconazole

Lowest unoccupied molecular orbital

Methyl isobutyl ketone

Minimum inhibitory concentration

Methicillin-resistant Staphylococcus aureus

Anticancer agent

Ribonucleic acid

Reverse transcriptase

Ruthenium-catalyzed azide-alkyne cycloaddition

Structure-activity relationship

Simian immunodeficiency virus

Tert-butyldimethylsilyl

Class A-lactamases commonly found in

Escherichia coli and Klebsiella pneumoniae pathogens responsible for urinary tract, respiratory tract, and bloodstream infections

Tertbutyldimethylsilylspiroaminooxathio ledioxide Voriconazole. 


\section{Data Availability}

The datasets used and analyzed during the current study are available from the corresponding author upon reasonable request. All data are presented in the form of figures.

\section{Ethical Approval}

This research has been ethically approved (IR.FUMS.REC.1400.012).

\section{Conflicts of Interest}

The authors declare that they have no conflicts of interest.

\section{Authors' Contributions}

EZ designed, wrote, and finalized the manuscript and supervised. The first draft of the manuscript was written and revised by MM. Also, MF, ZK, AS, and AK helped in writing and revising the manuscript. All authors approved the final manuscript.

\section{Acknowledgments}

The authors wish to acknowledge the support of Noncommunicable Diseases Research Center, Fasa University of Medical Sciences (Grant no. 99289).

\section{References}

[1] S. Ahmad, O. Alam, M. J. Naim, M. Shaquiquzzaman, M. M. Alam, and M. Iqbal, "Pyrrole: an insight into recent pharmacological advances with structure activity relationship," European Journal of Medicinal Chemistry, vol. 157, pp. 527-561, 2018.

[2] P. Phukan and D. Sarma, "Synthesis of medicinally relevant scaffolds-triazoles and pyrazoles in green solvent ionic liquids," Current Organic Chemistry, vol. 25, no. 13, pp. 1523-1538, 2021.

[3] R. Varala, H. B. Bollikolla, and C. M. Kurmarayuni, "Synthesis of pharmacological relevant 1,2,3-triazole and its analogues-a review," Current Organic Synthesis, vol. 18, no. 2, pp. 101-124, 2021.

[4] K. Bozorov, J. Zhao, and H. A. Aisa, "1,2,3-Triazole-containing hybrids as leads in medicinal chemistry: a recent overview," Bioorganic \& Medicinal Chemistry, vol. 27, no. 16, pp. 3511-3531, 2019.

[5] B. Wu, M. Hussain, W. Zhang, M. Stadler, X. Liu, and M. Xiang, "Current insights into fungal species diversity and perspective on naming the environmental DNA sequences of fungi," Mycology, vol. 10, no. 3, pp. 127-140, 2019.

[6] T. J. Gintjee, M. A. Donnelley, and G. R. Thompson, "Aspiring antifungals: review of current antifungal pipeline developments," Journal of Fungi, vol. 6, no. 1, pp. 28-39, 2020.

[7] M. H. Afsarian, M. Farjam, E. Zarenezhad, S. Behrouz, and M. N. S. Rad, "Synthesis, antifungal evaluation and molecular docking studies of some tetrazole derivatives," Acta Chimica Slovenica, vol. 66, no. 4, pp. 874-887, 2019.

[8] M. K. Kathiravan, A. B. Salake, A. S. Chothe et al., "The biology and chemistry of antifungal agents: a review," Bioorganic \& Medicinal Chemistry, vol. 20, no. 19, pp. 56785698, 2012.
[9] N. Thamban Chandrika, E. K. Dennis, S. K. Shrestha et al., "N,N'-diaryl-bishydrazones in a biphenyl platform: broad spectrum antifungal agents," European Journal of Medicinal Chemistry, vol. 164, pp. 273-281, 2019.

[10] R. Calderone, N. Sun, F. Gay-Andrieu et al., "Antifungal drug discovery: the process and outcomes," Future Microbiology, vol. 9, no. 6, pp. 791-805, 2014.

[11] M. E. Rodrigues, S. Silva, J. Azeredo, and M. Henriques, "Novel strategies to fight Candida species infection," Critical Reviews in Microbiology, vol. 42, no. 4, pp. 594-606, 2016.

[12] S. Czurda and T. Lion, "Broad-spectrum molecular detection of fungal nucleic acids by PCR-based amplification techniques," in Human Fungal Pathogen Identification, pp. 257-266, Humana Press, New York, NY, USA, 2017.

[13] R. Van Daele, I. Spriet, J. Wauters et al., "Antifungal drugs: what brings the future?” Medical Mycology, vol. 57, no. 3, pp. S328-S343, 2019.

[14] M.-V. H. Nguyen, M. R. Davis, R. Wittenberg et al., "Posaconazole serum drug levels associated with pseudohyperaldosteronism," Clinical Infectious Diseases, vol. 70, no. 12, pp. 2593-2598, 2020.

[15] R. Huisgen, "1,3-Dipolar cycloadditions. 76. Concerted nature of 1,3-dipolar cycloadditions and the question of diradical intermediates," Journal of Organic Chemistry, vol. 41, no. 3, pp. 403-419, 1976.

[16] K. N. Houk and H.-U. Reissig, "Rolf Huisgen's legacy," Inside Cosmetics, vol. 5, no. 10, pp. 2499-2505, 2019.

[17] A. D. Moorhouse and J. E. Moses, "Click chemistry and medicinal chemistry: a case of "cyclo-addiction"," ChemMedChem, vol. 3, no. 5, pp. 715-723, 2008.

[18] E. Zarenezhad, M. N. Soltani Rad, S. Behrouz, S. Esmaielzadeh, and $\mathrm{M}$. Farjam, "Immobilized [Cu(cdsalMeen)] on silica gel: a highly efficient heterogeneous catalyst for "click" [3+2] Huisgen cycloaddition," Journal of the Iranian Chemical Society, vol. 14, no. 2, pp. 509-519, 2017.

[19] C. W. Tornøe, C. Christensen, and M. Meldal, "Peptidotriazoles on solid phase: [1,2,3]-triazoles by regiospecific copper (I)-catalyzed 1,3-dipolar cycloadditions of terminal alkynes to azides," Journal of Organic Chemistry, vol. 67, no. 9, pp. 3057-3064, 2002.

[20] V. V. Rostovtsev, L. G. Green, V. V. Fokin, and K. B. Sharpless, "A stepwise Huisgen cycloaddition process: copper (I)-catalyzed regioselective "ligation" of azides and terminal alkynes," Angewandte Chemie, vol. 114, no. 14, pp. 2708-2711, 2002.

[21] L. Ackermann, H. K. Potukuchi, D. Landsberg, and R. Vicente, "Copper-catalyzed "click" reaction/direct arylation sequence: modular syntheses of 1,2,3-triazoles," Organic Letters, vol. 10, no. 14, pp. 3081-3084, 2008.

[22] V. K. Tiwari, B. B. Mishra, K. B. Mishra, N. Mishra, A. S. Singh, and X. Chen, "Cu-catalyzed click reaction in carbohydrate chemistry," Chemical Reviews, vol. 116, no. 5, pp. 3086-3240, 2016.

[23] M. Empting, O. Avrutina, R. Meusinger et al., ““'Triazole bridge": disulfide-bond replacement by ruthenium-catalyzed formation of 1,5-disubstituted 1,2,3-triazoles," Angewandte Chemie International Edition, vol. 50, no. 22, pp. 5207-5211, 2011.

[24] M. Breugst and H. U. Reissig, "The huisgen reaction: milestones of the 1,3-dipolar cycloaddition," Angewandte Chemie International Edition, vol. 59, no. 30, pp. 12293 12307, 2020

[25] A. K. Agrahari, P. Bose, M. K. Jaiswal et al., " $\mathrm{Cu}(\mathrm{I})$-catalyzed click chemistry in glycoscience and their diverse 
applications," Chemical Reviews, vol. 121, no. 13, pp. 7638-7956, 2021.

[26] F. Himo, T. Lovell, R. Hilgraf et al., "Copper(I)-catalyzed synthesis of azoles. DFT study predicts unprecedented reactivity and intermediates," Journal of the American Chemical Society, vol. 127, no. 1, pp. 210-216, 2005.

[27] S. Lal, H. S. Rzepa, and S. Díez-González, "Catalytic and computational studies of N-heterocyclic carbene or phosphine-containing copper(I) complexes for the synthesis of 5iodo-1,2,3-triazoles," ACS Catalysis, vol. 4, no. 7, pp. 2274-2287, 2014.

[28] B. C. Boren, S. Narayan, L. K. Rasmussen et al., "Rutheniumcatalyzed azide-alkyne cycloaddition: scope and mechanism," Journal of the American Chemical Society, vol. 130, no. 28, pp. 8923-8930, 2008.

[29] L. Molloy, I. Abdulhamid, R. Srivastava, and J. Y. Ang, "Ceftolozane/tazobactam treatment of multidrug-resistant Pseudomonas aeruginosa infections in children," The Pediatric Infectious Disease Journal, vol. 39, no. 5, pp. 419-420, 2020.

[30] J. Zheng, Z. Chen, Z. Lin et al., "Radezolid is more effective than linezolid against planktonic cells and inhibits Enterococcus faecalis biofilm formation," Frontiers in Microbiology, vol. 11, p. 196, 2020.

[31] P. Actor, D. H. Pitkin, G. Lucyszyn, J. A. Weisbach, and J. L. Bran, "Cefatrizine (SK\&F 60771), a new oral cephalosporin: serum levels and urinary recovery in humans after oral or intramuscular administration-comparative study with cephalexin and cefazolin," Antimicrobial agents and chemotherapy, vol. 9, no. 5, pp. 800-803, 1976.

[32] K. Das, J. D. Bauman, A. S. Rim et al., "Crystal structure of tert-butyldimethylsilyl-spiroaminooxathioledioxide-thymine (TSAO-T) in complex with HIV-1 reverse transcriptase (RT) redefines the elastic limits of the non-nucleoside inhibitorbinding pocket," Journal of Medicinal Chemistry, vol. 54, no. 8, pp. 2727-2737, 2011.

[33] R. Ju, K. Fei, S. Li et al., "Metabolic mechanisms and a rational combinational application of carboxyamidotriazole in fighting pancreatic cancer progression after chemotherapy," Journal of Pharmacology and Experimental Therapeutics, vol. 367, no. 1, pp. 20-27, 2018.

[34] Y. Yang, B. A. Rasmussen, and D. M. Shlaes, "Class A $\beta$-lactamases-enzyme-inhibitor interactions and resistance," Pharmacology \& Therapeutics, vol. 83, no. 2, pp. 141-151, 1999.

[35] J. Fischer, "Analogue-based drug discovery," Chemistry International-Newsmagazine for IUPAC, vol. 32, no. 4, pp. 12-5, 2010.

[36] R. G. Micetich, S. N. Maiti, P. Spevak, M. Tanaka, T. Yamazaki, and K. Ogawa, "Synthesis of $2 \beta$-azidomethylpenicillin-1,1-dioxides and $3 \beta$-azido- $3 \alpha$-methylcepham1,1-dioxides," Synthesis, vol. 1986, no. 4, pp. 292-296, 1986.

[37] K. Michalska, I. Karpiuk, M. Król, and S. Tyski, "Recent development of potent analogues of oxazolidinone antibacterial agents," Bioorganic \& Medicinal Chemistry, vol. 21, no. 3, pp. 577-591, 2013.

[38] E. Skripkin, T. S. McConnell, J. DeVito et al., " $\mathrm{R} \chi-01$, a new family of oxazolidinones that overcome ribosome-based linezolid resistance," Antimicrobial Agents and Chemotherapy, vol. 52, no. 10, pp. 3550-3557, 2008.

[39] G. G. Zhanel, R. Love, H. Adam et al., "Tedizolid: a novel oxazolidinone with potent activity against multidrug-resistant gram-positive pathogens," Drugs, vol. 75, no. 3, pp. 253-270, 2015.
[40] S. Lemaire, P. M. Tulkens, and F. Van Bambeke, "Cellular pharmacokinetics of the novel biaryloxazolidinone radezolid in phagocytic cells: studies with macrophages and polymorphonuclear neutrophils," Antimicrobial agents and chemotherapy, vol. 54, no. 6, pp. 2540-2548, 2010.

[41] M. B. Gravestock, N. J. Hales, and H. K. Huynh, "Oxazolidinone derivatives and their use as antibacterial agents," US 2006/0058314A1, 2006.

[42] K. Michalska, E. Gruba, M. Mizera et al., "Application of spectroscopic methods (FT-IR, Raman, ECD and NMR) in studies of identification and optical purity of radezolid," Spectrochimica Acta Part A: Molecular and Biomolecular Spectroscopy, vol. 183, pp. 116-122, 2017.

[43] C. C. Felder, A. L. Ma, L. A. Liotta, and E. C. Kohn, "The antiproliferative and antimetastatic compound L651582 inhibits muscarinic acetylcholine receptor-stimulated calcium influx and arachidonic acid release," Journal of Pharmacology and Experimental Therapeutics, vol. 257, no. 3, pp. 967-71, 1991.

[44] E. C. Kohn, M. A. Sandeen, and L. A. Liotta, "In vivo efficacy of a novel inhibitor of selected signal transduction pathways including calcium, arachidonate, and inositol phosphates," Cancer Research, vol. 52, no. 11, pp. 3208-3212, 1992.

[45] W. J. Wasilenko, A. J. Palad, K. D. Somers et al., "Effects of the calcium influx inhibitor carboxyamido-triazole on the proliferation and invasiveness of human prostate tumor cell lines," International Journal of Cancer, vol. 68, no. 2, pp. 259-264, 1996.

[46] K. J. Luzzi, H. J. Varghese, I. C. MacDonald et al., "Inhibition of angiogenesis in liver metastases by carboxyamidotriazole (CAI)," Angiogenesis, vol. 2, no. 4, pp. 373-379, 1998.

[47] E. C. Kohn, C. C. Felder, W. Jacobs et al., "Structure-function analysis of signal and growth inhibition by carboxyamidotriazole, CAI," Cancer Research, vol. 54, no. 4, pp. 935-942, 1994.

[48] T. W. Moody, J. Chiles, E. Moody, G. J. Sieczkiewicz, and E. C. Kohn, "CAI inhibits the growth of small cell lung cancer cells," Lung Cancer, vol. 39, no. 3, pp. 279-288, 2003.

[49] M. H. Taylor, A. Sandler, W. J. Urba, A. M. P. Omuro, G. S. Gorman, and R. A. Karmali, "Effect of carboxyamidotriazole orotate, a modulator of calcium-dependent signaling pathways, on advanced solid tumors," Journal of Cancer Therapy, vol. 6, no. 4, pp. 322-333, 2015.

[50] G. L. Dunn, J. R. E. Hoover, D. A. Berges et al., "Orally active 7-phenylglycyl cephalosporins. Structure-activity studies related to cefatrizine (SK\&F 60771)," The Journal of Antibiotics, vol. 29, no. 1, pp. 65-80, 1976.

[51] G. L. Dunn and J. R. Hoover, "3-Heterocyclic thiomethylcephalosporins," US patent 3867380, 1975.

[52] J. Balzarini, M. J. Perez-Perez, A. San-Felix et al., " 2 ', 5 '-BisO-(tert-butyldimethylsilyl)- $3^{\prime}$-spiro- $5^{\prime \prime}$ - $\left(4^{\prime \prime}\right.$-amino- $1^{\prime \prime}, 2^{\prime \prime}$ oxathiole- $2^{\prime \prime}, 2^{\prime}$-dioxide)pyrimidine (TSAO) nucleoside analogues: highlyselective inhibitors of human immunodeficiency virus type 1 that are targeted at the viral reverse transcriptase," Proceedings of the National Academy of Sciences, vol. 89, no. 10, pp. 4392-4396, 1992.

[53] J. Balzarini, M. J. Pérez-Pérez, A. San-Félix, S. Velazquez, M. J. Camarasa, and E. De Clercq, " $\left[2^{\prime}, 5^{\prime}\right.$-Bis-O-(tertbutyldimethylsilyl $)]-3^{\prime}$-spiro- $5^{\prime \prime}-\left(4^{\prime \prime}\right.$-amino- $1^{\prime \prime}, 2^{\prime \prime}$-oxathiole- $2^{\prime \prime}, 2^{\prime \prime}$-dioxide) (TSAO) derivatives of purine and pyrimidinenucleosides as potent and selective inhibitors of human immunodeficiency virus type 1," Antimicrobial agents and chemotherapy, vol. 36, no. 5, pp. 1073-1080, 1992. 
[54] M. J. Camarasa, M. J. Perez-Perez, A. San-Felix, J. Balzarini, and E. De Clercq, " 3 '-Spiro nucleosides, a new class of specific human immunodeficiency virus type 1 inhibitors: synthesis and antiviral activity of $\left[2^{\prime}, 5^{\prime}\right.$-bis-O-(tert-butyldimethylsilyl)-.beta.-D-xylo- and -ribofuranose]-3' -spiro$5^{\prime \prime}$-[4"-amino-1", $2^{\prime \prime}$-oxathiole $2^{\prime \prime}, 2^{\prime \prime}$-dioxide] (TSAO) pyrimidine nucleosides," Journal of Medicinal Chemistry, vol. 35 , no. 15 , pp. 2721-2727, 1992.

[55] J. Balzarini, M.-J. Camarasa, and A. Karlsson, "TSAO derivatives: highly specific human immunodeficiency virus type 1 (HIV-1) reverse transcriptase inhibitors," Drugs of the Future, vol. 18, no. 11, pp. 1043-55, 1993.

[56] M. J. Pérez-Pérez, A. San-Félix, J. Balzarini, E. De Clercq, and M. J. Camarasa, "TSAO analogs. Stereospecific synthesis and anti-HIV-1 activity of 1-[2', $5^{\prime}$-bis-O-(tert-butyldimethylsilyl)-. beta.-D-ribofuranosyl]-3' - spiro- $5^{\prime \prime}$-( $4^{\prime \prime}$-amino$1^{\prime \prime}, 2^{\prime \prime}$-oxathiole- $2^{\prime \prime}, 2^{\prime \prime}$-dioxide) pyrimidine and pyrimidinemodified nucleosides," Journal of Medicinal Chemistry, vol. 35, no. 16, pp. 2988-2995, 1992.

[57] J. Balzarini, L. Naesens, C. Bohman et al., "Metabolism and pharmacokinetics of the anti-HIV-1-specific inhibitor $\left[1-\left[2^{\prime}, 5^{\prime}\right.\right.$ Bis-O-(tert-butyldimethylsilyl)- $\beta$-d-ribofuranosyl]-3-N-methylthymine]- $3^{\prime}$-spiro- $5^{\prime \prime}$ - $\left(4^{\prime \prime}\right.$-amino- $1^{\prime \prime}, 2^{\prime \prime}$-oxathiole- $2^{\prime \prime}, 2^{\prime \prime}$-dioxi de)," Biochemical Pharmacology, vol. 46, no. 1, pp. 69-77, 1993.

[58] J. Balzarini, M. J. Pérez-Pérez, A. San-Félix et al., "Kinetics of inhibition of human immunodeficiency virus type 1 (HIV-1) reverse transcriptase by the novel HIV-1-specific nucleoside analogue $\left[2^{\prime}, 5^{\prime}\right.$-bis-O-(tert-butyldimethylsilyl)-beta-D-ribofuranosyl]-3'-spiro- $5^{\prime \prime}$ - $\quad\left(4^{\prime \prime}\right.$-amino- $1^{\prime \prime}, 2^{\prime \prime}$-oxathiole- $2^{\prime \prime}, 2^{\prime \prime}$ dioxide)thymine (TSAO-T)," Journal of Biological Chemistry, vol. 267, no. 17, pp. 11831-11838, 1992.

[59] R. Alvarez, S. Velázquez, A. San-Félix et al., "1,2,3-Triazole[2,5-bis-O-(tert-butyldimethylsilyl)-. $\quad$ beta.-D-ribofuranosyl]-3'-spiro-5" - $4^{\prime \prime}$-amino-1", $2^{\prime \prime}$-oxathiole $2^{\prime \prime}, 2^{\prime \prime}$-dioxide) (TSAO) analogs: synthesis and anti-HIV-1 activity," Journal of Medicinal Chemistry, vol. 37, no. 24, pp. 41854194, 1994.

[60] M. Le Corre, "Nouvelle voie d'accés aux esters $\alpha$-cétoniques $\beta$ éthyléniques," Comptes Rendus de L'Academie des Sciences Serie C, vol. 270, pp. 1312-11314, 1970.

[61] S. Velázquez, R. Alvarez, C. Pérez et al., "Regiospecific synthesis and anti-human immunodeficiency virus activity of novel 5-substituted N-alkylcarbamoyl and N,N-dialkyl carbamoyl 1,2,3-triazole-TSAO analogues," Antiviral Chemistry and Chemotherapy, vol. 9, no. 6, pp. 481-489, 1998.

[62] S. de Castro, C. García-Aparicio, K. Van Laethem et al., "Discovery of TSAO derivatives with an unusual HIV-1 activity/resistance profile," Antiviral Research, vol. 71, no. 1, pp. 15-23, 2006.

[63] D. W. Woolley, "Some biological effects produced by benzimidazole and their reversal by purines," Journal of Biological Chemistry, vol. 152, no. 2, pp. 225-232, 1944.

[64] A. H. Groll, S. C. Piscitelli, and T. J. Walsh, "Clinical pharmacology of systemic antifungal agents: a comprehensive review of agents in clinical use, current investigational compounds, and putative targets for antifungal drug development," Advances in Pharmacology, vol. 44, pp. 343-500, 1998.

[65] R. Myers, “Antifungal agents' eds," Immunizing and Antimicrobial Agents, vol. 401, pp. 1-16, 2006.

[66] M. Serafini, T. Pirali, and G. C. Tron, "Chapter three-click 1,2,3-triazoles in drug discovery and development: from the flask to the clinic?" Applications of Heterocycles in the Design of Drugs and Agricultural Products, vol. 1, p. 101, 2021.

[67] K. Shalini, N. Kumar, S. Drabu, and P. K. Sharma, "Advances in synthetic approach to and antifungal activity of triazoles," Beilstein Journal of Organic Chemistry, vol. 7, no. 1, pp. 668-677, 2011.

[68] S. V. Akolkar, A. A. Nagargoje, M. H. Shaikh et al., "New N -phenylacetamide-linked 1,2,3-triazole-tethered coumarin conjugates: synthesis, bioevaluation, and molecular docking study," Archiv der Pharmazie, vol. 353, no. 11, Article ID 2000164, 2020.

[69] R. Dharavath, N. Nagaraju, M. R. Reddy et al., "Microwaveassisted synthesis, biological evaluation and molecular docking studies of new coumarin-based 1,2,3-triazoles," RSC Advances, vol. 10, no. 20, pp. 11615-11623, 2020.

[70] H. M. Savanur, K. N. Naik, S. M. Ganapathi, K. M. Kim, and R. G. Kalkhambkar, "Click chemistry inspired design, synthesis and molecular docking studies of coumarin, quinolinone linked 1,2,3-triazoles as promising anti-microbial agents," ChemistrySelect, vol. 3, no. 19, pp. 5296-5303, 2018.

[71] M. H. Shaikh, D. D. Subhedar, B. B. Shingate et al., "Synthesis, biological evaluation and molecular docking of novel coumarin incorporated triazoles as antitubercular, antioxidant and antimicrobial agents," Medicinal Chemistry Research, vol. 25, no. 4, pp. 790-804, 2016.

[72] M. H. Shaikh, D. D. Subhedar, F. A. K. Khan, J. N. Sangshetti, and B. B. Shingate, "1,2,3-Triazole incorporated coumarin derivatives as potential antifungal and antioxidant agents," Chinese Chemical Letters, vol. 27, no. 2, pp. 295-301, 2016

[73] R. Gondru, S. Kanugala, S. Raj et al., "1,2,3-triazole-thiazole hybrids: synthesis, in vitro antimicrobial activity and antibiofilm studies," Bioorganic \& Medicinal Chemistry Letters, vol. 33, Article ID 127746, 2021.

[74] N. D. Thanh, D. S. Hai, V. T. Ngoc Bich et al., "Efficient click chemistry towards novel $1 \mathrm{H}-1,2,3$-triazole-tethered $4 \mathrm{H}$ chromene-d-glucose conjugates: design, synthesis and evaluation of in vitro antibacterial, MRSA and antifungal activities," European Journal of Medicinal Chemistry, vol. 167, pp. 454-471, 2019.

[75] S. P. Khare, T. R. Deshmukh, J. N. Sangshetti et al., "Design, synthesis and molecular docking studies of novel triazolechromene conjugates as antitubercular, antioxidant and antifungal agents," ChemistrySelect, vol. 3, no. 46, pp. 13113-13122, 2018.

[76] V. S. Dofe, A. P. Sarkate, D. K. Lokwani, S. H. Kathwate, and C. H. Gill, "Synthesis, antimicrobial evaluation, and molecular docking studies of novel chromone based 1,2,3-triazoles," Research on Chemical Intermediates, vol. 43, no. 1, pp. 15-28, 2017.

[77] R. Kant, D. Kumar, D. Agarwal et al., "Synthesis of newer 1,2,3-triazole linked chalcone and flavone hybrid compounds and evaluation of their antimicrobial and cytotoxic activities," European Journal of Medicinal Chemistry, vol. 113, pp. 34-49, 2016.

[78] S. Maddila, K. Nagaraju, and S. B. Jonnalagadda, "Synthesis and antimicrobial evaluation of novel pyrano[2,3-d]-pyrimidine bearing 1,2,3-triazoles," Chemical Data Collections, vol. 28, Article ID 100486, 2020.

[79] K. Lal, P. Yadav, A. Kumar, A. Kumar, and A. K. Paul, "Design, synthesis, characterization, antimicrobial evaluation and molecular modeling studies of some dehydroacetic acid-chalcone-1,2,3-triazole hybrids," Bioorganic Chemistry, vol. 77, pp. 236-244, 2018. 
[80] D. González-Calderón, R. García-Monroy, A. RamírezVillalva et al., "Synthesis of novel benzylic 1,2,3-triazole-4carboxamides and their in vitro activity against clinically common fungal species," Journal of the Mexican Chemical Society, vol. 65, no. 2, pp. 202-213, 2021.

[81] Naveen, R. K. Tittal, V. D. Ghule, P. Yadav, K. Lal, and A. Kumar, "Synthesis, antimicrobial potency with in silico study of Boc-leucine-1,2,3-triazoles," Steroids, vol. 161, Article ID 108675, 2020.

[82] C. P. Kaushik, R. Luxmi, M. Kumar, D. Singh, K. Kumar, and A. Pahwa, "One-pot facile synthesis, crystal structure and antifungal activity of 1,2,3-triazoles bridged with amineamide functionalities," Synthetic Communications, vol. 49, no. 1, pp. 118-128, 2019.

[83] S. V. Akolkar, A. A. Nagargoje, V. S. Krishna et al., "NewNphenylacetamide-incorporated 1,2,3-triazoles: [Et3NH] [OAc]-mediated efficient synthesis and biological evaluation," RSC Advances, vol. 9, no. 38, pp. 22080-22091, 2019.

[84] T. R. Deshmukh, S. P. Khare, V. S. Krishna et al., "Design and synthesis of new aryloxy-linked dimeric 1,2,3-triazoles via click chemistry approach: biological evaluation and molecular docking study," Journal of Heterocyclic Chemistry, vol. 56, no. 8, pp. 2144-2162, 2019.

[85] W. Yan, X. Wang, K. Li et al., "Design, synthesis, and antifungal activity of carboxamide derivatives possessing 1,2,3triazole as potential succinate dehydrogenase inhibitors," Pesticide Biochemistry and Physiology, vol. 156, pp. 160-169, 2019.

[86] J. Brahmi, S. Bakari, S. Nasri, H. Nasri, A. Kadri, and K. Aouadi, "Synthesis and SPAR exploration of new semicarbazone-triazole hybrids in search of potent antioxidant, antibacterial and antifungal agents," Molecular Biology Reports, vol. 46, no. 1, pp. 679-686, 2019.

[87] C. P. Kaushik and R. Luxmi, "Facile expeditious one-pot synthesis and antifungal evaluation of disubstituted 1,2,3triazole with two amide linkages," Synthetic Communications, vol. 47, no. 23, pp. 2225-2231, 2017.

[88] C. P. Kaushik and R. Luxmi, "Synthesis and antimicrobial activity of 2-(4-(hydroxyalkyl)-1H -1,2,3-triazol-1-yl)-N -substituted propanamides," Journal of Heterocyclic Chemistry, vol. 54, no. 6, pp. 3618-3625, 2017.

[89] C. P. Kaushik, K. Kumar, B. Narasimhan, D. Singh, P. Kumar, and A. Pahwa, "Synthesis, antimicrobial activity, and QSAR studies of amide-ester linked 1,4-disubstituted 1,2,3-triazoles," Monatshefte für Chemie-Chemical Monthly, vol. 148, no. 4, pp. 765-779, 2017.

[90] X. Wang, Z.-C. Dai, Y.-F. Chen et al., "Synthesis of 1,2,3triazole hydrazide derivatives exhibiting anti-phytopathogenic activity," European Journal of Medicinal Chemistry, vol. 126, pp. 171-182, 2017.

[91] S. Saidugari, L. Vadali, K. Vidya, and B. Ram, "Synthesis, characterization and antimicrobial evaluation of novel (E)- $\mathrm{N}^{\prime}$ (4-(1-((3,4-dimethoxypyridin-2-Yl)methyl)-1H-1,2,3-triazol4-Yl)benzylidene)benzohydrazide derivatives," Oriental Journal of Chemistry, vol. 32, no. 4, pp. 2155-2161, 2016.

[92] A. Kamal, S. M. A. Hussaini, M. L. Sucharitha, Y. Poornachandra, F. Sultana, and C. Ganesh Kumar, "Synthesis and antimicrobial potential of nitrofuran-triazole congeners," Organic and Biomolecular Chemistry, vol. 13, no. 36, pp. 9388-9397, 2015.

[93] W. Tan, Q. Li, F. Dong et al., "Novel cationic chitosan derivative bearing 1,2,3-triazolium and pyridinium: synthesis, characterization, and antifungal property," Carbohydrate Polymers, vol. 182, pp. 180-187, 2018.
[94] Q. Li, W. Tan, C. Zhang, G. Gu, and Z. Guo, "Novel triazolylfunctionalized chitosan derivatives with different chain lengths of aliphatic alcohol substituent: design, synthesis, and antifungal activity," Carbohydrate Research, vol. 418, pp. 44-49, 2015.

[95] W. Tan, J. Zhang, F. Luan et al., "Synthesis, characterization, and antifungal evaluation of novel 1,2,3-triazolium-functionalized starch derivative," International Journal of Biological Macromolecules, vol. 101, pp. 845-851, 2017.

[96] Q. Li, L. Qiu, W. Tan, G. Gu, and Z. Guo, "Novel 1,2,3triazolium-functionalized inulin derivatives: synthesis, free radical-scavenging activity, and antifungal activity," RSC Advances, vol. 7, no. 67, pp. 42225-42232, 2017.

[97] W. Tan, Q. Li, Z. Gao, S. Qiu, F. Dong, and Z. Guo, "Design, synthesis of novel starch derivative bearing 1,2,3-triazolium and pyridinium and evaluation of its antifungal activity," Carbohydrate Polymers, vol. 157, pp. 236-243, 2017.

[98] W. Tan, Q. Li, F. Dong, S. Qiu, J. Zhang, and Z. Guo, "Novel 1,2,3-triazolium-functionalized starch derivatives: synthesis, characterization, and evaluation of antifungal property," Carbohydrate Polymers, vol. 160, pp. 163-171, 2017.

[99] Q. Li, W. Tan, C. Zhang, G. Gu, and Z. Guo, "Synthesis of water soluble chitosan derivatives with halogeno-1,2,3-triazole and their antifungal activity," International Journal of Biological Macromolecules, vol. 91, pp. 623-629, 2016.

[100] S. Punia, V. Verma, D. Kumar, A. Kumar, and L. Deswal, "Facile synthesis, antimicrobial evaluation and molecular docking studies of pyrazole-imidazole-triazole hybrids," Journal of Molecular Structure, vol. 1223, Article ID 129216, 2021.

[101] J. Nalawade, A. Shinde, A. Chavan et al., "Synthesis of new thiazolyl-pyrazolyl-1,2,3-triazole derivatives as potential antimicrobial agents," European Journal of Medicinal Chemistry, vol. 179, pp. 649-659, 2019.

[102] S. P. Khare, T. R. Deshmukh, J. N. Sangshetti, V. M. Khedkar, and B. B. Shingate, "Ultrasound assisted rapid synthesis, biological evaluation, and molecular docking study of new 1,2,3-triazolyl pyrano[2,3-c]pyrazoles as antifungal and antioxidant agent," Synthetic Communications, vol. 49, no. 19, pp. 2521-2537, 2019.

[103] M. Bhat, G. K. Nagaraja, R. Kayarmar, S. K. Peethamber, and R. M. Shafeeulla, "Design, synthesis and characterization of new 1,2,3-triazolyl pyrazole derivatives as potential antimicrobial agents via a Vilsmeier-Haack reaction approach," RSC Advances, vol. 6, no. 64, pp. 59375-59388, 2016.

[104] J. Sindhu, H. Singh, J. M. Khurana, J. K. Bhardwaj, P. Saraf, and C. Sharma, "Synthesis and biological evaluation of some functionalized 1H-1,2,3-triazole tethered pyrazolo[3,4-b] pyridin-6(7H)-ones as antimicrobial and apoptosis inducing agents," Medicinal Chemistry Research, vol. 25, no. 9, pp. 1813-1830, 2016.

[105] M. V. Dubovis, G. F. Rudakov, A. S. Kulagin et al., “A new method of synthesis of substituted 1-(1H -imidazole-4-yl)-1 $\mathrm{H}$-1,2,3-triazoles and their fungicidal activity," Tetrahedron, vol. 74, no. 6, pp. 672-683, 2018.

[106] D. González-Calderón, M. G. Mejía-Dionicio, M. A. MoralesReza et al., "Azide-enolate 1, 3-dipolar cycloaddition in the synthesis of novel triazole-based miconazole analogues as promising antifungal agents," European Journal of Medicinal Chemistry, vol. 112, pp. 60-65, 2016.

[107] N. Rezki, "Green microwave synthesis and antimicrobial evaluation of novel triazoles," Organic Preparations and Procedures International, vol. 49, no. 6, pp. 525-541, 2017. 
[108] C. P. Kaushik, K. Kumar, K. Lal, B. Narasimhan, and A. Kumar, "Synthesis and antimicrobial evaluation of 1,4disubstituted 1,2,3-triazoles containing benzofused N-heteroaromatic moieties," Monatshefte für Chemie-Chemical Monthly, vol. 147, no. 4, pp. 817-828, 2016.

[109] G. Xu, S. Mao, L. Mao, Y. Jiang, P. Zhang, and W. Li, "Design, synthesis, and antifungal evaluation of novel 1,4disubstituted 1,2,3-triazoles containing indole framework," Zeitschrift für Naturforschung B, vol. 71, no. 9, pp. 953-958, 2016.

[110] M. N. Soltani Rad, S. Behrouz, M. Behrouz et al., "Design, synthesis and biological evaluation of novel 1,2,3-triazolyl $\beta$ -hydroxy alkyl/carbazole hybrid molecules," Molecular Diversity, vol. 20, no. 3, pp. 705-718, 2016.

[111] X.-Y. Huo, L. Guo, X.-F. Chen et al., "Design, synthesis, and antifungal activity of novel aryl-1,2,3-triazole- $\beta$-carboline hybrids," Molecules, vol. 23, no. 6, pp. 1344-1355, 2018.

[112] S. Deswal, Naveen, R. K. Tittal, D. Ghule Vikas, K. Lal, and A. Kumar, "5-Fluoro-1H-indole-2,3-dione-triazoles- synthesis, biological activity, molecular docking, and DFT study," Journal of Molecular Structure, vol. 1209, Article ID 127982, 2020.

[113] R. Sakly, H. Edziri, M. Askri, M. Knorr, C. Strohmann, and M. Mastouri, "One-pot four-component domino strategy for the synthesis of novel spirooxindole-pyrrolidine/pyrrolizidine-linked 1,2,3-triazole conjugates via stereo- and regioselective $[3+2]$ cycloaddition reactions: in vitro antibacterial and antifungal studies," Comptes Rendus Chimie, vol. 21, no. 1, pp. 41-53, 2018.

[114] M. R. Aouad, "Click synthesis and antimicrobial screening of novel isatin-1,2,3-triazoles with piperidine, morpholine, or piperazine moieties," Organic Preparations and Procedures International, vol. 49, no. 3, pp. 216-227, 2017.

[115] M. H. Shaikh, D. D. Subhedar, F. A. K. Khan et al., "Synthesis of novel triazole-incorporated isatin derivatives as antifungal, antitubercular, and antioxidant agents and molecular docking study," Journal of Heterocyclic Chemistry, vol. 54, no. 1, pp. 413-421, 2017.

[116] A. R. Nesaragi, R. R. Kamble, P. K. Bayannavar et al., "Microwave assisted regioselective synthesis of quinoline appended triazoles as potent anti-tubercular and antifungal agents via copper (I) catalyzed cycloaddition," Bioorganic \& Medicinal Chemistry Letters, vol. 41, Article ID 127984, 2021.

[117] M. H. Shaikh, D. D. Subhedar, S. V. Akolkar et al., "Tetrazoloquinoline-1,2,3-triazole derivatives as antimicrobial agents: synthesis, biological evaluation and molecular docking study," Polycyclic Aromatic Compounds, vol. 40, pp. 1-22, 2020.

[118] M. Irfan, B. Aneja, U. Yadava et al., "Synthesis, QSAR and anticandidal evaluation of 1,2,3-triazoles derived from naturally bioactive scaffolds," European Journal of Medicinal Chemistry, vol. 93, pp. 246-254, 2015.

[119] S. Bitla, A. A. Gayatri, M. R. Puchakayala et al., "Design and synthesis, biological evaluation of bis-(1,2,3- and 1,2,4)-triazole derivatives as potential antimicrobial and antifungal agents," Bioorganic \& Medicinal Chemistry Letters, vol. 41, Article ID 128004, 2021.

[120] D. Ashok, M. R. Reddy, R. Dharavath, K. Ramakrishna, N. Nagaraju, and M. Sarasija, "Microwave-assisted synthesis of some new 1,2,3-triazole derivatives and their antimicrobial activity," Journal of Chemical Sciences, vol. 132, no. 1, pp. 1-9, 2020.

[121] A. Zambrano-Huerta, D. D. Cifuentes-Castañeda, J. Bautista-Renedo et al., "Synthesis and in vitro biological evaluation of 1,3-bis-(1,2,3-triazol-1-yl)-propan-2-ol derivatives as antifungal compounds fluconazole analogues," Medicinal Chemistry Research, vol. 28, no. 4, pp. 571-579, 2019.

[122] B.-L. Wang, Y.-Z. Zhan, L.-Y. Zhang, Y. Zhang, X. Zhang, and Z.-M. Li, "Synthesis and fungicidal activities of novel 1,2,4-triazole thione derivatives containing 1,2,3-triazole and substituted piperazine moieties," Phosphorus, Sulfur, and Silicon and the Related Elements, vol. 191, no. 1, pp. 1-7, 2016.

[123] M. Pertino, C. Theoduloz, E. Butassi, S. Zacchino, and G. Schmeda-Hirschmann, "Synthesis, antiproliferative and antifungal activities of 1,2,3-triazole-substituted carnosic acid and carnosol derivatives," Molecules, vol. 20, no. 5, pp. 8666-8686, 2015.

[124] S. Jagadale, A. Chavan, A. Shinde, V. Sisode, V. D. Bobade, and P. C. Mhaske, "Synthesis and antimicrobial evaluation of new thiazolyl-1,2,3-triazolyl-alcohol derivatives," Medicinal Chemistry Research, vol. 29, no. 6, pp. 989-999, 2020.

[125] K. Thotla, V. Noole, and C. K. Reddy, "Synthesis and antimicrobial activity of a novel hybrid benzo[b]thiophene1,2,3-triazole analogues," Chemical Data Collections, vol. 27, Article ID 100361, 2020.

[126] A. V. Costa, L. C. Moreira, R. T. Pinto et al., "Synthesis of glycerol-derived 4-alkyl-substituted 1,2,3-triazoles and evaluation of their fungicidal, phytotoxic, and antiproliferative activities," Journal of the Brazilian Chemical Society, vol. 31, no. 4, pp. 821-832, 2020.

[127] Y.-Q. Jiang, S.-H. Jia, X.-Y. Li et al., "Design, synthesis, and antifungal evaluation of novel benzoxazole derivatives containing a 1,2,3-triazole moiety," Journal of the Chinese Chemical Society, vol. 64, no. 10, pp. 1197-1202, 2017.

[128] A. Ramírez-Villalva, D. González-Calderón, R. I. RojasGarcía et al., "Synthesis and antifungal activity of novel oxazolidin-2-one-linked 1, 2, 3-triazole derivatives," MedChemComm, vol. 8, no. 12, pp. 2258-2262, 2017.

[129] D. González-Calderón, M. G. Mejía-Dionicio, M. A. Morales-Reza et al., "Antifungal activity of 1'-homo$\mathrm{N}-1,2$, 3-triazol-bicyclic carbonucleosides: a novel type of compound afforded by azide-enolate $(3+2)$ cycloaddition," Bioorganic Chemistry, vol. 69, pp. 1-6, 2016.

[130] Z. Liang, H. Xu, Y. Tian, M. Guo, X. Su, and C. Guo, "Design, synthesis and antifungal activity of novel benzofuran-triazole hybrids," Molecules, vol. 21, no. 6, p. 732, 2016.

[131] P. Yadav, K. Lal, L. Kumar et al., "Synthesis, crystal structure and antimicrobial potential of some fluorinated chalcone1,2,3-triazole conjugates," European Journal of Medicinal Chemistry, vol. 155, pp. 263-274, 2018.

[132] K. Lal, P. Yadav, and A. Kumar, "Synthesis, characterization and antimicrobial activity of 4-((1-benzyl/phenyl-1H-1,2,3triazol-4-yl)methoxy)benzaldehyde analogues," Medicinal Chemistry Research, vol. 25, no. 4, pp. 644-652, 2016.

[133] Y. Jiang, B. Ren, X. Lv, W. Zhang, W. Li, and G. Xu, "Design, synthesis and antifungal activity of novel paeonol derivatives linked with 1,2,3-triazole moiety by the click reaction," Journal of Chemical Research, vol. 39, no. 4, pp. 243-246, 2015.

[134] J.-B. He, H.-F. He, L.-L. Zhao et al., "Synthesis and antifungal activity of 5-iodo-1,4-disubstituted-1,2,3-triazole derivatives as pyruvate dehydrogenase complex E1 inhibitors," Bioorganic \& Medicinal Chemistry, vol. 23, no. 7, pp. 1395-1401, 2015.

[135] Y. Ren, Y. Liu, S. Gao, X. Dong, T. Xiao, and Y. Jiang, "Palladium-catalyzed selective ortho $\mathrm{C}-\mathrm{H}$ alkoxylation at 4aryl of 1,4-disubstituted 1,2,3-triazoles," Tetrahedron, vol. 76, no. 10, Article ID 130985, 2020. 
[136] S. Pulya, Y. Kommagalla, D. G. Sant et al., "Re-engineering of PIP3-antagonist triazole PITENIN's chemical scaffold: development of novel antifungal leads," RSC Advances, vol. 6, no. 14, pp. 11691-11701, 2016.

[137] Y. Li, S. Lei, and Y. Liu, "Design, synthesis and fungicidal activities of novel 1,2,3-triazole functionalized strobilurins," ChemistrySelect, vol. 4, no. 3, pp. 1015-1018, 2019.

[138] K. Pyta, M. Blecha, A. Janas et al., "Synthesis, structure and antimicrobial evaluation of a new gossypol triazole conjugates functionalized with aliphatic chains and benzyloxy groups," Bioorganic \& Medicinal Chemistry Letters, vol. 26, no. 17, pp. 4322-4326, 2016.

[139] Y. Chen, K. Yao, K. Wang et al., "Bioactive-guided structural optimization of 1,2,3-triazole phenylhydrazones as potential fungicides against Fusarium graminearum," Pesticide Biochemistry and Physiology, vol. 164, pp. 26-32, 2020.

[140] T. F. Santos, J. B. de Jesus, P. M. Neufeld et al., "Exploring 1,2,3-triazole derivatives by using in vitro and in silico assays to target new antifungal agents and treat Candidiasis," Medicinal Chemistry Research, vol. 26, no. 3, pp. 680-689, 2017.

[141] J. J. Shah, V. Khedkar, E. C. Coutinho, and K. Mohanraj, "Design, synthesis and evaluation of benzotriazole derivatives as novel antifungal agents," Bioorganic \& Medicinal Chemistry Letters, vol. 25, no. 17, pp. 3730-3737, 2015.

[142] Y. P. Subedi, M. N. Alfindee, J. P. Shrestha et al., "Synthesis and biological activity investigation of azole and quinone hybridized phosphonates," Bioorganic \& Medicinal Chemistry Letters, vol. 28, no. 18, pp. 3034-3037, 2018. 